\title{
REFLECTIONS ON CARE: OLDER PEOPLE SPEAK ABOUT EXPERIENCES OF NURSING CARE IN ACUTE MEDICAL AND SURGICAL WARDS
}

\author{
by \\ Christine Wilson
}

A thesis submitted to the Victoria University of Wellington in fulfilment of the requirements for the degree of Master of Arts, part 11, In Nursing 


\section{ABSTRACT}

This phenomenological study describes what it is like for people over 74 years to experience nursing care in acute medical and surgical wards, and relates their insights to implications for nursing practice. The six people who took part responded to newspaper stories inviting older people who had been in hospital recently to speak with a nurse researcher about the times they spent with nurses. They included eight episodes of hospitalisation in seven acute care public hospital wards. All chose to be interviewed in their own homes.

The approach followed van Manen's (1990) method for researching lived experience. Their stories are contained in this thesis as individual chapters. The analysis moved from description largely in the respondents' own words, to the researcher's portrayal of the "free act of seeing" resulting in explication of salient features or structures of each story, and then to hermeneutic reflection using the four existentials of lived body, lived space, lived time and lived relation to others.

Aggregation of the concerns revealed in each story illuminates the commonalities and differences of each and uncovers aspects of lived care for these people. Notions of care may be experienced negatively, as when care is absent or deficient in meeting patient need and expectation, or positively as when care is fully realised in the nurse-patient encounter. Nursing which includes negotiating the systems, mediating interpersonal issues, and practical help was excellent care for these patients. Value was given to the ability to quickly evaluate a patient's life ways of being and acknowledge these as of equal importance to the expected health outcomes from the particular medical diagnosis and intervention. 
The description of older people's experience of nursing care is useful for the potential to increase understanding of the needs and expectations of older people in acute wards. Through the phenomenological practice of reflecting and re-writing new perspectives on nursing are developed. These are expressed through myth and metaphor as one means of enhancing the caring work of nursing toward older people. The study offers some implications for nursing education, practice and the organisation of health (illness) care. 


\section{ACKNOWLEDGEMENTS}

This thesis was written with many people as helpers, guides, and supporters. First, I am deeply grateful to, and offer sincere thanks to those people who shared their personal stories, who telephoned with a story to tell. I trust their participation in this research will have some small impact in making positive changes for those older people who follow them into the public health care system.

Second, my supervisor, Associate Professor Cheryle Moss has been a constant mentor, stimulus, and source of wisdom. For her unfailing readiness to respond to questions, her ability to see where paths would lead, and her encyclopaedic knowledge so freely shared, I owe a debt of thanks.

Third, I would like to make mention of my family, especially John and Mark for the computing assistance, and also colleagues at the School of Nursing, Whitireia Community Polytechnic for their support. Especially I would like to thank Kay Laracy who read all the central chapters. Kay gave valuable feedback, commenting on ethical issues to ensure participant anonymity and the reliability of the conclusions as they emerged from the transcripts.

Finally I wish to acknowledge the financial support from the Research Committee at Whitireia Community Polytechnic.

Natis carissimis 


\section{KEY TO FONTS}

Ordinary type is the body of the narrative and editorial comment.

Italic script in small size is the italicisation of words normally italicised in English (such as foreign words).

Italic script is the direct words of the interviewee.

Italic script enclosed by "speech marks" is the interviewee's recounting of direct speech either their own or another person's.

Bold indicates special emphasis given to a word. Where the bold is also in italics, it indicates the speaker specially emphasised these words.

"Quote marks surrounding a section indicate a direct quote from the literature of less than three lines in length."

An indented paragraph indicates a quotation from the literature of more than three lines in length, or a direct quotation from a transcript, which is more than three lines in length. 
TABLE OF CONTENTS

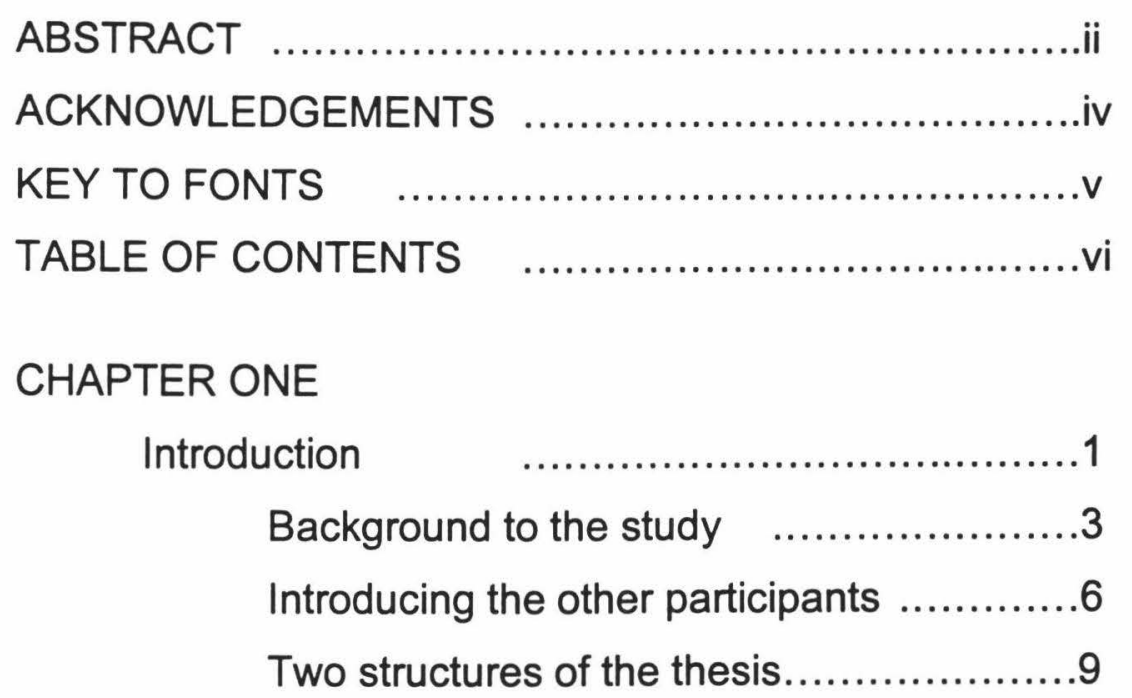

CHAPTER TWO

Care, illness and age...................................19

Care and Nursing ...........................19

Sociological aspects of aging................27

Developmental and psychodynamic understandings of old age .....................33

Depictions of age in English literature........37

Illness as an existential project...............42

Conclusion and commentary ................ 46

\section{CHAPTER THREE}

Practical essentials of the project....................49

Making Contact.................................49

Interview............................................51

Ethical issues.....................................53

Phenomenological writing.....................54 
CHAPTER FOUR

Researching lived experience

.58

A rationale for hermeneutic

phenomenological research in nursing....58

Historical philosophical roots:

Husserl.........................................61

Heidegger ................................64

Existentialists: Sartre., Merleau-Ponty......66

Lived body..............................69

Van Manen........................................70

Reflecting on stories of lived experience..74

Contested stances: nurses and

phenomenology ...............................77

Summary ...................................... 83

CHAPTER FIVE

Taking notice and taking time......................86

Personal profile..................................86

Admission................................ 88

Living in the ward...........................89

Commentary................................98

CHAPTER SIX

All sorts of tricks..................................106

Personal profile...........................107

Admission.................................108

Living in the ward...........................110

Commentary .................................117 


\section{CHAPTER SEVEN}

Suffering, but it could be worse.................126

Personal profile............................128

Admission....................................130

Living in the ward.........................130

Commentary................................141

CHAPTER EIGHT

Sort of standing up for myself....................149

Personal profile............................149

Admission......................................151

Living in the ward...........................152

Commentary................................159

CHAPTER NINE

It was urgent one way or another................168

Personal profile.............................168

Admission....................................174

Living in the ward..........................175

Commentary..............................187

CHAPTER TEN

Like going to a picnic.............................194

Personal profile..............................194

Admission.................................196

Living in the ward............................200

Commentary ..................................209

\section{CHAPTER ELEVEN}

Small additions:unanticipated corroborations..216 
CHAPTER TWELVE

Experiencing non-care.

.220

Introduction to the structures

of non-care.

Failing to acknowledge who the

patient is. .222

Reifying technology

Failing to communicate between departments and systems.

Failing to give practical help.

Commentary.

CHAPTER THIRTEEN

Mirrors of care.

Mediating interpersonal issues.

Initiating the relationship.

Walking through the

relationship.

Practical help. .254

Negotiating the systems

CHAPTER FOURTEEN

Concluding Comments...........................265

Limitations.................................267

Implications for nursing practice.......270

Implications for nursing education.....273

Implications for nursing systems......274

Implications for nursing research......275

Conclusion. 


\section{Chapter 1 Introduction}

In 1987 Wither and Hodges completed a review of New Zealand research with elderly people. They commented that

"In the past, the personal, subjective experiences of elderly people have made only a minimal showing in New Zealand research...More efforts are needed to ensure the views and perspectives of elderly people are communicated...a research orientation made possible by notepads, tape-recorders, and people with time to listen."

(Wither and Hodges 1987 p 54)

In 1997 Gilling and Gilling reviewed research for the years 1986 1996. They commented that Withers and Hodges' concerns had remained substantially unaddressed.

This study seeks to explore the experience of some older people in the health care system in New Zealand in relation to nursing care. Nurses provide services and relate to older people as they are admitted to hospital. Older peoples' health care is a significant contributor to hospitalisation in New Zealand, and is likely to continue to be so in the next 40 years.

It has become a truism to say that there is an expectation of a significantly increasing older population in the next 40 years. In 1991 New Zealanders aged 65 and over constituted about 11 per cent of the total population. By 2031 this is expected to rise to 19 percent. The growth in those aged 85 years or more is predicted 
to increase from 4 percent in 1991 to 13 percent by 2031 (Statistics New Zealand 1995).

If numerically the indicators are of an increase in older people in acute hospitals, the question arises as to the type of care nurses are going to be increasingly called upon to give. The current understandings of being old and ill, and the preparation of nurses for a professional response to those needs may require examination. Information and knowledge about patients' needs for and expectations of nursing are useful to the profession. This project draws on the international nursing literature, but is firmly contextualised in the stories of people of New Zealand.

The Ministry of Health Public Health Group (1997) draws attention to the inherent paradox at the interface of health and growing old. "...having positive attitudes, both as individuals and as a society, towards aging as a normal stage of development, in addition to support for maintaining independence and preparation for increasing frailty and dependence associated with growing older, are key contributory elements influencing the other determinants of wellbeing in old age."

(Ministry of Health 1997 p 23-24)

The nexus between maintaining independence and preparing for dependence is a complex one. Acute illness is a time of dependence for all ages, but the overall life project or goal for other age groups (if not a terminal illness) is independence. As older people have this paradoxical orientation we can expect it to be brought into sharper focus at the time of admission to medical and surgical wards. Nurses in acute wards need to be able to 
help older people with their unique set of needs which may be personal and unique, cohort related, or disease related.

This thesis is based on a phenomenological study which set out to explore retrospectively the individual needs of a small number of patients, and then through reflection on their stories, to relate their experiences to the world of nursing practice and literature. It is an attempt not to draw hard distinctions between biomedical and other ways of conceptualising illness, but rather to focus on the person's needs from nurses in relation to illness, and the experience of the acute ward(s) generally.

\section{Background to the study}

My personal interest in this topic developed over a period of twenty years. Originally I was asked to 'help out' at the only hospital in the town where I lived and found it was a long-term geriatric unit. I discovered I thoroughly enjoyed relating to older people. There were many contrasts in the way a smallish country hospital treated older clients compared to the large internationally recognised 'teaching' hospital in which I had trained. It seemed to me that although patients still had myocardial infarctions and diabetic comas and other "acute" medical crises in the small-town hospital, older patients were happier here than in the large teaching hospital. Here they were closely interwoven into the life of the town. The local GP was the Medical Superintendent, and he and all of the care staff including cooks and cleaners had regard for who the patients were. As people they were 'known' to us, the health professionals, and we to them. 
This experience had a profound effect on my later practice in a variety of areas, including other long-term care settings, a spell as a practice nurse, and two Assessment and Rehabilitation units. In all of these places I frequently accompanied patients to and received them back from the acute care wards, and tried to help them make sense of their experiences there. Later still I worked in acute medical and surgical wards as a nurse educator. Often the students I was working with were assigned to older patients.

It seemed to me that nurses (and others in hospitals) had considerable knowledge of the ill person, yet little context of the person's life apart from the knowledge of the disease itself. We often know little about a person's history, their social relationships when well, or their future expectations. We do not know how their lives are conducted outside the acute ward. Indeed with older clients it is sometimes assumed that they have no future projects such as younger people do. We, as nurses, identify with the hopes and dreams of people closer to our own age.

Sometimes, too, I was uncomfortably aware that as nurses we had little experience and understanding of how people lived their lives in the wards. This raised dilemmas for me particularly as a nurse educator when I was made privy to both the perceptions of the patients and the ward staff, and I realised the differences there were in understanding some situations.

A further point of discomfort for me was the growing awareness that nurses sometimes exist in a powerful relation to patients which provides solutions and acts of behalf of patients whether or not that is the patient's understanding of their own best interest. This realisation caused a re-examination of the nursing 
relationships and interventions. A feminist critique of interdisciplinary relations provided a powerful model. The need for nurses to work in multi-disciplinary teams where there may be differing (and sometimes opposing) theoretical understandings of the illness event and the person's experience, illustrates the importance of nurses increasing their awareness of the patient's expectations, since the patient is the central focus of the team work. It is only as client need is explicated, responded to, and reflected upon, that relationships which are not exploitative of the other, that are truly enabling in setting realistic humane treatment plans and in evaluating need, can be explored by nurses.

A feminist analysis of power relations leads naturally to an analysis of relations between nurses and older patients, which is based on ageism. Indeed in the initial proposal I expressed an expectation that ageist attitudes and communication styles may impact on the relations between nurses and patients in acute wards. In spite of this expectation of mine, such an analysis has not been able to be sustained from the stories of these participants. Except in minor ways, and on relatively rare occasions, the interactions with nurses were not open to an analysis of ageism. Instead the understandings that were made of nursing by the older adults were extraordinarily generous, and when nursing was not so well thought of, the understandings were couched in the individual psychology or life events of particular nurses, or in the systems that the nurses were forced to work in. 


\section{Introducing the 'others'}

The six people who responded to the invitation to tell their story of nursing after acute hospitalisation all had a story to tell, and did so in measured ways. This thesis depended on their willingness to share their stories of the acute ward experience. It has been difficult to fix on one word to describe these people as at different times in the research they were in different roles. I have called them respondents when their role seemed primarily to consist of responding to newspaper stories. This is not merely a passive role, as they were under no obligation to respond, but they had to ring an unknown person, and agree to share their story.

At a later time in the project I have referred to them as participants or interviewees. They were participants in the conversations with me. Although I began each interview with the same question, and I had some general notions about the types of areas which might prove fruitful, each interview was as much the work of the other person as it was mine. I followed their lead as much as I could, asking them to tell me more about anything which might be indicative of their needs from nursing, and particularly the phenomenological existentials (lived space, lived body, lived time, and lived human relations) as they already were present in the stories.

At yet other times I have referred to these people as patients or clients when it seemed to me they were describing a time when their patient (or client) role was most surfaced. Although it is not a firmly enforced distinction, I have referred to patients when indicating the lived experience of the person, and I have tended to 
use the term client when referring to the nurse(s)' response to them.

Each of these terms captures some aspect of the parts played. None does justice to all the roles performed. The individuals are introduced further in each of the chapters which relate to their stories. At this point suffice to introduce the group.

Six others took part in conversations with me. They ranged in age from 74 to 82 years. They described eight admissions to acute wards in the preceding six months: surgical (6), medical (1), holding(1). This latter (holding) appeared to be an adjunct to the hospital Emergency Room intended for patients overnight only. The hospitals were all Crown Health Enterprises and were located all over central New Zealand. All indicated that they had been in hospital on numbers of occasions before

The medical diagnoses which gained them admission to acute wards included investigations following a gastric haemorrhage, fractured hip (2), revision of a hip joint replacement, elective knee replacement, and fractured arm and shoulder following a motor vehicle accident. Orthopaedic conditions were the most common. Patients who had experienced surgery were much more likely to respond than those with medical conditions.

All people were European or pakeha and all were long-term residents of New Zealand or citizens by birth. By marital status they were: married and living with a spouse (2), single and living alone (1), widowed and living alone with family and other support (3). There was one male and five females. 
As might be expected from a recruiting method, which involved responding to newspaper invitations to participate, they were welleducated, confident and articulate.

Having introduced the people involved in the study, I now turn to introducing the approach to the study itself. Throughout the thesis there is an interweaving between the theoretical and the practical, between the historically situated context and the hermeneutic meaning derived from it. This interweaving occurs both within some chapters (for example in the stories of the acute ward existences and the analytic commentary which are contained within Chapters 5-10), and also between individual chapters (for example Chapter 2 is theoretical, setting out the conceptually informing texts in the project, whereas Chapter 3 is essentially practical, describing the actual research practices engaged in.)

The bare demographic and personal data as laid out above is one means of describing the boundaries of the project. A second way of depicting the structures of the project is to introduce the methodology. The methodology used constrains the type of knowledge that is able to be gleaned and evaluated from such a project.

The methodology used was a hermeneutic phenomenological approach to researching lived experience as described by Max Van Manen (1990). Such an approach is concerned with multiple perspectives. What follows are two approaches to structure in the thesis as indicators of processes used and signs of the paths into and out of the project. 


\section{Two structures of the thesis}

Van Manen (1990) suggests that there is no method to phenomenological research. Rather there is a tradition, a body of work recognised by scholars as 'phenomenology'. One only comes to understand phenomenology by 'doing it.' For Van Manen 'doing it' means writing, rewriting and rewriting the original 'text' in such a way as to reveal the essences underlying the phenomenon of investigation. Though there may be no method, there is, he suggests, a "methodical structure of human science research." (Van Manen 1990 p 30 -31).

Particularly in the early stages of this project I adhered closely to Van Manen's suggestions for "methodical structure." He identifies six research activities which interact dynamically throughout the study process. These are:

\section{I) "turning to a phenomenon of interest."}

This involved identifying the issue of concern. In my case it was how older people experienced nursing care acute care wards. It involved formulating and refining the research question, which was, "what is it like for people over 75 years of age to receive nursing care in acute medical and surgical wards?"

Turning to the phenomenon was not a once-for-all event, however. It also involved explicating, clarifying and becoming increasingly aware of one's own contribution to the dialogue. Throughout the thesis I have indicated the thoughts and feelings I had, and the interpretations I made as a nurse about aspects of each person's story. 
2) "investigating the experience as it is lived rather than as it is conceptualised."

This means the researcher examines the "practical wisdom" which exists in multiple aspects of the phenomenon of concern. Literature, the meaning of words and phrases used, first person accounts, and observations of the phenomenon are all actively explored for insights as to previously hidden aspects.

Although there are first person accounts of patients' experiences in medical and surgical wards, such as Cousins (1979) and Sacks (1984), there are very few which relate to the experience of someone over the age of seventy. One example is that of Brand (1993), a surgeon, who portrays a grim picture of his postoperative experience of gall bladder surgery in an American hospital in 1974.

All day long I lay in a spare white room void of any distractions except a TV set and its irritating lineup of daytime programs. (Why doesn't someone decorate hospital ceilings since that is what most patients stare at?) A parade of technicians file through my cell... "Roll up your sleeve." "Pull down your pants." "Keep still." "Roll over." "Give me your arm." "Breathe deeply." "Cough."

The nurse who ordered my pants down was holding a rubber catheter tube. I summoned the courage to protest. "Why do I need a catheter?" I knew the danger of infection, and besides, who wants a rubber tube jammed up his private parts?

"You haven't passed any urine since your surgery, " was his stern reply. 
I felt a flicker of guilt. "That's because I haven't had much fluid input! It's my gall bladder that's missing, not my bladder! Give me a few minutes." He left the room, I staggered over to the pot, clutching my wounded abdominal wall, and with much effort triumphantly produced a few drops. It was my one proud moment in an otherwise grim day.

Brand went on to describe other indignities and the increasing fragmentation of his care. Tellingly he described himself as "all alone with my pain." (Brand and Yancey 1993 p 261)

This bleak experience of an internationally known medical practitioner, in early old age, in a modern hospital is quite chilling. Responsibility for the quality of such a dehumanising experience seems to me to rest squarely with nurses. It needs urgent investigation, or many others will continue to be degraded in such a way. Furthermore it raises the question whether such treatment is a cultural phenomenon peculiar to the United States, or indeed the particular hospital he was in, or whether such experiences are more widespread.

Practical access to such lived experiences requires a practical method accessible to nurses. In this project interviewing was such a method. The interviews were conversational and began with the question, Can you tell me about yourself? How would you describe yourself? I had certain themes for which I was looking, such as their experience of lived body, space, time and human relations. These were not, however explicitly sought. Rather, as the person spoke of their experiences, I asked them to 
expand on certain cues which seemed to be illustrative of these themes.

\section{3) "reflecting on essential themes."}

The essences or the "things themselves" reveal the meaning of the issue of concern. In this aspect of phenomenological research the 'experience as lived' is portrayed -even arranged - so as to bring to attention the essential elements in the phenomenon as it was described in the individual interviews. This is written in the Commentary sections of chapters 5 to 10 .

A second aspect of such reflection was to inquire again of each story and analysis for the existential structures of lived body, lived space, lived time and lived human relations of the other. Thus common aspects of phenomenological thought which had been found to be useful to earlier researchers in the tradition were used to draw commonalities in the experiences of the interviewees. These were the initial 'informing points' of myself as researcher, and it seemed appropriate to return to the ground of the interviews after a period of free conversation and free analysis.

The concluding statement of each story drew on the notion of 'lifeworld' expanded on in chapter 3.

\section{4) "the act of writing and rewriting."}

In Van Manen's view (1990 p 32) writing "brings to speech" language and thoughtfulness on an aspect of lived experience. "Re-thinking, re-flecting, and re-cognizing" are all ways of doing "justice to the fullness and ambiguity of the experience." (Van Manen 1990 p 131) An analytic process which can encompass ambiguity in the inquiry process is necessary for findings which 
can usefully reveal aspects of the acute care experience for older people. An ongoing thoughtful and reflective stance in relation to the elements of practice is valued by many nurse scholars as a means to phenomenological praxis.

5) "maintaining a strong and oriented relation to the phenomenon."

Throughout the process of interviewing, analysing, and writing it is important to keep closely connected to the fundamental research question. Because I was a nurse, and advertised as such to the respondents, I had two orientations to maintain. Firstly I was a nurse with a particular work history, and I was strongly oriented to discover what nurses needed to know about the needs of older people. I had some clues from my previous work experiences, but did these match the patients' understanding of their needs?

Second, I was oriented by the research question to the meaning of the experience for the people who were experiencing nursing. These were two sides to one coin, as it were, viewed through one lens, the perspective of the patients.

\section{6) "balancing the research context by considering parts and whole."}

This aspect of human science research involves considering at several points on the journey how parts of the research structures relate to the project as an overall text; how the description relates to the interpretations made by the researcher; and how the findings relate to the articulation of those findings. One aspect of the way I have attempted to demonstrate the consideration of "the parts and the whole" relates to the interweaving of the specific and situated, with the general and theoretical, referred to above. 
In this project I have been guided largely by the writings of Van Manen (1990). It is clear from the foregoing that this type of qualitative research is not a linear and rigid process. Nevertheless the conventions require a linear presentation of the project.

At this point I introduce another structure of the thesis to guide the reader. Chapter 1 introduces the topic and the need for such research. The important people and concepts, both methodological and content-related, are introduced. Finally there is this guide to the structures of the thesis.

Chapter 2 explores the concepts of care, illness and identity as they relate to older people. These notions are discussed in relation to the nursing literature and in relation to such concepts as have been incorporated into nursing thought and practice from the social sciences. For instance, the idea of identity is explored not from the stance of the original writers about 'identity' as a concept, but from the way the term is utilised in nursing texts and writings.

Chapter 3 describes the study design and begins the discussion of some of the assumption and inferences of choosing Van Manen's phenomenology to answer the research question.

Chapter 4 sets out the conceptual underpinnings of Van Manen's approach to human science research. $\mathrm{He}$ has an eclectic approach to the many 'schools' of phenomenology consistent with his emphasis on praxis. Put crudely this may be described as: if there is an intellectual and rational 'fit' and it works, then it is 
useful to the research. Some voices challenging aspects of phenomenological research in nursing are considered, and the stance adopted in this project explicated.

The central core of the thesis is found in the six chapters, $5-10$ which constitute the individual stories as they were recorded in conversations. Each 'core' chapter follows the same pattern of writing. Each begins with a brief summary of the reasons why, and the events leading up to how, this person came to be a patient in an acute medical or surgical ward. The data is similar to that a nurse would receive from another department about such a patient.

This is followed by a brief overview of the person's description of themselves in their life context, a coming to understand what is the person's understanding of 'who they are' at the time of the interview. The circumstances of admission are briefly recounted, and then selected events, thoughts and feelings from the person's recounting of the times they spent in acute medical and surgical wards with nurses are described. For practical reasons the selection is necessarily shorter than the entire conversation. It is a 'organized' version but not, I hope, an altered version of the meaning the person intended to convey. The primary selection criteria for inclusion in these chapters from the transcripts was whether the choice conveyed the tone of the experience being recounted, both in its details and in its entirety, and whether the addition contributed any new aspects to the picture of care already in place.

Following the description of life in the ward there is a commentary where analysis of the individual patient story is explored. The 
analysis concludes with a consideration of the four 'lived existentials' and a brief description of the lifeworld of the individual ward.

Chapter 5 introduces Mrs Roy-Jenkins, an 82 year old woman, after she had been in hospital with a fractured hip.

Chapter 6 introduces Mr Snell, a 74 year old man after he had a prosthesis in his hip repaired.

Chapter 7 introduces Miss Shepherd, an 80 year old woman after she had been in hospital with a fractured hip.

Chapter 8 introduces Mrs Lorna O'Fee, an 82 year old woman who had been in hospital with fractures in her arm and other bruising after a motor vehicle accident.

Chapter 9 introduces Mrs Brown who had been discharged from hospital following a gastric haemorrhage.

Chapter 10 introduces Mrs Mains who had experienced an elective knee replacement.

Chapter 11 portrays the type of response I received from a second group of people who responded to the publicity recruiting participants to the project. The second group were the relatives of other older people who had been treated, the relatives felt, quite badly in the hospital system, and who wanted the story told. This provided some ethical challenges since my principal orientation was to the lived experiences of patients themselves. However, since they provided important corroboration for some aspects of 
the stories of the older patients themselves, a representative 'relative story' from the published nursing literature has been included here.

Chapter 12 gives a collective view of the encounter with non-care, or absent care as the participants in Chapters 5-10 experienced it. Not all of the negative experiences related to nursing practice, but it appeared that there was an expectation that nurses would take account of the negatives in the hospital experience as a whole. These people looked for a nurse with understanding to acknowledge the quality of such events for the patient, and, in some cases, advocacy to smooth the patient's path through the system(s).

Chapter 13 lays out the structures of nursing 'care' when it was realised in its fullness. The stories are like so many mirrors held to the practice of nursing. Once brought together for multiple views of nurses, the light can shine more clearly on the structures and essences of care. It is seen, not directly, but reflected in their stories. Consideration is given to the ways nurses can engage in reflection on practice.

Nursing which includes negotiating the systems, mediating interpersonal issues, precise technological care, and practical help was excellent care for these patients. Value was given to the ability to quickly evaluate a patient's life ways of being and acknowledge these as of equal importance to the expected health outcomes from the particular medical diagnosis and intervention. 
Chapters $12-13$ both conclude with hermeneutic writing which captures the essence of the aggregated stories and re-presents the phenomenon of care through analogy and metaphor.

Chapter 14 describes the limitations and implications for nursing practice and research, and contains the conclusion.

A principal concern of the type of hermeneutic phenomenology practised in this thesis is to uncover the meaning of a person's or group's orientation to the world of a particular context. Thus the concern is for depth of understanding, not representativeness, breadth, or even objectivity. An important way of approaching the meaning in such an endeavour is through multiple perspectives.

Chapter 1 has introduced two perspectives relating to the structures of the thesis. A further 'structure' is set out in Chapter 3 where the practical events in the research are described, and other 'structures' are evident at other points in the thesis.

In Chapter $2 \mathrm{I}$ turn to the perspectives of the intellectual context of the world of nursing which influence the experience of care older people receive from nurses in medical and surgical wards. 


\section{Chapter 2 Care, illness and age}

This chapter explores the concepts of care and illness as they are discussed in various literatures in relation to old age. Literatures discussed are those thought to have influence on the concerns and practice of nursing. First, there is the nursing literature regarding care, in particular the concept of care from the perspective of recent research findings with adult and older adult patients in acute settings. Second, there is a brief consideration of sociological concepts particularly as these are incorporated into nursing. Third being old is an ascribed identity as well as chronological passage of time over a life, and a discussion of the place of developmental and psychodynamic literature in nursing's understanding of old age is explored. Finally there is consideration of popular literary conceptualisation of old age and a reflection on illness as an existential project. As a way of being, both ascribed by others and lived by the individual, old age is an orientation and a contextual component which may assume new importance at times of acute illness, and so is of concern to nurses.

\section{Care and Nursing}

Although not unique to nursing, care has emerged as one of the important concerns in nursing over the last two decades (Leininger, Benner \& Wrubel 1989, Morse 1990, Watson 1985). Standards of practice often include 'care' as a primary responsibility of the nurse. In 1988 more New Zealand nurses cited 'caring for patients' as the most important facet of their practice than any other (Walton 1989). There is a voluminous 
body of literature on care in nursing. To review all here is beyond the scope of this project, and so first there is a need to lay out the senses in which 'care' is being considered in this project.

Radsma has pointed out that there is no consensus as to the actual care work of nursing. Language, history, intent and context all alter the nature of what is considered 'care' by nurses. Radsma points out the widespread use but ill-defined nature of the term care in relation to nursing:

the fact that caring is a human need is indisputable. That caring is at the root of nursing history is also questionable. That caring is the essence of nursing must be determined.

(Radsma, 1994 p 448)

It is not my intention to contribute to this debate in this project, but rather to bypass such a conceptual approach to care, and ask, 'what is care for patients?' As a human science nursing cannot ignore lay conceptions in relation to our professional practice.

Some have sought to understand the nature of care by observing, or interviewing nurses (Benner 1984, Bishop \& Scudder 1990, Nelms, 1996). Swanson (1991) compared five caring processes which emerged from three studies with elements from three models of care by Cobb, Watson and Benner. More recently there have begun to be aspects of care in nursing work explored from the point of view of the patients' own expression of their needs.

The use of the term 'need' may require clarification. What is considered patient need can be approached from multiple 
perspectives: from the medical practitioner a diagnosis is required and treatment prescribed, from the dietician advice and food which sustains life and relieves symptoms is required. From the nurse, many commentators feel there is a need for 'care.'

In this study I have followed the use of the term 'need' as exemplified by the following definition.

A need is generally defined as a requirement of a person... it supplies, relieves or diminishes immediate distress or improves his or her immediate sense of adequacy or well-being."

(Orlando 1996 p 6)

A number of different research methods have been used to explore patient needs in acute care settings. Reimen (1986 p 33) using a phenomenological approach analysed ten accounts of both caring and non-caring behaviours by nurses, and asked " Why do [non-caring] interactions come to mind so quickly, even years after they have taken place? " Her tentative explanation is that patients when acutely ill have heightened sensitivity. Radsma (1994) points out that caring is most evident by its absence.

Mayer (1986) identified that cancer patients and their families valued competent clinical skills ahead of expressive interpersonal caring. Similarly Cronin and Harrison (1988) reported 22 patients post-myocardial infarction in the coronary care unit valued physical status monitoring and professional competence more highly than interpersonal or psychosocial aspects of care. As Duffy observes the life-threatening nature of these conditions supports these findings, but that "no research has been found 
regarding the impact of nurses' human caring behaviours on the health status of patients while hospitalised." (Duffy, 1992 p 118) Duffy tested the effect of nurse caring behaviours on patient satisfaction, health status, length of stay, and nursing care costs, using a correlational design. She found that the only variable influenced by nurse caring behaviour was patient satisfaction.

Miller, Haber and Byrne (1992) in a phenomenological study asked, 'what is the lived experience of a caring nurse-patient interaction from the perspectives of nurses and hospitalised patients?' They derived five parallel themes: holistic understanding, connectedness/shared humanness, presence, anticipating and monitoring needs, and beyond the mechanical. The range of ages they interviewed was not specified. They recommended that

replication of nurse-patient caring studies using patients at different lifecycle stages, experiencing acute, critical and chronic illnesses, will clarify the concept of caring as lived by patients.

Very few studies explored the nature of need for care from the point of view of people over 65 years of age.

Cameron (1993) in a grounded theory approach examined the construct of comfort as an aspect of care. She found that patients, once aware of discomfort entered upon a process of 'integrative balancing' which equipped the informants with specific strategies called 'monitoring', 'networking' and 'enduring'. Their needs for comfort were highly specific and variable. She quotes an elderly participant with a radical neck dissection following 
cancer of the salivary glands. He was in pain with an excessively dry mouth, and awake at night.

And Sister came through the wall. I couldn't see her face but she was rubbing her hands and saying, "It's all right. You're a good chap, you'll be ok- hang on." She looked at me and vanished. I was not frightened. It seemed to me more as a sign that \{another patient and I'll be all right.

(Cameron 1993 p 247)

This patient explained the hypervigilance and monitoring patients do when seriously ill.

Thus it is possible to gather useful information about what patients experience. This data can be examined for what they expect and need from nurses. Such an approach, however, may gather data that is unique to some individuals, as the example from Cameron graphically illustrates. It is of importance to nurses to gather such individual data, and respond with care-fulness. It is also important to the profession to examine the concerns of identifiable groups in the health care system. Some aggregation of the individual stories must take place in order for systematic response by the profession. Formerly older people as a group were excluded from many types of biomedical research, and also from the initial work on nurse caring.

More recently there have begun to be explorations of the practice of human care from the perspective of older people as well. Poole and Howat (1994) explored what elderly home care clients (average age 78 years) needed from nurses. Although their data collection method was a single interview with five patients, their 
results were reported as numerical incidence /prevalence of themes. Although specifically invited to identify non-caring behaviours ("were there things that you would have liked me to do?"), no patients did so. The fact that individual caregiving nurses asked these questions of their own patients illustrates just how difficult it is for patients to express their needs to their nurses while receiving care.

So far, in this discussion of the place of nursing care for older people, I have noted some key nurse theoretical considerations of care which I take as self-evident for the discipline. (This is not to imply that I endorse all the views or methods of Benner, Watson, Bishop and Scudder, or Swanson. It is to state that I believe there are enough commonalities among their views on care and those of practitioners to be stated as a presupposition. I am aware of those who wish to contest such a position, but I believe a general endorsement of 'care' as a construct has wide enough resonance to be asserted here as a key element in nursing practice.) Second, I have reviewed various research findings in relation to acute patients and older people's need for care. In the section that follows I review one article which gives indication as to some of the differences between nurses' and patients' understandings of the acute care experience.

Hudson and Sexton (1996) asked 45 acute care nurses and 22 patients over 65 years with acute hospital experience in the preceding six months to rank in importance 39 care-giving activities. (Figure 1) Some interesting differences emerged in the priorities of nurses and those of older people. Older people gave top priority to help with urinary elimination, whereas nurses ranked this number eleven in their priorities. Older people gave high 
TABLE

Caregiving Activifies Rafed by Elders and Nurses

\begin{tabular}{|c|c|c|c|}
\hline Item * & Statement & $\begin{array}{l}\text { Eders' } \\
\text { Ronk }\end{array}$ & $\begin{array}{l}\text { Nurses' } \\
\text { Rank }\end{array}$ \\
\hline 17. s & See that the bed pan or urinal are provided when needed & 1 & 11 \\
\hline 28. $R$ & Relieve my anxiety by explaining reasons for my symptoms & 2 & 23 \\
\hline 12. & Notice when I am in pain and give me medications if ordered & 3 & 3 \\
\hline 15. & Observe the effects of treatments ordered by the physician & 4 & 5 \\
\hline 24. & Give prescribed modications on time & 5 & 17 \\
\hline 46. $\mathrm{C}$ & Corry out doctor's orders & 6 & 10 \\
\hline 11. & Help me to assume a comfortable or appropriate position & 7 & 15 \\
\hline 23. $\mathrm{E}$ & Encourage me to take more responsibility for my own care while in the hospital & 8 & 31 \\
\hline 19. & Check on bowel functioning and report problems to the doctor & 9 & 12 \\
\hline 29. 1 & Make me feel you are happy to care for me & 10 & 25 \\
\hline 45. $T$ & Toke time to listen to me & 11 & 7 \\
\hline 42. 1 & Notice changes in my condition and report them & 12 & 1 \\
\hline 4. $\mathrm{P}$ & Provide me with a clean, comfortable bed & 13 & 37 \\
\hline 27. $F$ & $\begin{array}{l}\text { Provide a comfortable, pleasant environment (proper vemperalure, } \\
\text { free from odors and disturbing noises) }\end{array}$ & 14 & 40 \\
\hline 25. $T$ & Teach me about the medications thot I will be taking at home & 15 & 6 \\
\hline 1. $T$ & Take my temperature and pulse & 16 & 21 \\
\hline 34. 5 & See that my food is served property & 17 & 41 \\
\hline 48. & $\begin{array}{l}\text { Give me pamphlets to read and/or talk with me about my illness in } \\
\text { order to help me understand how to care for myself }\end{array}$ & 18 & 28 \\
\hline 9. & See that the unit is clean and tidy & 19 & 48 \\
\hline 7. & Provide privacy during my bath and trealments & 20 & 16 \\
\hline 6. & Be sure that I hove necessory equipment-glass, towel, soop, blanket, etc. & 21 & 38 \\
\hline 18. 1 & Help me mointain or restore normal elimination & 22 & 9 \\
\hline 8. & Take special care of my skin so it does not become sore & 23 & 2 \\
\hline 20. 1 & Help me in and out of bed & 24 & 27 \\
\hline 22. & Discuss with me the amount and type of activity I should hove at home & 25 & 39 \\
\hline 36. 1 & Help me understand how to plan the diet I will need at home & 26 & 32 \\
\hline 32. & Assist me with meals & 27 & 18 \\
\hline 44. & Be understanding when I am irritable and demanding & 28 & 30 \\
\hline 21. 1 & Help me get necessary exercise while I am in the hospital & 29 & 35 \\
\hline 37. & Be sure I have a copy of my diet & 30 & 43 \\
\hline 49. & Arrange for a public health nurse to visit me at home & 31 & 26 \\
\hline 47. & Explain about diagnostic lests ohead of time so that I will know what to expect & 32 & 8 \\
\hline 2. & Give or assist me with a daily bath & 33 & 42 \\
\hline 33. & See that I hove food and/or fluids between meals & 34 & 33 \\
\hline 35. & Ask the dietician to serve me soff foods that I am able to chew & 35 & 24 \\
\hline 14. 1 & Make me comfortable by rubbing my bock & 36 & 44 \\
\hline
\end{tabular}

Hudson K.A. \& Sexton, D.L. (1996)

Figure 1

priority to physical and psychosocial comfort (especially communication and meaning), whereas nurses gave top priority to their monitoring role. It does not require a great deal of imagination to understand the conflict or anxiety that may result when such differences in priorities are made explicit to patients. 
There were similarly large discrepancies between priorities in the items 'give prescribed medications on time' (nurses ranking it number 17, elders' number 5), and 'take special care of my skin so it does not become sore' (nurses 2, patients 23). Such large discrepancies indicate that there may be a need for better understanding or different communication strategies in the nurse/patient dyad. Indeed Chapters 5-10 show that many of these same issues were raised by some older people in New Zealand hospitals.

Interestingly too, in Hudson and Sexton's (1996) survey, nurses and patients agreed on the place of pain management in the importance of the care-giving constellation. As chapter 11 discloses, even if there is such agreement as to the importance of pain management, there may still be gaps in understanding and the co-creation of meaning. It is precisely this gap that phenomenological methods of inquiry throw light on. Thus this research project seeks to explore new possibilities in the practice dynamic of care through the practice exercise of interviewing.

In considering the needs of older people there are a number of prevailing systems of thinking in nursing which influence care.

Older people are vulnerable in unique kinds of ways when they enter the health care system. Apart from visitors and families, there is no one of their age and cohort to understand their life contexts in the modern hospital since compulsory retirement was introduced. There are many disciplines which deal with ageing and being old. It is quite beyond the scope of this project to consider them all comprehensively. I have selected influential systems of thought, which have had impact on the way nursing 
relates to older people. I propose to consider one or two examples of thought from each of the 'human science' disciplines of:

- Sociology

- Developmental psychology

- Existential writings

- Popular literature

\section{Sociological aspects of aging}

In considering aspects of aging as these are expounded in the discipline of sociology, I have chosen four analytic positions to consider. The choice of these four is not intended to imply any sense of representativeness. The first two sociological positions considered (Simone de Beauvoir and Bytheway) are intended firstly to illustrate the pervasive critique that results in accusations of ageism, which is held by sociologists generally. There are a number of concepts relating to old age which have become part of the 'common sense' realities of our society (certainly the social world of the helping professions). Ageism is seen as a form of systematic stereotyping and discrimination.

More specifically the second two sociological theoretical perspectives (Disengagement theory and Activity theory) are included as examples of pervasive sociological framing of the experience of older adults in nursing texts.

Firstly two sociological perspectives relating to ageism will be considered. Simone de Beauvoir intending to "compel my readers to hear the voices of [the old]" (1972 p8), believes "age takes the 
wish to learn away from us" ( $p$ 503), and supports the view that age is the fading of curiosity. Her analysis is wide-ranging and aims to show how denigration of the old is inevitable in a "bourgeois society." All psychological ills flow from this sociopolitical framing. For de Beauvoir, the old person who is creatively working, such as Verdi, who wrote his finest operas in old age, does so without pleasure and against a background of disillusionment. "The old person is condemned to boredom," and, "biologically, economically and socially their status has declined" (de Beauvoir, 1972, p 513, 514).

Even the presence of grandchildren which de Beauvoir allows are the cause of the warmest and happiest feelings that old people experience, is the cause of 'reversed Oedipus'. Grandparenthood signals the onset of complicated, turbulent and ambivalent times. In the end it may not be worth it, Beauvoir implies, complicated by women's competition for the mothering role with their daughters. Even the older person who does retain affection for and from his/her family becomes detached and egocentric.

Beauvoir's thesis is that the bourgeois capitalist society allows older people no other option. The ambivalence of society toward the old derives even more strongly from the class struggle. The aged people look upon themselves as the victims of fate, society and those around them. Even those who rail against the fate allotted to them are forced into the mould of these strong expectations.

As a general rule nurses have been slow to take up the socialist cudgels. As low-paid workers their commitment to socialist causes has been ambivalent at best. Certainly resistance to 
hegemonic capitalism has been a pre-occupying concern of very few nurses. Those nursing organisations who have taken up such a position have not recruited many adherents. It is very difficult to imagine such New Zealand groups such as the Nurse Executives or Nurse Educators in the Tertiary Sector calling for education for nurses in acute care wards to take account of sociological perspectives such as Simone de Beauvoir's, although they would not endorse ageist values in relating to older people. The implications of Beauvoir's argument can be usefully integrated across the thinking in the discipline. While it may be useful to devalue ageism, there is limited support, or political possibility for such an analysis applied more broadly.

As the stories which follow in Chapters 5-10 indicate, there were very few occasions when older people attributed puzzling nurse action to such a political analysis, although they were very aware of health 'reform' and restructuring and their effects of the nurses.

Such an analysis as Beauvoir's has limited effect on nursing. The second sociological analysis I wish to consider is social rather than sociopolitical. Bytheway suggests "it is the death of others which lead people into a sense of being old." (1989 p 103) The accumulated griefs and losses of spouse, siblings, parents, pets and friends parallel the losses of physical function, and eventually overwhelm the older person, even if their body is not overwhelmed. Further he points out that the role of chronological age is extremely important for the poor old in accessing state provision of housing, income support and health and welfare services generally. This effect is so pronounced that the poor old equate old age with their experience of social services. The difficulties and rejection that the poor old experience at the hands 
of bureaucrats parallel the grief they are required to negotiate in their psychological lives.

Here is a picture of the sociological context being used an explanation for the psychological experience of older people as they age in Western society. As a social worker, Bytheway is concerned to explore the experiences of those people who come in contact with the official helping agencies. Again, whatever the legitimacy of such an analysis for the helping agencies, there is no hint of such a perspective in the interpretations of the people I interviewed. Such a perspective was not part of their interpretations. This may reflect a cohort perspective, but does illustrate how an analysis or perspective can be drawn by academics, and other helping professions, which is not shared by the very subjects with whom the analysis purports to be concerned. Such a discrepancy seems likely to enhance distance and difficulty in a helping relationship.

The experience of aging outlined by Bytheway is so common in Euro-centric cultures that Cumming and Henry in 1961 developed a theory of disengagement. They have had a much more pervasive influence on the teaching and practice of nursing and the way we think about the old. Their theoretical position is summed up by Perlmutter and Hall:

Limited physical and psychic energy supposedly led older adults to withdraw from active participation from a society which was simultaneously withdrawing from them. (cited in Permutter and Hall, 1992 p 287). 
Even recent nursing texts continue to mention the place of disengagement theory. (See for example Peterson 1996 p 626629)

This notion is now largely discredited as a normative aging process, largely because the inner reality of older people does not equate with this external process which occurs around them. Adjustment to a mutual disengagement is one option for aging, but as Bytheway points out, is more likely to be thrust upon the poor.

The fourth and final theoretical position relating to sociology of aging is Activity theory. This is a much more positively cheerful theory, but no less deterministic than Disengagement theory. Activity theory is an easy one to satirise, and as such it is often not taken seriously, although often espoused at a day-to-day level. Activity theory posits that people are happiest and experience least ill health when active. The particular activity is left to the choice of the individual. What is important is that people who age well are active. It is a most pervasive theory in New Zealand society even being endorsed at an official level through the "use it or lose it" campaign run by the Ministry of Health in the eighties.

The 'fit' of both sociological theories with the complexities of being 'old' is under question. If disengagement theory, or its antithesis activity theory, influence the thinking of nurses as a profession, then the most positive construct of old age is a form of meliorism. Meliorism is the notion that the primary goal of old age is to resist deterioration. Such sociological theories would imply that ageing 
well involves clinging to middle age as long as possible, and avoiding mutually constructed discourse with other age cohorts.

The discipline of sociology at once highlights and calls for a change in the ageist structures of society, and the ageist attitudes, and behaviours of practitioners. This can be quite difficult to do when such an analysis is not shared by those whom it is intended to benefit. However difficulty alone should not deter us from the task if it can be shown to produce more aware, more knowledgeable, in short, more caring practitioners.

There is however one insurmountable difficulty in adopting such an approach in nursing. In health care it is thought necessary to emphasise aspects of loss and frailty to workers from younger age cohorts, since these are likely to be the issues of old age that bring the older person to the health care service in the first place. Knowledge of these issues is critical, but the anxiety generated in the not-yet-old by these issues leads many workers to distance themselves from the older person as person, leading to objectification of the human concerns (Biggs, $1993 \mathrm{p} \mathrm{104).} \mathrm{It} \mathrm{is}$ necessary therefore to look at other conceptualisations of old age.

\section{Developmental and psychodynamic understandings of old age.}

There are obvious advantages in emphasising to nurses in acute care wards the special physical needs of older people. Their reaction to medications tested largely on younger patients is seen as 'slower.' They are more likely to experience other chronic illnesses which impede their 'recovery' than younger age groups. In short it is the special needs of the older body which is at the 
forefront of the reason for older people's admission to acute medical wards. (Interestinalv, it is often the special social neeskn nf. the older person which are at the forefront of discharge planning. People with social needs as conceptualised in the discipline of sociology are sometimes referred to as "bed blockers" in acute care wards.) We must ask if there are other ways of conceptualising old age which enable nurses to meet the needs of older people as older people see their needs.

For reasons indicated above, it seems inevitable that nurses will need knowledge of human development. How such messages are delivered and how such messages are interpreted are beyond the scope of this project, but it is important to explore the actual message for its relevance to this project.

In terms of physical development, messages such as the following are frequent in the developmental literature health professionals and nurses are exposed to: "between the ages of 25 and 85 , vital lung capacity decreases by 40\%" (Perlmutter and Hall 1992, p 94). The picture of old age is one of decline and loss.

Such a conceptualisation of old age as decline from early adulthood is challenged in the excerpt from the following anonymous poem:

You should die first, get it out of the way. Then you live twenty years in an old age home.

You get kicked out when you're too young,

You get a gold watch, you go to work.

You work forty years until you're

Young enough to enjoy your retirement.

You go to college, 
you party until you're ready for high school,

you become a little kid and you play,

you have no responsibilities,

you become a little boy or girl, you go back into the womb,

you spend the last nine months floating.

And you finish off as a gleam in someone's eye.

The current discourse surrounding physical ageing in nursing texts is likely to assist nurses in their relations with older people in very limited ways only. The question then arises, is the psychological literature any less alienating? A key figure in articulating developmental understandings of old age is Erikson. It is a rare medical-surgical text which does not include chapters or section on Erikson's Ages and Stages (see for instance, Beare and Myers, 1990 Chapter 3). In Erikson's schema all ages of life are characterised by ambiguity. The person has two options based on developmental crises which occur and recur over the course of a life. The old age crisis of integrity versus despair is predicated upon the notion of epigenesis where each preceding stage must be successfully negotiated for successful resolution of the current stage to occur.

Erikson has proposed a theory of successfully negotiating the rapids of old age which is less negative than Cumming and Henry's. In Erikson's view, people must achieve a sense of ego integrity which is a meaning-making effort in regard to the whole of one's life, and he suggests the principal way for older people to age "successfully" is to reminisce. Erikson has had wide resonance among developmental theorists and among the helping professions generally. The strength of Erikson's theory lies in its 
recognition of the interaction which occurs between the individual and the social context. Disengagement sociologists Cumming and Henry may have over-emphasised the role of the social context in growing old but, at best, Erikson's options for the older person are ambivalent, as the alternative to integrity in old age is despair.

Woodward (1991) criticises Erikson's approach for being overly prescriptive. The Eriksonian stages describe the acceptable face of aging in the current social context, or at least the social context of Erikson's youth. "There can be little doubt that the discontinuity of family life as a result of dislocation contributes greatly to the lack in old age of that ... vital involvement that is necessary for staying alive." (Erikson 1982, p 63)

Erikson's call for planning in mid-life to 'successfully' negotiate old age fails to take account of the circumstances where others' choices, either political or personal, may impact on the best-laid plans of older people. We have recently seen an example of this in New Zealand where the rules of eligibility for superannuation were changed. Another objection is that, if the older person is to capitalise on the middle-age investment in generativity through care for succeeding generations, how are the succeeding generations to exercise any choice of their own?

Grandparent hood is another example of the limitations of the psychodynamic approach to old age which, when combined with a strongly individualistic approach to responsibility, limits the universal applicability value of Erikson's theory. No doubt a source of real pleasure and fulfilment to many, being a grandparent is not necessarily available to all. Indeed the debate 
on grandparenthood and its place in being old has barely begun among developmental theorists. Even when succeeding generations have been obliging through procreation and proximity, it is at best a derived identity, similar to the derived identities that were ascribed to women during the post-war cult of domesticity ('somebody's wife/mother').

The Eriksonian view of old age, while descriptive of many middle class realities, is limited in its scope and, in my view, puts an undue weight of responsibility on some older people to be accountable for things which in a democratic society, an individual cannot control. It is thus, for many, an unrealiseable prescription.

Generativity and stagnation are not the only options for older people, and nurses who relate to older patients on such a prescriptive basis are unlikely to engage with the lived realities of older people in acute care wards. As a profession we must look elsewhere for the informing elements of the dialogue.

\section{Depictions of age in English literature}

Nurses, in common with all those in their culture grow up, go to school, and live their daily lives under the influence of ideas and beliefs and opinions of the culture generally. Some may have independent and novel ideas, but all begin their thinking with the values and beliefs of the culture into which they are born and socialised. In this section I propose to consider some of the wider cultural ideas concerning old age in Western systems of thought and belief. As all the people interviewed in this project were from a European/New Zealand cultural heritage, the discussion is limited well-known Western notions concerning old age. Nursing, 
as a profession, is heir to all these concepts and influenced by them as a participant in our own society. This discussion is not intended to argue against such cultural values, but rather to highlight the ideas so that our actions are informed by a knowing awareness of their influences. An enhanced awareness of the profession's implicit values and beliefs may lead to more informed knowing and acting.

A striking aspect of European culture has been a fundamental ambivalence towards old age. The image of the old woman as a crone or witch, and someone to be feared and ostracised, indicates one aspect of the European idea.

Shakespeare's description of the old man "sans teeth, sans eyes, sans taste, sans everything" is perhaps the most widely disseminated image of old age. Similarly Shakespeare's portrayal of King Lear (one of the few aged central figures in English literature) shows old age as insanity even though Lear is not mad at the beginning of the play. It is his own folly that illustrates the tragic futility of human existence. When the image of the old man - even a rich and powerful man like a king - is added to the image of old women as crones or witches, who were killed to rid small towns of evil, then the European idea of being old is not one to be eagerly anticipated.

Shakespeare also alludes to the alternative image of aging. Speaking to King Lear, the Fool says, "Thou should'st not be old else thou had'st been wise (Act 1 Scene 5 L 43)." The losses of old age are somehow compensated for by the acquisition of wisdom. 
In general, however, until very recently English literature was particularly negative in tone with regard to old age. Continental art and literature on the other hand is much more celebratory of a variety of experiences in old age. It must be remembered that our idea as to the age one is 'old' has changed as more people live longer. Nevertheless, the images of 'old age' whatever the chronological age of the individual, are still vivid in the cultural memory and attitudes.

Gerrit Dou's $17^{\text {th }}$ century painting shows an aging woman about to water the flowers. She is moving from a darkened interior to a world of sunlight. Mckee (1987 p 175) comments on this painting:

Dou shows us an aging woman moving from a darkened and confined interior to a larger world of sunlight beyond. As she crosses the symbolic division between these worlds, she reaches out to nurture some flowers with water- that symbol of the wisdom and reaffirmation of life in old age.

McKee suggests that this work illustrates a much more recent anonymous poem on growing old:

When I was young

I dreamed of many goals I must reach

The great deeds I must accomplish

And the important things I must possess

Now I know there is only one great thing

To live

And see the great light that fills the world.

(Mckee 1987 p 175) 
Featherston and Hepworth (1989) point out that the articulate middle classes are elaborating a public vocabulary in direct opposition to the traditional negative image of being old. Recently Shakespeare has been parodied by Shirley Meredeen of the Hen Co-op:

... shrunk in body

But sans guilt at enjoying the fullness of a life

Avec her own teeth, avec bespectacled eyes, avec

Appreciation of good taste in most things.

Avec almost everything.

(The Hen Co-op, 1995, p 55)

But this is a very recent development, and is certainly a minority perspective. Indeed some of the power of the Hen Co-op is that they represent a protest against the stereotyped view of aging, especially for the older woman. Although they represent a protest, there are other developments in popular culture generally, such as the University of the Third Age and masters' games which also indicate new mainstream cultural perspectives on what it means to be old, and which indicate a change from the way we have viewed old age in preceding centuries.

Here is modern writing expressing a modern view:

Aging? You've never heard of anything in nature aging, or a sunflower saying, "Well, I'm growing old," and leaning over and vomiting. You know it ripens, it drops its seed and (the) cycle goes on. So I'm ripening. For "Age" you can say "ripening."

(Le Sueur 1986 p 9) 
The modern picture of old age is not solely positive. Nancy Fox, a New Zealand poet portrays the 'companion' of old age:

“...ERGO SUM.'

As we grow older we learn to live with pain,

a respected but by no means welcome guest.

At first he does not linger,

Drops in while passing to another host.

Later, decides to stay a day or two.

Eventually...moves in...

To stay.

In this cool house that looks out to sea

Where oleanders lean in open windows

And the morning breeze moves in the pohutukawas

I half awake to a pearl and pewter dawn...

Floating?...dreaming?...'being' or not-being?

Honoured guest, old familiar, sleep,

Sleep on, I will wait for you.

Eastward, pearl to rose, pewter to silver...

And the Sleeper wakes.

I hurt. Therefore I am.

(Fox 1989 p 24)

It is perhaps not unrealistic to suggest that both conceptualisations (the frail and the fit) co-exist in contemporary taken-for-granted assumptions about old age. Fox's poem suggests a different way of 'being' for the person in old age while living within a world of images of great beauty. Thus an aware knowing of which conceptualisation is foremost in themselves, their patients and their families, may be an increasingly complex expectation of nurses. 


\section{IIIness as an existential project}

When a person enters a medical or surgical ward, by definition they have an acute physical problem, or signs which indicate the potential for an acute corporeal crisis which need to be diagnosed and responded to. The physical problem or the disease which legitimates the person's assistance from the acute health care system is distinguished from their experience of illness. Illness evokes the

innately human experience of symptoms and suffering...The illness experience includes categorizing and explaining, in common-sense ways accessible to all lay persons in the social group, the forms of distress caused by those pathophysiological processes.

(Kleinman 1988 p3-4)

It is in this sense that people in acute wards experience the disease processes in and through their own bodies. The patient's experience we call illness, but much of the work and educational expectations of the nurse relate to the disease process

The symptoms and suffering of the illness and the expectations of nursing itself may carry culturally salient meanings which change over time, and indeed over the course of an older person's lifetime. Each person has a world of personal experience which interacts with the social world and which can be expressed in language. This is not the symbolic approach of classical psychoanalysis which determines a cause and effect relationship between past experiences and the present. In the hermeneutic phenomenology of lived experience, the 'text' expressed in inner 
and outer layers of meaning, often through metaphor and story, seeks to uncover the connections between the context of the life of the person.

For persons in acute care wards the context is often strange and inherently alienating (as Brand's description reveals Chapter 1). When the body, the mediator of the external world is simultaneously menaced, patient need in relation to those around them is extremely complex indeed.

Kleinman 91988 p 50) points out that

patients order their experience of illness-what it means to them and to significant others- as personal narratives [which] the patient tells and significant others retell, to give coherence to the distinctive events...Illness story making and telling are particularly prevalent among the elderly. They frequently weave illness experience into the apparently seamless plot of their life stories, whose denoument they are constantly revising. In the terminal phase of life looking backward constitutes much of the present. The gaze back over life's difficult treks is as fundamental to this ultimate stage of the life cycle as dream making is in adolescence. Things remembered are tidied up...retold in a story rapidly approaching its end. ...Illness, assimilated to a life story, helps the elderly patient illustrate life's high and low points.

It is deeply ironic that in spite of an insightful explication of the needs of older patients (of which the above is only part) in regard 
to illness, Kleinman, a psychiatrist, goes on to write composite case studies from his practice experience. The oldest of the patients he describes is fifty-five. This illustrates how even the most committed, knowledgeable and aware practitioner can overlook, or turn their face from, the needs of the older person. We can repudiate overt ageism and judgementalism, but we sometimes find it too difficult to contemplate those whose stories are oriented to a different time.

Older people challenge the 'recovery' orientation of the acute ward. Even when the illness event is satisfactorily resolved, their meaning making in the course of the "ultimate stage of the life cycle" needs to be shared with those to whom it is significant. "Denial is most often a social act." (Kleinman 1988 p 53)

Literature is perhaps the most revelatory of the existential projects of old age. The content of Shakespeare's 'sans eyes, sans teeth' passage points to bodily decay while the tone indicates a pervasive loss of former function, roles, and values and personality. All these relate very closely to the phenomenological themes of the body, time and altered social relations. Seemingly with the passage of time the body betrays the will in its attempt to control the environment and engage in deeper and richer relations in the social world. The physical loss of function is echoed in the social losses as friends, lovers, children move away or die and it is increasingly difficult to replace them. One cannot continue to have new children indefinitely.

In other instances the experience of loss is always present because the place the individual held in the older person's life is so intrinsically entwined in the psyche that the loss leaves a great 
wound which is too sensitive to allow another to touch at that point. Bytheway suggests "it is the death of others which lead people into a sense of being old". The elderly woman who, after her husband's death, sleeps for years on the sofa rather than the marriage bed that she shared with the spouse of fifty or more years shows the deep woundedness of the loss of the other. Not only is her social world altered but the things in the physical space are different as well. She hangs onto the bed because of its meaning for her, but it is forever altered. She has lost a part of her very self, and nothing can be the same, or even similar again.

The body puts limits on the human potential but is simultaneously the gateway to the world. The body only moves to the foreground when stretched to its limits or when challenges are unable to be met, especially challenges which threaten the activities of daily living needed for survival. In Woodward's terms "old age is understood as a . . narcissistic wound to the ego" (Woodward, 1991, p 62). Woodward further notes the discontinuity of the aging body and the continuity of the sense of self.

New Zealand's then Governor General, Dame Catherine Tizard, speaking in 1995 at a function to recognise 'senior achievers', said, "We can't prevent ourselves looking old, but we don't have to act old and we don't have to be old." This ambivalence to 'being old' remains a deep-seated aspect of the cultural psyche, certainly the European or pakeha one.

\section{Conclusion and Commentary}

All the participants in this study were heirs to just such a cultural heritage. Understandings from sociology emphasise the 
distinctions between disease and illness as culturally mediated factors. Explanations of illness are different according to the social positions occupied. Furthermore the representations and framings of the orientations of old age in Western thought as represented by sociology, developmental theory, and English literature are seen as ambivalent at best. The bi-polar options (the fit and the frail, the wise and the senile, the active and the withdrawn) are rejected as sufficiently complex to account for the realities of people's lives.

When the older person is also acutely ill, with the further need to maintain independence and prepare for dependence, the shape of nursing care for older people is seen as potentially different from care for other age groups.

In this chapter I have attempted to set out some important general ways of thinking about being old and ill in (some of) the contextual ideologies which frame nursing care in New Zealand hospitals. The specific stories which the older people bring to this project in Chapters 5-10 illustrate, challenge and cause a reconceptualisation of some of these dominant texts in nursing. All had families who provided support, and who were woven into the seamless plot of their own lives along with the illness experience. For all, the nursing team(s) appeared to become threads in the weaving of lives with numerous projects and interests. Whether we were aware of it or not, nurses had roles in the dramas of others' lives especially at times of vulnerability, confusion and pain.

For many younger patients there will often be some member of the acute hospital staff who can find overlapping interests and 
understandings in sharing general cultural events. For a five year old, someone will remember their first day at school. For an adolescent another may recall their first love. This is not to say we directly communicate our memories to those patients as a kind of self-centred projection, but it is to indicate that we have enough confidence in the evocations of shared aspects of our own story to date, that we can engender confidence in the patient as well. The ongoing project of their life has a companion on the journey. Even though, as nurses, we may not have shared the actual events of the patients in our care, yet we may still in a general sense share the cultural knowledge of events and attitudes. For almost all people younger than 60 years, some member of the hospital staff will have lived through particular events, and have understanding of a range of cultural meanings attached.

With elderly patients we cannot share their particular events, nor can we share their cultural and social past. When the others are people whose mythic re-workings are established on historical events we cannot share (but only know about), the question arises as to how the nurse establishes mutual human recognition. Advice sometimes given to students is to imagine the older patient is an elderly family member and behave accordingly. The question for this project is to seek the views of some older patients themselves. What is helpful, or not, for them?

Unlike Kleinman, nurses in an acute ward cannot actually 'leave out' the concerns and needs of the elderly. We are not writing a book, but rather dealing on a daily basis with the concerns of human bodies, and real people and with whom none of us shares a past. Kleinman does provide an indication, however, of how easy it may be to overlook some needs of the patients in our care. 
In this chapter I have dealt briefly with the various ideas and conceptual framings which are prevalent in the literature informing nursing education and practice regarding older people, and their place in the social context. Linking both the concerns of the research project and the needs of the older people in the acute wards, I have engaged in a brief consideration of the existential meaning of illness in western society.

The movement from the general to the specific takes place on a second level in the next chapter where I turn to the specifics of the methodology which underpins the exploration of the needs of the participants in the study. As the early nursing writers on care remind us how easy it is to overlook the needs of older people, we need a research methodology which may explore the reflections from the hidden ways that older people exist as patients in acute care wards. Practical events in the research story are considered in Chapter 3. 


\section{Chapter 3 Practical essentials of the project}

The purpose of this study was to explore with older people through their individual stories, their experience of nursing care in medical and surgical wards. A secondary goal was to explore a phenomenological research method for its applicability to nursing practice.

As noted in Chapter 1, many research projects exclude the older patient on the grounds of their perceived frailty and vulnerability. As I explored in Chapter 2 this frailty and vulnerability in respect to the aged person may or may not be accurate. Their exclusion from many research studies may be an example of the culturally conditioned practice of overlooking the elderly. Be that as it may, this study was designed to meet current standards of ethical research practice, and be mindful of the current cultural ways older people are perceived.

In the current chapter there is a further 'structure' of the thesis which outlines the events which occurred in the study. The outline summarises the elements in the actions engaged in to find and interview participants, work with the data, and consider the implications for nursing. The study was designed mindful of the potential vulnerability of all clients after acute physical illness. There was no attempt to recruit while they were in wards.

\section{Making contact.}

A press statement was released by Victoria University Media Relations department in accordance with university policy (see appendix 1). In various forms this was published firstly by a number of local suburban newspapers, and later, when numbers of eligible respondents remained low, by national and two provincial newspapers. The press story invited interested 
participants who had been in surgical or medical wards within the last two months to take part in an interview with a nurse researcher. Two months was selected as the time frame which would allow currency of information, and be considerate of the convalescent state of the interviewees. Interested people over the age of 75 years who could sustain an interview of approximately one hour in English were asked to ring a free 0800 calling service and leave their name and number.

The reason for the age limit was an attempt to ensure that the participants represented the concerns of 'older' people and not those of a younger age group. Although officially classified as 'elderly' at age 65, not all 65 year old people agree they are 'old' at this age, and have more in common with middle-aged people than with the elderly. Many elderly do not feel at all 'old', but most 75 year-old people agree that others, such as nurses, see them as old. In the event one respondent was three months away from the $75^{\text {th }}$ birthday, and thus the age range was $74-82$.

I called all respondents back, and visited those who indicated further interest in an interview. At the time of the initial contact by telephone, I discussed briefly their age, the nature of their admission to hospital, confirming that their admission to hospital had involved time spent in a medical or surgical ward. Also at the time of the telephone conversation I arranged a mutually convenient time to call on them, leave the information sheet and consent form and allow them to consider their participation in a conversation with me.

At the first visit the purpose and requirements of the research were explained, and the information sheet and the consent forms were left with the participants (see appendices 1 and 2). Two people indicated at the first phone conversation that there was no 
need for two visits, and the information sheet was posted to them before the interview. One person held the consent form until after the interview was completed, and the transcript had been viewed before giving consent.

The variety of responses to this aspect of the process was surprising to me, I had thought the procedure of a) phoning, b) meeting me, and reading the information sheet c) considering whether they wanted to go ahead with the conversation, d) setting up a meeting and being interviewed, was a simple plan which would meet ethical requirements for informed consent. I sometimes felt uncomfortable with the variations participants required (especially interviewing without formally written consent). However this was a study inquiring about the needs of older people, and as such their needs were paramount in the research dyad.

Two people made contact after suggestions from colleagues of mine, but both indicated they had seen the newspaper articles, and the personal contact of a friend or a relative had been an added incentive to tell their story.

\section{Interview}

In preparation for the interview numbers of texts on research interviewing were read. Minichiello (1990), interestingly, has no specific advice to give concerning speaking with or interviewing older people. This may be seen as admirably treating all potential interviewees equitably. That is, no particular groups have special needs. Keats (1988) on the other hand includes interviewing the very old under a chapter entitled "Some difficult cases." She says, "cultivate a taste for tea." I did not find the interviews difficult, nor was I required to drink tea. These people were volunteers to the 
process, and they welcomed me. All offered food and drink, but there was no sense of obligation. On some occasions it was difficult to negotiate consent about the taping before they told their stories. In my view the practice skills of nursing prepared me particularly well for this aspect of the research. At times I was aware of a tendency on my part to ask 'nurse assessment questions' regarding their symptoms, and I worked actively to restrain this, and to listen with phenomenological 'tact'.

Each respondent was asked to take part in an interview of about an hour's duration. Each interview began with a request to the older people to tell me something about yourself. If they sought clarification as to what exactly I wanted, then I replied along the lines of, if you had to describe yourself to someone else, what would you say? These two questions were quite sufficient to produce rich and thoughtful responses. What was important was the way they chose to reveal themselves. There was no attempt at validation or detail confirmation.

The interview did not follow a structured format, but specific phenomenological 'themes' were sought, including lived space (spatiality), lived body (corporeality), lived time (temporality), and lived human relation (relationality or commonality). (Van Manen 1990, p 101).

The interview was summarised on tape, in order to check that what had been said was what was intended (after Maloney 1994). This was also an opportunity for respondents to clarify points, add to or correct my understandings of the conversation. On the consent form was an opportunity to indicate whether participants wished to see the transcript of their own conversation. People were invited to phone me, or write, if they wished to add or change their interview in any way. I personally transcribed all interviews 
to maintain confidentiality, and to enhance the analytic process ('dwelling with the data').

In the event the interviews ranged from one hour to well over two hours. Some participants expected me to take tea with them and I always did so, if offered. With two people I watched the evening news in the middle of the interview. These were social and conversational occasions.

Six interviews took place, on one occasion each, in the older people's own homes which was their nominated venues. Two people had subsequent brief phone conversations principally to discuss their response to the transcript.

\section{Ethical Issues.}

Safety and well-being of the participants was paramount. All respondents had recourse to the faculty supervisor, and to the local Regional Health Authority Ethics committee.

It was thought that participants, as voluntary respondents to newspaper stories were likely to be seeking opportunities to discuss their experiences. This is considered a helpful process in the developmental literature. However the possibility that some respondents would become distressed by recalling particularly unpleasant or inadequate aspects of care, remained. In the event, no such episodes occurred, although at apparent signs of fatigue the interviewer did offer to terminate one interview twice. On both occasions the offer was declined.

Informed consent was sought by giving participants the opportunity to consider their wish to participate after meeting the interviewer and having the consent forms and information sheets 
to consider for some days. In addition people were informed they could withdraw information (that is, request that it not be used) after the interview was completed, if they had second thoughts. One person withdrew one incident after seeing the transcript.

Maintenance of confidentiality was an issue with low numbers of participants and the telling of individual stories. Individual details which were not germane to the story have been changed. In addition, a nurse colleague acted a 'critical friend', with a special brief to protect the privacy of both the individual participants, and that of the wards they were in. She read all the analytic chapters, and asked critical questions of details which she felt may be revealing of people's privacy, or which may inadvertently identify the institution.

The interviewer knew the identity of the respondent for practical reasons, but this was not retained beyond the study period. No transcript or tape which has identifying material was retained beyond the study period. Patients were referred to throughout by pseudonyms.

\section{Phenomenological writing.}

Analysis involved constant conceptual comparison of the transcripts both with each other, and with other texts in the nursing literature, in phenomenological literature, and in popular published material. The goal was to describe the lived experience in such a way as to reveal its quality and significance both in the context of the older person's life and its implications for nursing. Van Manen's approach to data analysis was followed closely particularly in the early stages of analysis. His approach involves insight, discovery, and the "free act of seeing meaning" by a) attending to the text as a whole and identifying a phrase which 
carries the whole meaning, b) looking for statements which seem especially revealing of the phenomenon, and c) a detailed line by line examination of the sentences and paragraphs.

Attending to the text as a whole and identifying a phrase which carries the whole experience is reflected in the headings and subheadings of Chapters 5-10. Some of these headings were established early at the first reading of the transcripts (for instance, the Chapter 7 heading pockets full of Panadol, which characterises Miss Shepherd's relations with nurses). The early establishment of the wholistic phrase was aided when the person was very expressive in the tone of voice.

Other such wholistic phrases were only clear after much reflection and hermeneutic writing (for instance Lorna's characterisation of herself in Chapter 8 as sort of standing up for myself.)

Lorna's characterisation of herself is an example of the wholistic phrase referring to the patient view of herself, her lived experience. In others chosen phrases, however it refers to the patient expression of their expectation from nurses, that is what they would have like from nurses (Chapter 6 all sorts of tricks). In this way the dual orientations of the project are maintained through both perspectives in the chapter headings. The decision as to which orientation (the patient view of themselves or the patient expectation from nurses) was made after reflection by me as to what I considered was the pre-dominant motivation of the person in responding to the newspaper advertising. Some patients wanted mainly to talk about themselves, others wanted mainly to change things for others. All had both orientations, but when it came to naming the chapters 5-10 I made a judgement, based on the protracted period of 'dwelling with the data' as to which perspective was the most important. 
Looking for statements which seem especially revealing of the phenomenon is further explored in Chapter 4 alongside a consideration of the philosophical underpinnings of the project. A detailed line-by line examination led to a period of visually mindmapping the elements in each story. This was followed by a period of writing and phenomenological reflection, and re-writing.

Van Manen's understanding of writing and re-writing involves a four key elements, briefly outlined below.

First there is "attending to the speaking of language." He points to the purpose of the writing being in view throughout the project. In this project I was listening for the clues which inform nursing of older people. I was listening for "the sensitivity of the subtle undertones of language" (Van Manen 1990 p112). The language "spoke" in the interview, but also, in the reflecting and various methods used to re-visit the transcripts, new modes and subtleties of language were noticed.

A second issue is "silence-the limits and power of language." As a nurse I was attuned to picking up cues of happiness, indignation, sadness, and other underlying 'tone' in the conversation. As a researcher I only noticed the silences and power of the silences during a period of dwelling deeply with the data later on. Some of the silences are commented on in Chapter 12.

"Anecdote as a methodological device" is a further consideration. There are many stories in this work. They are not simply supporting illustrations for a pre-conceived position, but are evidence of the power place nurses have in the lives of older people in acute wards. Van Manen (1990 p124) indicates that anecdotes should be from various sources in order to provide a 
balanced picture of the phenomenon of concern. In the previous chapter I have indicated a number of sources of such story. In Chapters 12 and 13 the concluding commentaries are based on myth and metaphor.

The final aspect of writing which Van Manen considers is the mediation of action and reflection. Phenomenolgical research depends on language for its very existence. Thus the consistency of process in the gathering of information needs to be repeated in the analysis of data. This is true for all forms of research: data gathered numerically must be reported numerically. In this research writing and re-writing was a form of gathering the stories aligning one's thoughts and expressing that alignment. This is seen principally in the core chapters $5-10$. To write is to bring the patterns of meaningful relations into text, to exhibit the shared story of the research.

The next chapter explores in more detail the philosophical underpinnings of the research events described here. This chapter has been about actions and processes, the next is concerned with rationales, explanations and principles. The congruence of Van Manen's research method with the concepts of practice is also explored through the explication of the theoretical positions of the phenomenological movement utilised in this study. 


\section{Chapter 4 Researching lived experience}

This project utilises the hermeneutic phenomenological approach to human science inquiry described by Van Manen (1990) to understand what nursing care is like for people over 75 years in medical and surgical wards. The objective in this chapter is to lay out the philosophical presuppositions underlying the Van Manen's approach to researching lived experience.

\section{A rationale for hermeneutic phenomenological research in nursing}

The purpose of phenomenological research is to understand an event, a phenomenon from the perspective of the pre-conscious understanding of the person experiencing it. The field of study is the world of everyday experience, which is where most of our lives are lived.

One important class of such experiences is perception-seeing, hearing, touching, and so on. But ... there are also phenomena such as believing, remembering, wishing, deciding, and imagining things: feeling apprehensive, excited or angry at things: judging and evaluating things; the experiences involved in one's bodily actions, such as lifting or pulling things.

(Hammond, Howarth \& Keat, 1991 p 2)

Recently there has been a sustained call for nurses to investigate patients' experiences by attending to such concerns. (Benner and Wrubel, 1989, Watson, 1988, Morse,1991)

There is no doubt that nurses need empirical knowledge which is universal and general: in one sense every hip replacement is like 
every other, every intravenous pump is like every other pump of the same model. However nurses need to mediate this universal knowledge to the individual patients. The meaning of such universal events will be different with different patients. To one person the patient controlled analgesia (PCA) and the prosthesis seen on $\mathrm{x}$-ray are pain-relieving marvels of medicine. To another they are de-humanising indicators of a body which will no longer obey the will of its inhabitant and reminders of the immanent mortality. To yet another they may have both meanings simultaneously. Furthermore, each 'universal-individual' meaning event will take place in a slightly different context.

It is a fundamental assumption of phenomenological research that the discourse of every day experience (although not the commonsense judgements that people make about every day experience) reflects such human concerns as they are actually lived by people. This perspective is assuming new importance as the evidence mounts that the experience of health and illness is related to disease and recovery processes at the cellular level (West, \& Stein 1982). Patients do not experience such relationships as separate phenomena. However, the cellular activity is sometimes proffered as the only means of understanding the experience of illness. It is important that nurses bear in mind the physiological elements of illness experiences, and act accordingly. It is also of importance that nurses are able to influence the 'quality' of the patients' experience. I would contend that nurses often practise at the level of the person's experience, and that practice which is integrative of both perspectives is indeed quality practice. Phenomenological inquiry may be an alternative means to traditional quality indicators for considering the nature of 'care' for patients in hospital. 
It is a particular assumption of this project that nurses have a specific mandate to have concern for patient experiencesespecially those which might be called 'everyday'. (See, for example, Taylor 1995). To say this, however, is not to deny nurses' very real interest in the biophysical, nor is it to deny other health professionals an interest in the intersubjective. In this project I have opted for an integrating approach on the grounds that the balance of concern for nurses in acute care wards at this time is with the human relationship: what is it like for these persons to receive nursing? And, what shape of nursing is 'care' for older patients?'

Such an inquiry approach is also to assert that research methodologies which deal with being human are simultaneously relevant for the consideration of nursing practice and knowledge claims in the discipline. Riley and Omery (1996 p 7) cite Maxwell's approach to scholarship where

the previously separate world of facts and values will merge to create a shared world of experience that purposively guides both knowledge development and policy making. Scholarship viewed in this connected way indicates a greater commonality between intellectual pursuit and human issues.

A further implication of such an assertion is that the methodology which most closely parallels the practice experience of nurses is that of phenomenology (Bartjes 1991).

The section that follows is an attempt to historically situate the development of phenomenological thought and link selected epistemological claims to aspects of nursing practice which are significant for this inquiry project. Phenomenology is not a single unified philosophy, and it is necessary to indicate which choices 
and assumptions have been made; in short to situate the philosophical context of the study.

How are nurses to know what sense patients are making of their experience in hospital?

One answer to this question lies in the philosophical practice of phenomenology. As Spiegelberg and Schuhmann (1994, p $X X V I I)$ point out, with regard to phenomenology, "the varieties exceed the common features." Thus it is necessary to situate this project within the variety which constitutes the phenomenological movement as a whole.

\section{Historical roots - Husserl}

Historically phenomenology arose as an attempt to bridge the gap between the mind and the body which was a legacy of Cartesian dualism. One aspect of the relationship between the mind and the body in Cartesian terms was the allocation of a secondary role to consciousness. It was merely another object to be investigated in a world of objects. A corollary of the Cartesian stance is that consciousness is subjective and so outside the realm of scientific investigation. Husserlian phenomenological investigation rejects both of these alternatives. Rather it assumes that anything which appears to consciousness is a "manifestation of the essence of that which it is the appearance" (Stewart \& Mickunas 19 p 3).

In the years 1901-1906 Husserl placed equal emphasis on both subjective and objective aspects of experience as epistemological foundations of science. Cohen (1987) gives a readable historical account of the foundations of the phenomenologic movement. 
In Husserl's early thought he was concerned to point out the flaws he saw in logical positivism, and so developed the method of phenomenological reduction which he called the epoche or bracketing. It was Husserl's concern to suspend the 'natural attitude' until further verification was available. In the first phase of his philosophic development, Husserl believed the task of the phenomenological inquirer was to adopt the stance of a 'detached observer.' In suspending the 'natural attitude' the inquirer concentrated on only the self-validating cognitive experience itself. "He aspired to a philosophy without presuppositions" (Cohen 1987, p 32). Stewart and Mickunas (1974 p 26) claim Husserl's intent was not a "suspension of judgement... but a questioning of presuppositions until they could be established on a firmer basis."

There is agreement over the importance of eidetic science in Husserl's thought. Although he wanted to reject Cartesian assumptions, Husserl called for a return to the spirit of Cartesianism with a return "to the things themselves," (zu den sachen), an investigation of the essences of things (Stewart \& Mickunas 1974, p 22). Much criticised in this phase of his philosophical development, Husserl responded by reaffirming the non-ideal thrust of his method, and developed the significance of the lived-world (lebenswelt). While it is beyond the scope of this project to argue whether lebenswelt is a departure from, or an extension of his earlier concern with eidetic science (Stewart \& Mickunas 1974 p 47), this project does question Husserl's claim that it is possible to have a "philosophy without presuppositions," and it draws heavily on the notion of the lived world. Cohen (1987 p 32) claims that it was Husserl's belief following the death of his son in World War 1, that science needed contact with deeper human concerns which led to the development of the notion of the lebenswelt. 
The 'living' (lebens) that older people do in acute hospital wards is imperfectly understood. Even when understood by nurses who are oriented to the needs of people in the world (welt), this 'living' is not always facilitated. Thus phenomenological research deals with both the subjective realities of people, and the world as object. Husserl described this relationship of people to the world as one of intentionality. Nurses share the space of acute wards with patients, and are therefore both actors in the 'world' and part of the world of others. Husserl advocated the natural standpoint which constituted "the basic web of all human relationships to the world and to other people." (Stewart and Mickunas p 24)

A further concern of Husserl's was transcendence. The transcendental refers to the necessary conditions for both subjective and objective experience to occur. Within experience one can find levels which are both transcendent (that towards which consciousness points), and immanent (that which does not point beyond itself to something else.) It is important to note that for Husserl 'transcendence' does not mean the existence of anything outside of the experience itself.

Like lived-experience, transcendence has implications for the inquiry method. The 'thing' to which consciousness points is perceived in successive perspectives. A phenomenon or 'thing' retains its essential unity but our understanding of it is multiple depending on, for example, different vantage points, and different cognitive processes such as perceiving, remembering, and others.

In Chapter 1 I have laid out two structures of the thesis. At this point I draw on the idea of multiple standpoints in relation to the patient experience in an acute ward. A nurse may help a patient 
into bed, the patient is helped into bed. This is one event, but it has multiple perspectives, depending on whether one is the patient, the patient in pain and afraid, or the patient contemplating discharge home, the nurse, another patient observing the action, the researcher observing or hearing about the event, or the patient recalling the event some time later.

The phenomenological notion of intuiting (or anschauung) has relevance for the inquiry method also. "It is close to logical insight based on careful examination of representative examples." (Cohen 1987 p 32). In the multiple perspectives cited above, it is possible to understand the common elements in all perspectives.

\section{Historical roots - Heidegger}

Heidegger was a student of Husserl's at Freiberg, and succeeded to Husserl's chair. Although he repudiated the term 'existentialist', his critique of Husserl's transcendental phenomenology was to point out that to attempt to describe everything in terms of consciousness was to overlook basic dimensions of human experience such as dread, anxiety, and death, major concerns of the existentialist philosophical school(s) such as Sartre, Marcel and Jaspers. (Stewart \& Mickunas 1974 p 68ff). Such basic dimensions of experience are many of the concerns of the people in health and illness, especially in an acute ward where patients cannot often avoid the deaths and dreads of others as well as their own. The research endeavour then, does not begin with a 'blank slate' but such Heideggerrian and existentialist concepts as are already present in the phenomenological movement, inform the research.

Another distinction between the phenomenology of Husserl and that of Heidegger is the stance of the phenomenological 
philosopher. For Heidegger (1962) in Division One of Being and Time, it was impossible to describe the lived world from the position of a detached observer. Benner (1985, p 9), committed to a similar inquiry perspective, argues for hermeneutics as one research strategy which allows "the study of the person in the situation...and [which] overcomes the problem of extreme subjectivity or objectivity." Moreover the background preunderstandings are always present both for the teller and the listener. This background gives individuals "the conditions for their possibility," and enables the researcher to analyse the options in exploring a human concern such as need or care. I shall further discuss the place detachment or reduction when considering Van Manen's view.

For Heidegger, not even time was a correlate of consciousness. The method of investigating is to find the basic modalities of being-in-the-world. This reality he called 'being-there' (Dasein). The most basic mode of Dasein is care (Sorge), which may be authentic or inauthentic. As Munhall (1994 p 45) noted,

Dasein is ontologically related to the entities by an attittude of care. Research thus becomes...an act of caring to know what it means 'to be' in the world.

Thus, for Heidegger, being historical was more basic than transcendental investigation. This notion informed this research in that each conversation is situated historically in the context of the person's life. The nature of space of the hospital wards was also sought specifically.

Where Husserl claimed that consciousness is not merely one thing among all other things, Heidegger was concerned to say that Being is not merely another being among all others (Stewart and Mickunas $p$ 72). This is not to return to causality as the 
research preoccupation, rather to reorient the research endeavour towards a search for the meaning of being. Specifically in this research project, it was to ask the question, "what is it like for older people to 'be' in acute wards in the company of nurses?" As conversationalist, I too, was a nurse in their company, inviting them to describe their contexts, their experiences, their feelings, their expectations, and their judgements, and in turn re-making with them their understandings of the hospital experience.

\section{Historical roots - Existentialists: Sartre, Merlau-Ponty}

After World War 11 French philosophers continued phenomenolgy's critique of positivism. Sartre accepted Husserl's position that consciousness is central and that Cartesian duality is a mistake. "When one is studying man, what can be more exact or rigorous than to recognise human properties in him?" (Sartre, 1963 cited in Cohen, 1987 p 33). Thus science which demands a rigour foreign to the human condition cannot reveal anything about the human condition. For Sartre the human condition encompassed the paradoxical notions of situatedness and freedom. From Heidegger Sartre accepted the notion of situatedness, the "temporalization of the consciousness" (Stewart and Mickunas 1974, p 73). For Sartre the intentionality of consciousness is oriented toward being (Cohen 1987, p 34). In the present we are always projecting into the future, and this determines what the past will mean. (Stewart and Mickunas 1974, p 74).

Thus as these patients tell their stories the conscious articulation reveals a dialectic that is accessible to analysis. Sartre also indicates some clues as to what areas of analysis might be 
fruitful. He extends the notion of Being-in-Time to consider the experience of not-being. "For Sartre, man has no essence; he simply exists, and must construct his own essence through his own free choices." (Stewart and Mickunas 1974, p 74).

The experience of not meeting an expected friend is not simply an element of negative judgement, but is experienced as a lack or a gap.

Another existentialist, Martin Buber describes the missed and inauthentic relationship he felt was at the core of his relationship with his mother who left the family home following divorce when Buber was four. Van Manen comments on Buber's experience:

Buber grew up as a Jewish boy in the middle-class comfort of the care of his father, his grandmother and grandfather, each of whom contributed significantly to his education and growth. However, the central significance which his earliest memorable experience occupies, is his sensemaking of his mother's leaving him as a very young child.

(Van Manen 1990 p 84)

Similarly when nurses do not meet expectations, that sets up an experience of lack in the patients which can be explored. Patients do 'make sense' of their experiences and carry this choice with them into their next encounters with health 'care'. Nurses do not deal only with the patient's affected organ or disease, rather they deal also with the "historical, cultural, embodied, situated person". (Benner 1985 p 2). Phenomenological methods permit the researcher to ask how 
people maintain these elements of their personhood in the face of challenges.

"Every particular situation suggests a possibility that could be lived by any human being." (Stewart and Mickunas, $1974 \mathrm{p}$ 76). Through the study of the particular a window is opened to the "things" which underlie the specific phenomenon. Those things which help or hinder caring for patients in these wards need to be known by nurses.

The second notion from Sartre which influences this study is that of resistance. "One important aspect of the objectivity of nonbeing is its capacity to resist." (Hammond et al 1991, p 115). Thus Sartre's idea of freedom as a fundamental life experience became in later phenomenology the notion that through story we "can broaden the horizons of our normal existential landscape by creating possible worlds." (Van Manen 1990 p 70). New possibilities are uncovered in the telling and the analysing the personal lifeworld as well as the literary description. In this study the literature examined for its potential for insight into the human condition is the nursing literature rather than the artistic literature of poetry, drama and the artistic disciplines which van Manen advocates. If any "new possibilities" for people over 75 years in medical and surgical wards are to be enacted in practical ways, the 'other player' in the drama (the nurse) must also be involved in the textual analyses which reveal the disciplinary structures equally with the analyses which reveal the individual lived experience.

\section{Lived Body}

Although it may be implicit in Husserl's thought that consciousness is embodied (at least for the person describing the 
phenomenon of inquiry), others extended this and emphasised the impossibility of disconnecting the body. Merleau-Ponty's term 'owned body', and Marcel's 'I am bodily' expressed the concept of incarnate subjectivity. Merleau-Ponty based his notion of a situated body on the case of Schneider, a brain injured individual who had difficulty recognising an object as a pen unless the clip was turned to him. Merleau-Ponty's comment was that "the empiricist will try to provide a causal explanation of Schneider's difficulty - for example by reference to his defective vision." (cited in Stewart and Mickunas $p$ 167) The defect may be neural or cortical, but this explanation does not capture the quality of the patient's experience. It is this wholeness of the patient experience that the human science of lived experience seeks to elucidate. Nurses do need understanding of such causal explanations, but also other knowledge as well to attend to the needs of patients.

Moreover, Merleau-Ponty has a more limited view of human freedom than Sartre as his consideration of Schneider illustrates. "[Freedom] shrinks without ever disappearing altogether in direct proportion to the lessening of tolerance allowed by the bodily and institutional data of our lives." (Merleau-Ponty, 1962 cited in Hammond et al 1991). Schneider can only change his options in as much as his basic way of being in the world permits. Interpretive phenomenology then, in this tradition, seeks to uncover contextualised meaning, as well as future possibilities.

\section{Researching lived experience - van Manen}

One contemporary proponent of researching lived experience who draws on all the above notions in an eclectic fashion is Van Manen (1990). As do the existentialists, Van Manen reconciles 
apparently contradictory concepts from the competing versions of phenomenology by invoking the notion of paradox.

Van Manen's claim is that phenomenology is a way of studying the humanness of humans. He acknowledges the need for the researcher to understand the traditions intellectually, but real understanding of phenomenology only comes from 'doing it'. "In doing research we question the world's very secrets and intimacies which are constitutive of the world, and which bring the world as world into being for us and in us." (Van Manen 1990 p 5) Van Manen's concern is to investigate in such a way as to "bring one in more direct contact with the world", rather than controlling, predicting or classifying.

The idea of pre-conscious understanding becomes pre-reflection for Van Manen. It emerges from the "practice of living" (Van Manen $1990 \mathrm{p} \mathrm{146)}$ ). "Over the ages human beings have invented artistic, philosophic, communal, mimetic and poetic languages that have sought to (re)unite them with the ground of their lived experience." ( $p 9$ ) Thus the substance of language, or text, is the data of phenomenology. The scientific task is to svstematicallv make the tbemes of these texts explicit rather. than leave them implicit in the text as is usual in every day life.

To study a phenomenon while it is actually occurring is impossible for Van Manen. To think about being happy or to think about thinking already changes the nature of the happiness or the thought processes. Human science research for Van Manen is always reflective. "It is reflection on experience that is already passed or lived through." (Van Manen 1990 p 10) Behind the experience there is always meaning, which is co-created between the researcher and the researched, as well as between the writer and the reader and -1 would add- between the nurse and the 
patient. In this project patients reflected to me, the nurse/researcher, their experience of nursing care in acute wards. They literally re-called and re-flected upon their experience, and in turn metaphorically reflected this experience to me.

Reflection in this sense as a way of knowing is familiar to nurses. Tanner et al (1993) refer to the common experience that ICU nurses have when they cannot directly 'know' the unconscious and intubated patients, but they can come to 'know' the patient by the reflections in the faces and conversations of the family as they are around the patient. It is a form of observing those around the patient as they mirror the images of the patient from their shared past and their projected and hoped-for future(s).

Reflection as a metaphor for knowledge has a counterpart in Sartre's insight as to the dialectic nature of the relationship between consciousness and being which has major significance to a human scientist. The research endeavour is always dialogic both with the informant and the reader. This dialogue parallels the dialogue which occurs in practice also.

Van Manen draws on a range of notions in the phenomenological literature. He draws heavily on Husserl's notion of eidetic science: that which is essential to making a thing what it is. Through the particular details of a lived experience it is possible to uncover the meaning or "structures" of universal essentials.

Van Manen modifies Husserl's notion of bracketing, however.

Those interpretive phenomenologists who adopt a purist Husserlian stance require some form of 'bracketing' intrinsic to the research method. As an eclectic existentialist phenomenologist, Van Manen's approach to reduction (his term 
for bracketing) is much more attitudinal and ongoing than related to an event in the 'method'. He describes four aspects of reduction:

First, reduction involves the awakening of a profound sense of wonder at the mysteriousness of the belief in the world...

Next, one needs to overcome one's subjective or private feelings, preferences, inclinations, or expectations that would prevent one coming to terms with a phenomenon or experience as it is lived through.

Third, one needs to strip away the theories or scientific conceptions and thematizisations which overlay the phenomena...

Fourth ...one needs to see past or through the particularity of lived experience toward the universal, essence or eidos that lies on the other side of the concreteness of lived meaning.

(Van Manen 1990 p 185)

Van Manen emphasises that reduction is not an end in itself, but a "means to return to the world in an enriched and deepened fashion." (Van Manen 1990 p 185)

The structures of the world which may be hidden by our own precognitive theorizing emerge through a thoughtful process of reduction. To lose a sense of wonder, to project out of one's own beliefs and expectations or pre-conceived theories, and to dwell only with the concrete and the particular; all these need to be guarded against in the research project. Chapter 2 represents just such an effort on my part. Here I attempted to make explicit the theorizing which might hide the hidden ways of being in acute care wards. 
In the overall methodological approach to this study I have attempted to follow the approach of Van Manen in regard to reduction as well. It may be argued that I should have followed an approach of a nurse researcher such as Benner. However the intention was to engage in a research methodology which was as close as possible to practitioner action. Benner's (1985) methodology involves a team of researchers engaging in "expert consensual validation", a method of validation which is not usually available to the practitioner (and there is no guarantee that there is no bias latent in this group either. Thus "bias control strategies" (Benner 1985 p 11) can cause the project to dissolve in an everwidening series of circles of consensual validation which is nothing more than current political and academic fashion.)

This project follows Van Manen who does not specifically refer to problems of validation, rigor, bias, or any one of synonyms usual in discussions of qualitative research. Instead there is an assumption that the normal expectations of written text apply to writing phenomenological writing as well. The researcher should maintain integrity with the original data presented, and should help the reader understand the human experience. Interpretations should be internally consistent, and the reader also has a responsibility to examine the knowledge claims against their own experiences. Ways in which I sought to achieve these goals were described in chapter 2 . They were not attempts at 'bracketing' or validation, but rather aids to maintaining the orientation of the project.

From Heidegger and the existentialists Van Manen draws certain themes which are fundamental to the human condition and which inform this inquiry. These are: 
- lived space (spatiality)

- lived body (corporeality)

- lived time (temporality)

- lived human relationships (communality)

Thus the question of what it is like for older people to receive nursing care in acute medical and surgical wards has some initial inquiry points to guide the conversation.

\section{Reflecting on stories of lived experience}

Van Manen posits a particular method for uncovering such structures ("thematic statements") :

- the holistic or sententious approach

- the selective or highlighting approach.

- the detailed or line-by-line approach. (Van Manen 1990 pp 92-93)

In this research project the holistic approach is reflected in the chapter and section headings throughout chapters 5-10 which are an attempt to capture one fundamental phrase which sums up the significance of the story or text as a whole.

The highlighting approach was undertaken literally as well as figuratively. By this I mean that the 'highlight' of a particular section of transcript was identified not only by actual marks on the paper in relation to content, but also the dramatic and emotional highlights of the story were looked for. The transcribed text was read several times, sometimes as text alone, at other times it was read with a conscious effort to recall demeanour and tone of the conversation. As well, after the initial highlighting, the transcripts were read with the tapes playing in order to check the congruence of the interpretive decisions. For instance, there was deliberate checking of whether the decision to highlight a particular aspect of 
text was in accord with the interpersonal nuances on the audiotape.

The line-by-line approach led to the uncovering of what each sentence or paragraph seemed to reveal about the needs of these particular people in hospital, and also with regard to elements in the conversations which they seemed to share. There was no attempt at constant comparison, but when issues were raised by one respondent I would have a heightened alertness to that concern with later interviewees.

The common themes within each story and across the stories were noted and transferred to large sheets to visually chart the 'whole' of the patient's life history and their hospital experience. This was 'painted' together in a word portrait of the person's story at the end of each conversational report. As the writing and reflection continued, a commentary was added as the 'nurse' tried to 'hear' the voice of the respondents as a group. Each maintained their separate identities, but each interview informed the succeeding interviews, and there was an attempt to draw together common concerns and consider these in relation to nursing's own world view. This was not an attempt to read the issues and concerns of nursing into the concerns of the patients, but to consider the expressed needs of such patients as a commentary on the general practices of acute care nursing by comparison with other extant texts from and for the nursing community itself.

It is at this point that this project extended Van Manen's analytic process in the interests of situating the interviews. There were particular individuals speaking with and to a particular person. There was also a sense in which these stories were representative of older people's relations with nursing. I am a 
nurse. Respondents were specifically invited to 'speak with a nurse researcher'. The stories were oriented to their needs as they related to nursing, and the analytic process in Chapter 13 reflects this by acknowledging the context of the research attempt as well as the context for the respondents' original experience. The 'things themselves' that I returned to were the relations between older people and nurses in specific contexts. The dialogic space maintained the two orientations of hearing the voices of patients, and reflecting on the implications for nursing practice.

In this section I have attempted to set out the key concepts from the phenomenological movement which have informed this inquiry project. Although there are voices in the nursing literature advocating such approaches to inquiry, there are others who are less certain of the value of phenomenology as an inquiry method, and as an appropriate contribution to nursing. In the next section I dicuss some of the contested positions in regard to the use of phenomenological research in nursing.

\section{Contested stances - nurses and phenomenology}

As Crotty points, out phenomenology has taken a different turn in North America than in continental Europe. He claims that in the former it has been taken up by nurses via the philosophy and values of humanistic psychology, whereas in the latter, philosophical endeavours have continued "grounded in authentic phenomenology." (Crotty 1996 p 125). Crotty calls for nurse researchers to consider two possibilities: firstly to acknowledge their reliance on humanistic psychology, and secondly for some scholars to engage in the 'authentic phenomenology' as it has been preserved in Europe. 
As a critique of humanistic psychology, Crotty's concerns can be seen as a repudiation of a Rogerian science where there is a basic assumption of the inherent self-actualising potential of humans. In this I would concur with Crotty: There does not seem to be evidence of such an inherent potential. Given the history of the twentieth century, the judgement for optimism or pessimism about the human condition seems still moot, and thus to embrace the optimistic presuppositions of humanistic psychology seems, at the very least, premature.

However at another level Crotty's language reveals just how far his concerns are from the concerns of nurses. Speaking approvingly of Moustakas' heuristic inquiry model which stands in the endorsed European tradition, Crotty says "Moustakas is seeking to elucidate... loneliness and not just lonely people." (Crotty 1996 p 35 emphasis added) The notion that nursing as a practice discipline can deal with concepts as being of greater significance than the person to which the concepts apply is an astonishing one in a discipline which deals with 'people' on a daily basis. (In some of the stories in later chapters in this project there is vivid illustration of what occurs for the patient when nurses deal with 'the pain and not just pain-ful people.') If a nurse researcher is to follow Crotty's philosophical path, it seems to me that at a fundamental moral level there is dissonance between the expectations of patients, the performance of nurses, and a methodology for inquiry which supports a people-centred practice discipline.

Crotty also considers Van Manen fails to recognise that "phenomenological inquiry Is inescapably a first-person exercise.... In this kind of inquiry we cannot borrow other people's data" (Crotty 1996 p 176). Here Crotty seems on particularly 
shaky ground. Our conclusions may be offered with much less certainty when we 'borrow others' data,' since it is difficult to 'know' all the presuppositions and contexts, seen and unseen, which are present in any moment of living. However to proscribe the use of the data of others would seem to exclude from the category of 'inquiry' the activities of other writers widely acknowledged as part of "the phenomenological movement" (even authentic Europeans). I have already referred to MerleauPonty's famous description of Schneider's perceptions of objects in the world following brain injury.

Crotty performs a valuable service reminding us of the predominantly North American contexts of the current phenomenological nurse researchers. The essential optimism of such a cultural context may not be inherent in phenomenological inquiry. However there seems no sufficient argument to embrace what he perceives as authentic phenomenology, since many whom he regards as 'authentic' themselves use an eclectic approach to the notions of the phenomenological movement.

A second critique of phenomenology in nursing has come within the discipline itself. There have been attempts by some nurse scholars (e.g. Koch) to delineate between the differing schools in phenomenological thought in the interests of philosophical 'rigour'. While I do not wish to endorse a position antithetical to rigour, it is a fundamental position of this project, of Van Manen, and of the human science approach generally, that the overarching consideration in any inquiry is the human experience in the particular context, and not 'reason', rationality or cognition alone. Thus the lived experience of the research and the lived experience of the practice and the lived experience of being a patient are treated consistently in this project. The consistency is one of process, not one of conceptual rationalism. To argue for 
rationality at the exclusion of other human and everyday concerns while engaging in the very methodology which claims to deal with human and everyday concerns seems at the best ironic, and at worst fallacious.

Koch (1995) engages in some intellectual sleight of hand by her own terms. She distinguishes between Husserlian and Heideggerian phenomenology. The work of Benner \& Wrubel (1989) is characterised as " hermeneutics practised outside the circle." By this Koch means that Benner and Wrubel attempt a form of Husserlian reduction through "expert consensual validation" and the constant comparative methodology of grounded theory, while claiming Heideggerian philosophical undepinnings. Koch regards the methodologies used to have "diverse philosophical origins." To her, this is an example of research methodology which is confused about or which is unaware of the philosophical underpinnings of the two approaches. (Koch 1995 p 834).

Other scholars are not as sure as Koch and Crotty. Spiegelberg for instance entitles his magnum opus "The phenomenological movement." In this highly regarded history there is a clear understanding of the common streams of the philosophical positions which flow into the 'movement.' To speak of 'philosophical underpinnings' as if these were static commodities which could be taken out of the cupboard and always used in a particular way without consideration of the dynamic demands of the lebenswold would seem a disservice to the very movement Spiegelberg (and Koch) seek to explicate. Part Five of Spiegelberg's text is entitled "The Essentials of the Phenomenological Method." $\mathrm{He}$ is aware of the differences between scholars in the tradition, but nevertheless sees enough shared concerns to speak of "the movement." 
Van Manen, however, whom Koch quotes in support of her view, is quite clear that "there is no method... there is only tradition." In drawing lines between Husserl and Heidegger, Koch seems to be formulating rules. Where method ends and tradition begins for Koch is not clear at all. What does seem clear is that Koch, by her own canons, cannot have it both ways. Her argument is that the research project must either follow Husserl, or Heidegger, or at least reconcile the differences. If so, Koch cannot then approvingly quote Van Manen since he sees no contradiction in apparently combining aspects from both Husserl and Heidegger (and from others in the "tradition" such as Sartre). Van Manen seeks to follow the phenomenological tradition as a whole utilising the concepts and insights of those who have gone before him. I offer this project as evidence that it is possible to uncover knowledge which enhances practice by utilising practitioner skills and reflection.

Yet a third critique of the use of phenomenological research in nursing has come from those concerned about Heidegger's stance with regard to nazism (Holmes 1993). They ask, how can a practice discipline committed to the welfare of human beings draw on philosophical underpinnings which permitted their originator to support, at least tacitly, the rise of German fascism? In my view this is a serious charge against phenomenology as a research practice in nursing.

Holmes (1993 p 399) suggests that "sympathy for fascism is a likely, if not inevitable, consequence of championing any thoroughgoing Heideggerian philosophy." Benner meets this challenge by insisting, as I have indicated above, that her work is based on the early Heidegger, and, by implication, the Heidegger uncontaminated by his later contact with nazism. Thus she is not 
'thoroughgoing' in her commitment to Heideggerian phenomenology. Benner tempers Heidegger's rejection of valuing as "blasphemy against Being" (Holmes p 400), through an attendant commitment to the values of the North American humanists. (Incidentally it is this very commitment to humanist values which Crotty criticises in Benner's work.) Thus it would seem, if nurses adopt an eclectic approach to thinking phenomenology, which has resonance in their own cultural context, they are criticised for not understanding 'pure' phenomenology. If they do not take up an espoused value-laden position, they are criticised for promoting research practices which lead inevitably to fascism.

Humanist values may have resonance in a North American context. As I have indicated above in regard to the discussion on Crotty, I have no particular commitment to humanism. Rather, in this project, I have attempted to adopt a 'professional nursing' stance with regard to the values which inform the project. Heidegger's regard for fascism as "an antidote to nihilism and technologism to which humanism inevitably gave rise," (Holmes 1993 p 400) is one which New Zealand nurses' historical and embedded cultural context makes impossible in this project. Antidotes to technologism and nihilism may be needed but to propose fascism as the antidote is remote from the currently espoused professional values expressed in law and in the Codes of Conduct as they relate to nursing. One does not have to align with either fascism or humanism to engage in such an inquiry project as this work represents and as many other nurses have done. To claim, as Holmes does, that Heidegger's philosophic stance leads inevitably to fascism is to call into question the research values and practices of a great many nurse researchers. The social values of this research are endorsed through the various Ethics committees which approved the project, and may 
be thought of as a kind of democratic pluralism. Thus there is no appeal to "Being," or rejection of conventional ethics, as Heidegger in his later works seemed to do. Nor is there any appeal to any other grand moral or epistemological position.

The philosophical bases of this project are essentially those of Van Manen (1990). There has been sustained effort to understand the philosophy underlying the methodology through reading the works cited in this chapter. The main lodestone of the usefulness of any particular research activity and its associated fundamental principles has been a consideration of the 'fit' with nursing practice, as this is understood by one practitioner engaging with a range of disciplinary and cultural literature as set out in Chapter 2.

An example of a full explication of such an activity is the discussion above regarding the processes of establishing rigour in such a research process, and the reliance of this project on Van Manen's approach to reduction rather than to bracketing, validation, or bias control strategies, as other researchers conceive of related activities. This process has been followed throughout this chapter. I have attempted to 'lay out' two or three options for each pathway in the research process. Some paths have been explored, others rejected, and the reasons for the particular choices made given. The next section is a summary to guide the reader as to the terrain explored in the sometimes shifting ground that is hermeneutic phenomenology.

\section{Summary to Chapter 3}

This chapter began with a rationale for using hermeneutic phenomenolgy in nursing research, and argued some of the choices within the larger aegis of the phenomenological 
movement generally. Husserl's notion of eidetic science is a key consideration incorporated into the research, as is the notion of the lebenswelt, which is a means of connecting with deeper human concerns. The 'natural standpoint' is utilised as a way of the researcher making connection with the relationships between research participants, (in this case patients), the(ir) world, and other people in that world, such as nurses. Husserl's search for a pre-suppositionless science is rejected.

On the other hand Husserl's notion of transcendence has informed the inquiry process as a shared endeavour between rational inquiry as to fact, and human issues and values. Husserl's thought prompts one to ask, "how does one know as an older person in an acute ward?" Heidegger's critique of transcendence prompts one to ask, " what is it like to be an older person in an acute care ward?" Heidegger's extension of the notion of transcendentalism calls for renewed attention to the place and influence of time in the inquiry process, and its relation to the interpretations nurses make in regard to the needs of older people. The picture of the future presented determines what our past means too.

The inquiry process considers the paradoxical notion of situatedness and freedom from Sartre, and the notion of lived body from Merlau-Ponty. Merlau-Ponty's understanding of the lived body further refines the understanding of 'freedom.' The possibilities for humans in the world are not limitless, but are constrained by the inherent potential of the body and the situation.

Following Van Manen I have drawn on all these notions in an eclectic fashion. From Van Manen I have utilised the four phenomenologic existentials lived space, lived body, lived time 
and lived human relations as features in the terrain of the lebenswelt. The research task is to go more deeply, to examine the 'everyday' in the lived experience of older people, since it is by this means that nurses principally relate to patients. By looking at a range of texts which inform the acute ward context, previously unseen ways of being may be made manifest.

The experiences which have informed my particular view of nursing have been laid out in Chapter 1 as were my interests and assumptions. The disciplinary texts which inform and influence have been considered in Chapter 2. The 'story' of this research project was told in Chapter 3. Throughout the current chapter I have considered the values of the particular writers, their theories and espoused ways of working in relation to my practice. In the next six chapters I present the patient stories as they were told to me, and as I, as a nurse, began to respond to them.

The first patient story uncovers in Chapter 5 one way of being old, while having another chronic health condition, and recovering from surgery in an acute care ward. 
Chapter 5 Taking notice and taking time.

The phrase above captures an essential element of Mrs RoyJenkins' experience of nursing following an admission to an orthopaedic ward, and relates to a valued nursing practice which not many nurses achieved for this patient. The authentic practice of sorge was noticeable by its absence. Not many nurses 'noticed', and when the patient specifically asked for help, some did not 'take time.'

This interview relates to an admission to an acute surgical ward following a fall and a medical diagnosis of a fractured hip. Mrs Roy-Jenkins had had many previous falls and had previously also broken her other hip. She was 82 years old at the time of admission and lived alone in a flat with family and home help support.

\section{Life profile}

Mrs Roy-Jenkins was a small bent woman who often paused in her conversation to breathe deeply on the nasal oxygen she used constantly. She described her life as having been centered on her family. It has been a very interesting life, but it hasn't all been smooth sailing. She had traveled widely, on her own behalf, and also with her husband in his profession. Before and after marriage she had a number of jobs in event management, fashion and broadcasting all of which she described as "great fun."

If the joyful things of her life had been fun, she also accepted with equanimity a number of tragedies - her husband and eldest son had died of the same chronic illness, her son-in-law had died overseas at the same time as another son had had a serious accident which had left him disabled. Mrs Roy-Jenkins was the 
mainstay and support of others at these times, but also received support from both her children and her extended family. During these tragedies she was able to call on family contacts to get seats on planes and other necessary experiences to continue her family support. She was able to make decisions and prioritize between competing needs of others. She described herself as learning from both the sad times and the happy ones. Her three daughters live nearby and provide practical and other help. One of them sees her every day and brings meals.

Her family continues to be a source of joy and pride. Many of her family are talented in the arts. The practice nurses from her General Practitioner see her nearly every workday, especially if requested by Mrs Roy-Jenkins or her daughters. However Mrs Roy-Jenkins does not like to ask too often.

This degree of support is necessary because Mrs Roy-Jenkins has chronic obstructive respiratory disease (CORD) which she describes as hereditary. She also has osteoporosis and had experienced numbers of falls and admissions to hospital with broken bones before this admission. Previous recoveries from illness had been 'easier' and caused her fewer problems than this one. The first time she broke her hip was easy, too simple. I was running down the corridor in a few days I think. The experience of hospital that this conversation relates to was a more arduous time. Her experiences in this hospitalization have challenged her confidence.

I sometimes wonder where I'm going to fall next time I fall. What do you do when you haven't got another hip to break? l've been practising so I should do it some ways and break my wrists $1 \mathrm{CW}$ oh no - practising?\} l've been thinking about it - 
should you fall down the front, break your knees or something?"

\section{Circumstances of Admission - an arduous time}

The day of her admission to hospital began at 4 am when Mrs Roy-Jenkins just got out of bed and lay on the floor. She tried to get up but was unable to do so and activated her personal alarm, which triggered a response in the local ambulance control room. They rang back, and finding no response from Mrs Roy-Jenkins, they then rang the designated family member. Mrs Roy-Jenkins' daughter came and was also unable to get her mother up and so rang the ambulance again. Two great burly fellows came up and flung me on the bed and said "she's all right, she hasn't broken anything." They were wrong. Some time passed, and Mrs RoyJenkins' daughter had to go to work. By this time, the practice nurses were also at work. A second daughter came, and enlisted their help. Of course she (the practice nurse) confirmed that I had a broken hip. So eventually we got to hospital OK and that was a very arduous time.

In hospital Mrs Roy-Jenkins had a lot of fun with the nurses on the day of her admission. She was confused and aware of it. As a nurse I wondered about how long she had been kept fasting. She tried to continue her mater familias role.

I was hallucinating really. I don't know what they had given me.... I'm here and there - I don't know where I am- white coated chaps in with me and (I said) "I think you two ought to go down and have a meal." I thought I was in my own house! 
Because of her respiratory status, Mrs Roy-Jenkins had epidural anaesthesia, and remembered the time in Theater, where she enjoyed participating. The operation itself was

a very pleasant occasion. \{CW: do you know
why? How was that?\} I don't know why - they
were just lovely. There was one lovely nurse who
was at my head and talking and chatting - they
were great.... They were great fun, they were
chatting away. She wasn't a young nurse.

Mrs Roy-Jenkins asked for some of the bone that was cut out. Mrs Roy-Jenkins was feeling cold when she emerged from theatre. The pleasant occasion continued through into Recovery with the feeling that she was being looked after.

They put you in Recovery and they wrap you in warm blankets. Warm blankets! It was the most wonderful feeling. But it only lasted half an hour and I was thrown into a ward.

\section{The Ward}

The ability of the ward nurses to express understanding for Mrs Roy-Jenkins' experience of the day continued the atmosphere of a pleasant occasion in the midst of an arduous day.

I think I got into the ward at 10 o'clock at night - the nurses couldn't believe it. They said, "heavens - you did this at 4 o'clock this morning and you've just been put into our ward tonight?"

The day of admission had been an event - albeit an arduous one in a life well used to making the most of life's events. In contrast to the day of admission, not all the nurses were amiable in the post-operative ward. The style of nursing interaction was often 
bossy. The focus on independence did not suit Mrs Roy-Jenkins, especially as her oxygen consumption became a focus for independence retraining for one nurse. At home Mrs Roy-Jenkins used her oxygen independently at will. In this ward that was not always the case.

I was going down to the shower and I said, "I'd rather not walk there because I'm on oxygen and it takes up too much time." She (the nurse) said, "I know perfectly well, I know you can go without your oxygen the time it takes to take a shower - a quarter of an hour. I'm going to train you to go without your oxygen," she said. She knew nothing about my oxygen - nothing at all. $\{\mathrm{CW}$ You had been on it for a long time? Oh l've been on it for years - and you had to go and have a shower without it!

The tone of this sentence was one of indignation and bewilderment. Why the nurse in a post-operative orthopaedic ward concerned herself about the apparently prescribed oxygen for the CORD was a mystery to Mrs Roy-Jenkins. Up until now in the hospitalization process, her needs had been paramount. Her experiences had been to the foreground. Now in the ward she was someone with previously impaired mobility, recovering from a fracture, being issued with a challenge to another support in her life, her oxygen.

Mrs Roy-Jenkins interpreted the nurse's non-negotiable stance as laziness.

I don't know what it meant exactly -she had to carry it down probably. She had to get another cylinder and carry it down to the shower, I suppose it was really. 
She was a very bossy young nurse and I didn't care for her.

The nurse's interpersonal approach and youthfulness, and the content of her challenge to Mrs Roy-Jenkins combined to threaten her ability to mobilize. This was not 'fun'.

On other occasions Mrs Roy-Jenkins had difficulty getting a medication that she was used to having at home. She understood she was allowed it at her own discretion but

it depended on the nurses whether they were inclined to be authoritative or not... Some of the bossy nurses liked to use their own discretion and when I said "can I have one of my - half of my ones please?" one or two would withhold it from me. $\{\mathrm{CW}$ So you would liked to have had those pills yourself?\} Yes, of course I should. I should have had it myself. And they used to dish them out in halves and quarters. I said, "Look I only want half" which is enough just to calm me down that's all I want. My word that was difficult. I thought next time I'll keep them myself... I know exactly what I want. \{CW Do you mind telling me what they were? Yes, yes they're rather frowned on Lorazepams, Ativans. My GP gives them to me and the funny thing is I get thirty a month and I cut them in halves and quarters.... when I get panicked with my breathing they're wonderful for stopping my (breathes deeply) (CW relaxes your...? ? relaxes me completely. I say he's (GP) great. But when I went home, the funny thing is, they gave me 90! They gave me a jar with 90,90 ! 
Eventually Mrs Roy-Jenkins' resourceful spirit enabled her to extract some amusement from an event which was anything but fun at the time.

Once Mrs Roy-Jenkins had occasion to be grateful for the nurses' bossiness. She was particularly sensitive to noise and when the lady in the next bed just through the curtain had a large television, which she listened to all hours indiscriminately, Mrs Roy-Jenkins appealed to the nurses.

She (the other patient) just wanted the noise, and she wouldn't put her earmuffs on. I had a lot of trouble with that. $\{\mathrm{CW}$ Did you ever get it resolved?\} I think we did because I think the nurses said "Now look, you can't have this television on here unless you put your earmuffs on". (CW Did the nurses help (by doing that)?\} Yes they did - they bossed her around. I think she did and I would ring my bell and ask them to come and turn it down, and use her earmuffs. So they did they were helpful there. Yes they took notice of me - they were good there.

The noisiness of shared rooms was a constant source of difficulty to Mrs Roy-Jenkins. During the first two weeks post-operatively Mrs Roy-Jenkins was in a room with anything from 1 to 3 others. She saw herself as the quiet one, and struck up a friendship with another woman who was also quiet. The quiet one and I we related to each other, had fun, talked to each other across there.

Mrs Roy-Jenkins had told her family to restrict visitors to only a select one or two, but another patient had different support needs. 
There was this one where the whole family used to come in - the whole family! They were so noisy and the same lady couldn't control the friends...I only wanted to see one or two, but that one had the whole family in every day -every day! Husbands, inlaws, wives, children, and another lot here. They couldn't be controlled, of course. It was very trying.

Mrs Roy-Jenkins viewed the space around her as controlled by the nurses and she held them accountable, but she felt this situation was beyond their control. It remained a constant irritation.

One aspect of the space closely linked with her experience of her bodily needs, was the place where meals were eaten.

When I was in the room with the four of us we complained "gosh isn't that terrible." We couldn't all agree about what was edible and what wasn't... Meals, food it doesn't matter much - they were awful. But that doesn't matter much, does it? [CW well if you'd have liked something tastier?\} Yes well the family would bring me in something asparagus rolls or something and I managed with the food... I didn't cohabit or cohabitate or something with all the others down in rehab where people walked, were ambulatory. But I didn't have to do that. $1 C W$ was that because of your breathing?\} Yes and because I'm not very sociable. I don't like to cohabit with a lot of people too much, so I was excused because I couldn't eat with people round the table. 
Mrs Roy-Jenkins did hold the ward nurses accountable for their interactions with her even though they didn't have very much time for you. They didn't put much time in with you - of course they didn't have time. One nurse stood out as being particularly caring.

I still remember her. I said my feet were sore - it was nearly bedtime at the end of my day and she massaged my feet. That somebody would take time off to do that was wonderful...She took time and that stands out, not many of them did take time, they were so short-staffed and so on. ICW how did the nurse know you would appreciate your feet massaged?\} Oh I told her that I had hot burning feet...She was not my particular nurse. She was just one passing through and she said "are you ready (for bed)?" or something. And she just did it and it was just so wonderful that - it stands out a mile - that she could stand at my feet for oh ten minutes and could spend that much time like that.

If this interaction with a nurse was unexpectedly pleasurable, the reverse was true when Mrs Roy-Jenkins went for a shower. She experienced the nurse's conversational style as hostile.

We were pretty much made to do ourselves. It's quite easy with a hose. She stood by and threw these questions at me and of course I couldn't be bothered - didn't have the strength at this stage. She got me down there and said "righto - where do you live?" I was pretty groggy at this stage and I said "Fendalton". "Ooh aren't you the lucky one? I'd live there too if I had the means." I was trying to have this shower which was hard work, and - "Your name -how did you get that name of yours? Was it 
yours or your husband's or how did you do it?" And then she pushed me back into my ward and there was a nurse making my bed or something, and she flung out a nightie and I said, "Oh, I think I'll have this one," because I had a warm one or a cool one - I don't know what. She looked at the other nurse and said "Look she won't even take the nightie I give her so what can I do?"

Later this nurse tried to mend relations with Mrs Roy-Jenkins by acknowledging "we had a bit of a rough spin at the beginning, didn't we?" But she never regained a place of trust with Mrs RoyJenkins. I hadn't done anything to that nurse except have a double-barreled name and nothing else I did to her \{laughs\} nothing - and she was so hostile to me. Mrs Roy-Jenkins felt she had to be interested in the nurses but this was only sometimes reciprocated. The nurse in the shower adopted an interrogatory conversational style not acceptable to Mrs Roy Jenkins. The nurse told the patient details of her career plans in spite of Mrs Roy-Jenkins' concealed ambivalence towards the nurse: I couldn't stand her being near me or handling me or anything. Oh we got on all right - had to.

Mrs Roy-Jenkins had a detailed knowledge of other nurses. She especially liked one nurse who had previous contact with her family, and also Dee who was the sweetest little nurse.

Although Mrs Roy-Jenkins' presenting medical diagnosis was a fractured hip, her main problem in hospital related to her breathing which was a long-standing impairment. At the summary of the interview I said,

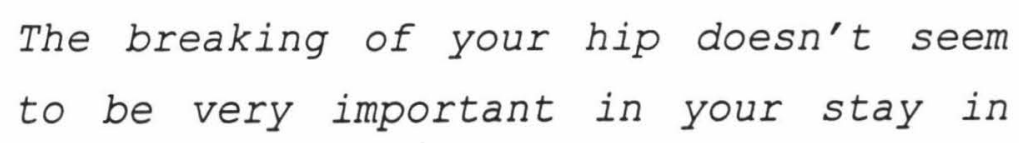


hospital to me. (She replied), no, it wasn't really, no it wasn't very painful, it was a long way back to walking, and I haven't mastered my walking yet, this time. I won't now, I won't master it. My walking is getting worse, but that is simply because of my breathing now. $\{\mathrm{CW} \mathrm{mm}\}$ Yes, so it's come to that. My hip has really played very little importance in the whole affair.

The experience of hospitalisation mirrors the pattern of her limited recovery. She compares the current hospitalisation with previous times, when the recovery was less complicated. The first time she broke her hip was easy, too simple. I was running down the corridor in a few days I think. This latest experience, however, reaches in to the present and causes fear for the future.

She sometimes wonders

where I'm going to fall next time I fall. What do you do when you haven't got another hip to break? I've been practising so I should do it some ways and break my wrists ( $\mathrm{CW}$ oh no - practising?\} l've been thinking about it - should you fall down the front, break your knees or something? 


\section{Commentary}

Mrs Roy-Jenkins portrayed herself as a person with access to external resources in the form of family connections which provided interesting options for her, competent family support and advocacy, excellent GP and practice nurse support, and residence in a 'middle class' suburb. She also had internal resilience, which enabled her to meet life's tragedies and physical challenges with courage and grace. The nurses in specialist departments such as Theatre and Recovery were solicitous of her comfort, both physical and interpersonal, but the ward nurses had a much less focused approach to her needs. Mrs Roy-Jenkins portrayed the nurses as harried, and in conflict with her for control of the environment and Mrs Roy-Jenkins' everyday activities. Even if this was a rehabilitation focus on the part of the ward nurses, it was not a perspective that Mrs Roy-Jenkins shared. She had had great fun with the theatre nurses. One stayed with her focusing on what was happening to her- I asked for a piece of the bone. None of her portrayals of ward nurses related to having fun, nor the fracture of her hip, and only one related to the physical symptoms that she experienced. She worries about future falls which she regards as inevitable. Should I fall down the front?

Two situations were particularly difficult for Mrs Roy-Jenkins. One involved a particular conflict with a particular nurse who wanted her to walk to the shower and go without her oxygen. The goal of "training" to go without oxygen, which had obviously been unsuccessful, was resisted by Mrs Roy-Jenkins.

The second difficult issue was a problem with a number of autocratic nurses. The incongruence of nurses withholding Ativan while in the 
ward, and then giving her 90 into her own care at home was simultaneously a source of irritation and amusement. She interpreted the nurses' behaviour as non-helpful and interested in their own comfort, not hers.

As with carrying the oxygen to the shower (something Mrs RoyJenkins managed herself at home when well), the issue of having access to the "relaxing" tablets was a particularly annoying one to a patient who knows exactly what she wants. I inferred from her amusement over being given 90 tablets, when the GP prescribed 30 once a month, that she understood some nurses' disapproval to relate to overdosage. Whatever the reason for the differing dispensing practices, there was apparently no attempt to explore with Mrs RoyJenkins her need for such a medication. It may well have been difficult. As Mrs Roy-Jenkins said, I know exactly what I want, and she expected her requests to be met as presented. On the other hand she was aware that they are rather frowned on and so may have been reluctant to expose herself to any disapproval in such a conversation. Clearly the discharging House Surgeon had no such concerns. The issue of not having access to tablets she controlled at home remained unresolved in her relations with nurses. She planned what she would do next time in hospital (a likely event in view of her recent history), and that is to withhold knowledge of such medication from nurses.

Mrs Roy-Jenkins spoke of the nurses as a group who related to her collectively. Although she did know the names of a couple of nurses she admired, they did not seem to figure prominently in her story. She seemed aware of particular nurses who were allocated to her, but it is not clear if this was a system of primary nursing. Mrs RoyJenkins described three occasions where nurses had initial contact 
with her. One was her allocated nurse, the other two seemed representative examples of the nursing team as a whole.

The nurse who was most attentive of her comfort was not her primary nurse, but went out of her way to ask Mrs Roy-Jenkins if she needed anything. This enrolled nurse did draw nearer to the patients even when not under any obligation as my particular nurse. She was oriented to the patients' needs before offering her help. Her offer even encompassed a situation where patients did not know what help they needed. This nurse's gift of time through massaging feet diverged from the usual approach from nurses.

Such a generous and considerate approach was in sharp contrast to a second nurse's challenges to Mrs Roy-Jenkins' name and her residence in a 'middle-class' suburb. This latter nurse challenged Mrs Roy-Jenkins' social status by saying, oh well it's all right for some (implying it is not all right for all, or indeed for this nurse) thereby maintaining her own distance at a time the patient wanted closer support. This nurse was allocated to care for Mrs Roy-Jenkins on a number of occasions, and clearly did not manage to progress the relationship beyond simple task performance. As Mrs Roy-Jenkins said, I couldn't stand her being near me or handling me, or anything.

The third occasion Mrs Roy-Jenkins described meeting nurses was on admission to the ward from Theatre. These nurses' consideration of the long day she had had when the ambulance men had not diagnosed her fracture showed they were considering the reality of life for her, and not just for themselves. Their consideration of how she must have spent her time that day indicated they were oriented to her needs even on their initial meeting when they would be unlikely to have explored a comprehensive nursing history. 
These initial encounters with individual nurses vary in their effectiveness in meeting Mrs Roy-Jenkins' expectations of nurses, but all illustrate the powerful impact such initial encounters have on subsequent patient understandings of relations with nurses, both as a collective and as individuals.

Apparently the charge nurse did not monitor relations between staff and patients either. (As an aside it is interesting to note that the charge nurse did not figure at all in Mrs Roy-Jenkins' story -in contrast to other interviewees who had less negative experiences.) As Mrs Roy-Jenkins said, oh we got on all right- had to. This sense of being captive to the allocated nurse was a potent source of discomfort. Each new nurse whether 'allocated' to this patient or not, began anew, and could either contribute to an experience of trust and support, or could challenge Mrs Roy-Jenkins' confidence and identity.

Who Mrs Roy-Jenkins was outside the ward was important to a comfortable relationship. This was true in a social sense and also in the sense of knowing her previous physical capacity. Mrs RoyJenkins' history of frequent falls and CORD meant she wanted and expected to receive support and consideration of these issues as well as nurses focusing on the fracture and "normal mobilization." She wanted to live the way she did at home, with, in addition, special consideration of the limitations to her stamina caused by the fracture and the surgery. She expected (and got from her family) special foods, and the nurses were helpful in bending the rules about where convalescing patients ate. Such consideration was expected from nursing staff as a way of compensating for the limitations. Instead, the occasions when her invalid status evoked 'special' thoughtfulness 
were rare, and she received a robust 'no-nonsense' approach where changing a nightie was making a fuss.

Two or three nurses were particularly helpful but their isolated tact and support was no longer in the picture, except to be noted in response to questions, by the time of the interview. The helpfulness by now was overwhelmed by the stress inherent from other patients in the environment and the overt challenges to her identity and status from other nurses. In some instances the courtesy of the nursing relationship was lacking. No nurse was able mobilize Mrs RoyJenkins' coping ability in spite of previous knowledge of her family.

The goodwill generated by a previously 'easy' recovery from a fracture and the special care from the departments preceding the ward stay, was eroded by the ongoing interpersonal difficulties. These were mirrored in her ongoing difficulties in regaining her mobility. As she said at the conclusion of a list of nurses' shortcomings, I haven't mastered my walking yet, this time. I won't now, I won't master it. My walking is getting worse, but that is simply because of my breathing.

Walking and breathing were two key aspects of Mrs Roy-Jenkins' experience of the lived body (corporeality) while in the acute ward. Challenges to what she saw as supports to her breathing were received by her as particularly poignant, and in fact were the reason she had been unable to regain her mobility with the same ease on a prior occasion. These challenges reached back into her family identity, as the CORD was a hereditary condition.

As well as linking to her family condition of CORD, the unusual nature of her recovery complicated her lived relations with nurses (relationality). Mrs Roy-Jenkins liked privacy and she liked fun. In her 
presence one nurse complained about her to another, thus turning the patient's simple request for practical help in changing a nightdress into an opportunity for censuring a person already fatigued after a shower. Relations with the censuring nurse were stressful for Mrs Roy-Jenkins, as she was sometimes dependent on her, as the allocated nurse, for getting through the daily activities. At the same time, proximity to this nurse evoked discomfort and indignation.

Some nurses were able to meet Mrs Roy-Jenkins on common ground. They were nurses who noticed her physical needs, or who were alert to her preceding experiences, and who met her expectations of courtesy as the initial gateway to care, either because they shared Mrs Roy-Jenkins understanding of courteous behaviour, or because they were particularly perceptive in considering who she was.

One aspect of human relations, which was comfortably negotiated, was that her family contact was facilitated and special food was brought in for her. This was a very important link to Mrs Roy-Jenkins' returning home as by the time of the interview, her family and their support of her were very much in evidence (although it is difficult to be explicit about this without identifying Mrs Roy-Jenkins or her family).

Nurses with positional power, such as a charge nurse, were absent from the story. This was surprising in view of Mrs Roy-Jenkins' earlier portrayal of herself as moving easily in a world of power and influence, but may reflect the increasing managerial focus of the charge nurse role. One can speculate on the absence such a clinical advocacy role had on Mrs Roy-Jenkins. 
In limited ways nurses were able to influence the lived space (spatiality) Mrs Roy-Jenkins experienced. She ate at her bedside, not in the shared space of the dining room. When there was conflict with the roommate who found the background noise of her television a reassurance, the nurses sided with Mrs Roy-Jenkins. The roommate apparently did not want to watch the TV, but the nurses required her to wear earmuffs in deference to Mrs Roy-Jenkins.

The noise intruded through the curtains which were apparently pulled most of the day. The curtains confined and circumscribed the space as a way of creating visual privacy. In general terms the noise was intolerable especially when the space was filled with other patients' visitors. The nurses did not share the patients' experience of this space, and from time to time nurses also contributed to the noise which inescapably filled the space.

Lived time was intrinsically entwined with the other three existentials. It is clear from the remark about not mastering walking this time, that Mrs Roy-Jenkins had re-interpreted her future expectations. The memories of her past that "somehow leave their traces on (her) being" (Van Manen 1990 p 104) called to Mrs Roy-Jenkins reminding her of an unfolding path of fascinating times, family living, fun, personal privacy, tragedies, and endurance.

The 'lifeworld' in this ward was that only one nurse had the gift of time to look on her body with interest and massage her hot tired feet. Most were in conflict with her or disinterested. Interest, fun and privacy were increasingly remote leaving only personal endurance and her family. Her role in the family was shifting from the one who was the main support of others to the vulnerable recipient of care. The 
fracture and subsequent hospitalization made this role change explicit to Mrs Roy-Jenkins.

The dual orientations of increasing dependence and increasing independence referred to in Chapter 1 are particularly noticeable in an analysis of Mrs Roy-Jenkins' account. The overall orientation in acute care wards is one of recovery and increasing independence. Mrs Roy-Jenkins' challenge to the expectation of more rapid independence seems to have left her bereft, at times, of the support she needed to make the transition to an acceptance of living with increasing vulnerability.

In the next chapter Mr Snell reveals how he experienced nursing support through a similarly slow experience of recovery. Mr Snell reveals important differences between his experience and that of Mrs Roy-Jenkins which enables further refinement of the consideration of care for older people in medical and surgical wards. 


\section{Chapter 6 All sorts of tricks}

The interview of the second respondent to newspaper advertising was delayed due to the patient re-gaining permission to drive a car from his surgeon. Like Mrs Roy-Jenkins, Mr Snell had an orthopaedic diagnosis, but the circumstances of his admission were different to hers. While Mrs Roy-Jenkins had just got out of bed to go to the toilet, Mr Snell had been swimming at the time of his fracture.

The phrase which introduces this chapter refers to one particular nurse whom Mr Snell, a lifelong student of human nature, admired. If Mrs Roy-Jenkins' need for nursing was characterised by a nurse who took notice and took time, Mr Snell's was characterised by a nurse who had all sorts of [practical] tricks.

He was admitted for a revision of a repair of a fractured hip. The hospitalisation this conversation relates to was the third and fourth revision of his hip joint. At the time of the interview it was four months after his most recent discharge he still walked very slowly with two elbow crutches. Mr Snell had been out of hospital only a month between the third and fourth revisions and spoke of them both during our conversation. The third revision had been done over Christmas, and the fourth during January when wards had been closed or amalgamated. He was 74 years old at the time of admission and lived with his wife in a pleasant recently redecorated villa. Mr Snell's wife made coffee and biscuits and we had these as we chatted. 


\section{Life Profile}

Mr Snell described his life mainly through his work history. World War Two provided him with opportunities, which enabled him to have faster access to educational bursaries than he might otherwise have experienced. Trained as a primary teacher before the war, he was offered a 'rehab bursary' which enabled him to complete an Honours degree in History and commence secondary teaching. He spent the major part of his career at the then Teachers' College as well as the local University. He had been married for 49 years at the time of our conversation, and had three adult children.

$\mathrm{He}$ is a keen observer of human relationships, and described himself as a fairly voracious reader, who also enjoyed the radio.

Over the preceding year when he had experienced ongoing health problems with his hip, he and his wife had moved into a smaller house (where they currently live) with a much smaller garden after having spent 44 years in the same suburb. He described the remodelling of the whole house simultaneously with his hospitalisation as rather stressful for my wife.

Mr Snell described himself as generally being very healthy, active and enjoying sports. He had first had a hip joint replaced five years previously because of arthritis. Two years after this a minor stumble had led to the fracture of the cement. While investigating this fracture, it had been discovered he needed a coronary bypass. Following the bypass he had a spinal laminectomy. Mr Snell felt that all his previous surgery had been highly successful and very satisfactory. It was a surprise to him when he did not continue to improve after the third hip revision, as he had done after previous surgery. So I was discharged from hospital on New 
Year's Day, and over the next week it became more painful and quite obviously something was seriously wrong.

\section{Circumstances of admission - something was seriously wrong}

The day of Mr Snell's admission to hospital for the third hip revision began at the local pool with a therapeutic swim.

I put my foot into my togs not suddenly or twistingly or anything like that and ouch and back again (to the doctor). An X-ray didn't show much originally, obviously it was a stress fracture in my lower femur, and into ward 25 a day or two before Christmas. It had really become quite serious...that operation meant having a metal plate put down and cables round the top and pins round the top and so on.

Mr Snell was driven to the consultant's rooms. The consultant called an ambulance from here. Later an X-ray at the fracture clinic showed that the cables at the top had come loose. Mr Snell was admitted to a single room. I was really resting for a couple of days while I was waiting to go to theatre and I had a room of my own which I appreciated.

Mr Snell's surgery took place on Christmas day. Plan ' $A$ ' was to have an epidural anaesthesia, but because of the scar tissue left from the laminectomy, this was not possible. He (the anaesthetist) said he'd do his best, he did his best and we went back to plan 'B', and Mr Snell had a general anaesthesia. 
Once out of Theatre and in Recovery, this sense of people doing their best even in the face of some challenges, continued.

I felt fine almost immediately, and I felt fine because I had to stay there for sometime. This shoulder became more and more sore - it got agonizing. I knew pretty well what it was because I have tendonitis and I take anti-inflammatories at breakfast time but of course I hadn't taken them that day, and so the nurse and I - the recovery nurse that is - had quite a long conversation - she was concerned it might be cardiac. ( $\mathrm{CW} \mathrm{mm}$, $\mathrm{mm}$ ) It could have been. I think there was a very small chance, so she got in the anaesthetist and he said well we better be absolutely sure, and so we'll show quite clearly that there was no cardiac (cause). I had to take an ECG $\{\mathrm{CW} \mathrm{mm}\}$ but it was Christmas day in the workhouse. The hospital was scoured but they couldn't find one, and meantime this was going on - l've never known anything so intense...So she and l engaged in a furious exchange of life experiences, as it was the only way of keeping my mind off it. [CW yes \} It was such intense pain... well I finally got the machine, but no operator.

The expertise of the personnel available in Theatre extended to careful monitoring, and good interpersonal support, but not to the extent of performing an ECG. But I was grateful to that nurse I must say, because there was somebody to talk to instead of having to lie there. Modern expectations also played a part. Nowadays we are not very used to this (enduring pain) - there's usually some sort of medication. 
$\mathrm{Mr}$ Snell thought he had waited about three quarters of an hour for the ECG machine. I have a fairly realistic appreciation of the passage of time. But, there were also some advantages to having surgery on Christmas day: Actually I was the only patient in there which was good from my point of view.

\section{The ward -a mixed blessing}

The pain of the surgery was not nearly as intense as the Recovery Room tendonitis which did recede once Mr Snell was back in the ward and able to gulp down a Voltaren. In the ward there were at least two systems of analgesia in place. Mr Snell had an intravenous line in his groin (femoral line) which was monitored by the pain relief team who were interested in his response to the analgesia. He attributed his general lack of pain post-surgery to this analgesia, although also partly also to the little button pressing thing. Mr Snell did not describe the ward nurses as being involved in his pain relief. On one occasion

the (ward) nurse really got quite insistent - I can't remember what her reasoning was - but "you really must have some stuff'... Often they didn't know that the pain team was coming and looking at it because they came when the nurse wasn't around.

The ward nursing staff focussed on the patient-controlled analgesia.

Although for the first day or so I was in full mental control and so on there was some kind of automatic delivery of analgesia stuff. It was only a day or so - I think, I'm not sure - that I was told I could administer it myself, but I didn't feel I really needed to. They 
had a standard question: " On the scale of ten", I kept saying zero.

Mr Snell compared his pain relief after the fourth revision with the previous revisions. On those other occasions when I've had the hip stuff - yes obviously the pain relief was very effective - but nevertheless people were surprised I felt none.

His previous experience of similar surgery also enabled him to interpret other symptoms.

And one of the post-operative phenomena is that my red cell count tends to get...(pauses) \{CW lower?\} $\mathrm{mm}$, and I need a transfusion. And the other thing is, is that late in the afternoon or early evening my temperature tends to soar \{ $C W$ oh yes\} but after I became used to that I was able to more or less convince the nurses that I wasn't going to go through the roof. $\mathrm{ICW}$ so when your temperature first started to go up what was the sort of response you got?\} Well typically the nurse would say "oh gosh your temperature is up this evening" ... as I became more experienced I was able to interpret that, and sometimes the nurses who might not have known me or who were nursing me for the first time that evening might be more concerned than I was and I was able to say "hey look this is going to be OK."

Mr Snell felt the need to reassure particularly the younger or less experienced nurses, but did feel the concern expressed by the inexperienced nurses was appropriate. He saw the hospital 
doctors as backups to the nursing judgement in the absence of the charge nurse.

Because this was an evening phenomenon the charge nurse had usually gone off duty...It seemed a proper response on their part...Sometimes the nurse said "hey I better get John or Elizabeth to come and just check this out".

Sometimes the inexperience of the nurses revealed itself in their management of monitoring equipment.

There are all sorts of new gadgets these days, some of which the nurses weren't very familiar with $1 \mathrm{CW}$ $\mathrm{mm}$ \} and some of which didn't behave quite...(pause) \{CW Were you curious? Oh yes generally what's my blood pressure tonight or today? \{CW Did they tell you?\} Sometimes they would say "oh it's fine" and l'd say "well what exactly?"

At other times their inexperience was revealed in their lack of awareness of $\mathrm{mr}$ Snell's ability to interpret charts. In any case it was recorded on the chart at the foot of the bed.

Mr Snell was interested in the relationship between the staff nurses and the charge nurse, and the change in social relations since he had a tonsillectomy during the war.

Compared with nowadays that was such a starchy and stiff $[\mathrm{CW} \mathrm{mm}]$ although young male patients can't help flirting with nurses and vice versa so there was a much more strict protocol in those days. And when the roster was drawn up by the charge nurse there was obviously a bit of give and take between her and the nurses...And even the way an ordinary 
registered nurse - you see in that holiday period the charge nurse was having her holidays and one of the staff nurses was temporarily charge nurse and that worked very well... about the only people who aren't addressed by their first names are the consultants and even some of those...so registrars certainly weren't sacrosanct. The relationship between charge nurses and nurses I think it's good.

Two nurses in particular impressed Mr Snell.

One l'm thinking of in particular - older she would be - oh in her forties, I think, twice or thrice married and never again!... She was a keen swimmer and talked about the various recreational things she was doing and sometimes she cursed her children - untidy rooms and this sort of thing... It certainly didn't interfere with the professional things she had to do.

A second nurse who impressed $\mathrm{Mr}$ Snell was an enrolled nurse. While $\mathrm{Mr}$ Snell was in hospital she was planning to go to Polytechnic to complete a nursing degree which pleased him.

There are natural nurses as well as natural teachers and so on. In some ways her duties were a good deal more limited and all that sort of thing, but she was a natural... She had all sorts of tricks - I'm thinking about in particular getting me out of bed and into a wheelchair, and looking after this operated leg and getting me down to the showers. I think she was the only one who realised how important it was to rub my back with the towel after a shower and so on. Although she didn't have the training and so on 
she had a great deal of nursing experience and I was delighted to hear she was going to train. And that made me think in some ways of the less pleasant aspects of being there: the showers, the toilets and so on -making smells...

The nurses in general impressed Mr Snell for their friendliness and outgoing behaviour.

I'm Mary and I'm going to be looking after you today - that kind of thing... After a while if I was meeting one for the first time, I preferred to say I was John rather than Mr Snell...None of them presumed to call me John but they were happy enough and relaxed enough to do it once (given permission).

The noisiness of shared rooms was a source of difficulty to $\mathrm{Mr}$ Snell.

While I was waiting to go to Theatre I had a room of my own which I certainly appreciated because there weren't any other distracting noises from other patients...four or five days before I was discharged in a four berth room and that's a mixed blessing: some patients are very hard to live with, others make very agreeable company, so that's the way of the world isn't it?

This aspect of hospital life gave Mr Snell new respect for nurses. Two patients in particular were significant in Mr Snell's experience of the nights in hospital. A friend of Mr Snell's was unexpectedly admitted to the four bed room to have a hip joint replacement. $\mathrm{Mr}$ Snell had previously been on holiday with this friend and knew 
his nocturnal noises - I like him very much but oh! And sometimes the nurses would say "Oh God". (I think) of the night duty nurses coming and making that patient more comfortable and getting him over on his back so he wasn't snoring so stridently.

More distressing was the presence of a confused elderly man. Immediately opposite me was an old man who had his 85th birthday in hospital. He was a great big strapping man, and he talked distressingly at night. I'll never forget I don't think the "oh mother, oh mother" - and his mother had been dead for over sixty years. But nurses can't do much about that, it's the nature of hospitals and unless you are fortunate enough to be in a room by yourself, which in some ways is the difference between the public and the private.

Mr Snell was appreciative of the nurses' attempts to help the confused patient. He coped with this by reading voraciously and by listening to the radio. He had his radio very close to his ear on the pillow, conscious at all times that he might be distracting others. Sometimes he was able to provide news items or weather forecasts when the other patients asked him. Mr Snell saw the night nurses in particular as being as helpful as they could in a limited way but also sharing in the patients' general inability to change external conditions in the ward: but gradually as the ward filled up other patients came along.

Nurses were also present as generic members of the multidisciplinary team.

I certainly do have a criticism that after the first operation (third hip revision) that all sorts of people: 
nurses and physios and registrars saw me up and down the wards and none of them said "Hey John, you are putting too much weight [on it]".

This comment was a reference to his slow recovery which was not apparent while he was in hospital, but had become increasingly significant to him since discharge and now he was still on bilateral elbow crutches four months after the surgery. In retrospect he wondered about the information he had been given in hospital and particularly before discharge after the third revision.

A friend had told him he was putting too much weight on his foot and given him a book (Pryor, 1991) from the public library which had explained just exactly what was "partial" and "non" weight bearing.

It's possible that my interpretation of non-weight bearing was not the way it was intended ...I don't think I am a critical person, but I think somewhere along the line some of those health professionals really ought to have been more observant.... You know l've gone over and over and over it in my mind because, ah, I don't know... So since the second operation (i.e fourth hip revision) I have been super careful, I can tell you. The orthopaedic people were either kind enough or diplomatic enough to say "I really don't know (why the recovery is slow)."

\section{Commentary}

Mr Snell portrayed himself as a person who was keenly interested in observing human relationships, and whose educational background gave him a framework to understand his observations. He was a person who had a very busy life until 
slowed by his hip problems. A very experienced patient he shared his knowledge of his observations about previous physical responses with young and inexperienced nurses.

A professional historian Mr Snell compared hospital systems and relationships between patients and nurses and between staff nurses and charge nurse with those he had experienced as a teenager. The more relaxed atmosphere was a bonus and extended to first name terms, permission for which was under the patient's control. Previously rigid forms of control had given way to looser ties in both the interpersonal and the technical.

The charge nurse was a key figure in Mr Snell's story. Although he did not describe any direct interactions with a charge nurse, the presence was assumed to be there, diagnosing, supporting the less experienced nurses, and attending to rostering which enabled 'give and take' in the area of nurses' personal lives. Mr Snell approved the less formal interpersonal relations. Nurses were always being observed even when not directly relating to the individual patient.

The newer complex areas of care were remote from some nurses' expertise. Mr Snell portrayed some nurses as concerned for his welfare, but not always being confident just what was in his interests. They didn't always know how to work the machinery, and some withheld basic information about his own status from him -even though it was all hanging on the end of the bed. Given Mr Snell's background and personality, it is difficult to understand why generally young nurses (and presumably more recent graduates with an emphasis on consumer rights) would withhold such information, or why such a patient would have to insist on this information. 
The concern expressed by some young nurses when his evening temperature rose was appropriate, he felt, but he was happy to reassure them that no action need be taken. He interpreted his physical signs in the light of patterns of physical responding from previous experiences of surgery. As a nurse I wondered how intensively other signs of infection had been sought, especially in light of his subsequent difficulties with the prosthesis, but Mr Snell felt the calling of a House Officer fulfilled the nurses' professional obligations.

The night nurses shared the patients' experience of the noisy patients, and tried to keep the noise down by turning snoring patients, or by attending to a distressed (confused) patient. All this was interesting to a practised observer of human relations, but the environment was still particularly noisy and understood as an inevitable consequence of being in a 'public' hospital. The nurses shared the sounds and smells of the shared sleeping quarters, and brought a humanising touch but did not influence the space directly. Mr Snell recalled holidays in shared quarters with another patient in the same room, and he did not enjoy the experience on either occasion. The private room of the preoperative days was a preferred option. Mr Snell met all such challenges to his well-being by distracting himself listening very quietly to the radio, which he then used as a source of information in his relations with others.

Stories where nurses' actions evoked gratitude included 'determined talk' during a painful episode of tendonitis from a recovery nurse on Christmas Day when hospital systems did not deliver the expected equipment. The personal lifestory of the nurse, and the reciprocal interest in the patient's lifestory were potent distractions from pain. In Mr Snell's experience, however they appeared to function as a substitute for the adequate delivery 
of more precise technological methods of assessment, and for appropriate medication.

The two teams delivering peri-operative care (ward and theatre) apparently did not consult regarding the place of Mr Snell's usual anti-inflammatories. They neither planned before the surgery, nor was there timely provision of equipment, skills and personnel after the surgery.

Similarly dual systems of analgesia delivery left the ward nurses ignorant of his pain management, or why his pain levels were so low. Mr Snell found the ward nurse's insistence that he have some more analgesia via PCA puzzling. If he felt no pain, what was the necessity to have analgesia? The ward nurses and the pain team may very well have been communicating, but, to $\mathrm{Mr}$ Snell there did not seem to be precision of understanding between them. He, as the common factor between the two teams, was not experiencing unity of care.

As with the episode of tendonitis, negotiating the systems of the different caring teams seemed a particular responsibility of the nurses. Mr Snell described the nurses as not focussing on him and the meanings he was creating concerning his lack of pain. Rather they were focussed on the technology, particularly at the level of didactic instruction, and even strong persuasion (you really must...) without addressing the patient's understanding. In short he was in agony when the recovery nurse expected him to be pain-free, and he was pain-free when the ward nurses expected him to be utilising the PCA, and he thus saw no need to use it. This lack of congruence in the understanding illustrates the distance some nurses could not bridge in their relations with patients. 
This was not the case with all nurses however. One admirable enrolled nurse was a natural. She had 'tricks' for moving patients. She had been able to move the operated leg. Her duties were much more limited, meaning she was free of the obligation to attend to the technology or to monitor the patient's physiological status, but she did realise when patients needed their backs rubbed in the shower. She was alert and aware of patients' need for practical help. Such helpful care was the result of being able to learn from experience, but the expertise was confined to too low a level in the hierarchy to be generally useful. Mr Snell was aware of changing educational opportunities for nurses and approved her decision to train for a degree.

A second 'older' nurse managed to combine the technical and the personal. She was able to speak with Mr Snell about the details of her life in such a way that it did not interfere with her professional duties. Being a friend bringing everyday social interest to the ward, as well as completing the technical and medical monitoring aspects of care was an unremarkable but rare combination in the nursing team. Mr Snell clearly enjoyed the forthright and amusing details of this nurse's private life, included divorces and messy children, but never at the expense of clinical expertise.

In retrospect, $\mathrm{Mr}$ Snell held senior nurses accountable after the third revision, along with other members of the multi-disciplinary team, for the lack of information about what level of activity to engage in -especially weight-bearing. The fact that such information was freely available in his local public library, and the book had been brought to his attention by a friend, not a health professional, mean that there was public domain knowledge which he had not had access to. The health professionals had this knowledge, but did not share it with him as the patient. He was a 
competent thinking adult, used to getting information from books all his life. He wondered why competent health professionals had not made such information available to him. Either they had overlooked 'who he was' in the world, or alternatively they themselves did not have such information, which undermined his confidence in their ability in other areas of their practice as well.

Mr Snell portrayed lived human relations over the two hospitalisations through two lenses. The first lens, the recounting of the actual hospital stories was, on the whole a positive one. Human relations were relaxed and easy between patients and nurses, between nurses and doctors, and between staff nurses and charge nurse. The nurses showed consideration for each other and this extended to patients. Mr Snell did not feel that relationship initiation or maintenance was in any way up to him, even though he did, on occasions, feel that he needed to reassure the young nurses. The fact that almost all nurses did not realise he needed help to dry his back in the shower did not seem a major irritant. Rather, it was a noteworthy achievement when one nurse did so. By personality and temperament $\mathrm{Mr}$ Snell accentuated the positive, and he did not waste time complaining.

The second lens through which he viewed his hospitalisation was that of ongoing disability. In this perspective he felt there was an absence of information on the part of the whole health care team. Reflecting back over his experience there was a felt need for literature or expert advice which should have given more clarity about the team's expectations in the area of mobilisation. By training and inclination $\mathrm{Mr}$ Snell was a reflective and analytic thinker and a lack of conceptual grasp of the reasons for the instructions given to him seemed, in retrospect, to cloud the commonality of understanding which he had previously valued. 
Through the lived body he experienced ongoing disability. The physical difficulty in mobilising post-surgery was not a problem to him while he had understood his faltering steps were steps on the road to recovery (as had been his experience in the past). When the recovery period extended, however, traversing the unknown territory of the road without the close support of the health care team, he was left with only the resources of himself and his wife. He looked back on the road through the ward examining each step on the way for clues to the journey.

On looking back he found other puzzles with regard to the body's experience of pain, and the mysterious never-explained evening fevers. These lived body experiences were occasions of new encounters with nurses where they seemed as mystified as he was. It seemed an act of faith that some unseen person perhaps the charge nurse or the duty doctor - was overseeing and understanding his body. The afternoon nurses in particular were concerned but had no meanings to offer.

The lived space around his bed was shared by other patients and nurses- especially night nurses. At night the space became alive with noise and smells and distressing recitals from other patients. He was captive to his bed at these times, apart from the outside world which arrived via the radio. Physically he was unable to move away from the space, and the practised observer in him was enticed, but his need to protect some psychological zone of privacy was stronger. As the curtains provided some visible symbolic privacy for Mrs Roy-Jenkins, so the radio functioned as a marker of aural personal space for Mr Snell. It had the advantage that it enabled him to resume social transactions by passing on information gleaned from the radio. 
Mr Snell reflected on his experience of lived time also. Unlike Mrs Roy-Jenkins, time had continued to provide positive experiences. The rigid starchiness encountered in hospital during the war was no longer necessary, although stricter protocols had been necessary when a young soldier flirted with young nurses. Although for Mr Snell the past was an important reference point in his understanding of the ward human relations, he did not portray his personal history as of interest to any nurse, except the one who was waiting for equipment to arrive in Recovery, and here the exchange of life experiences was a welcome distractor from pain.

His slow recovery delayed but did not extinguish his future plans. $\mathrm{He}$ and his wife were most apologetic when, given medical permission to drive again on the day I had an appointment to interview him, he had immediately gone driving. He had all sorts of projects in hand including overseeing re-modelling the house when his two fractures had intervened. Although he was interested in the future plans and lives of nurses, he did not portray his future plans as of interest to any nurse. Relating to time past and future and its relation to the present ward existentials is perhaps an overlooked aspect of nursing consideration.

The 'lifeworld' in this ward was relaxed and full of social interest. Changes in society were marked from past strict propriety to current easy companionship with a divorcee. Only two nurses (besides the charge nurse) seemed competent to meet expectations in all areas. The general inexperience of many nurses led to some misunderstandings, but these were of interest in themselves, showing that new technologies and new ways of education still furnished some ageless puzzles to solve. $\mathrm{Mr}$ Snell's lack of information and understanding had unnecessarily 
delayed his recovery somewhat and had burdened his wife at a busy time in their lives.

His need at the time of the interview was to make some sense of why the current period of recovery was different from earlier periods of recovery from hip surgery. Because an explanation to this puzzle did not seem to be an expression of his needs at the time he was in the ward, but only in retrospect, it is difficult to see how nurses could have responded to a need he was unable to state at the time. Nevertheless, thinking as a nurse, it is not unknown that patients should have an unusually long recovery period. I began to consider the identification of patients who might need "follow-up." Early identification to the patient that they are not progressing as expected may not always be helpful, but at some point, thoughtful and reflective patients, such as Mr Snell, are going to seek an explanation. A consideration raised by $\mathrm{Mr}$ Snell's story is the readiness of nursing as a profession to respond to this expectation of a better educated and more reflective generation of older people.

The mixed blessing of Mr Snell's living in the ward related to some very supportive and interesting experiences observing how times had changed and the more relaxed nature of social relations, juxtaposed alongside a sense of concern that appropriate clinical monitoring may not have taken place in regard to his afternoon temperatures and his understanding of partial weightbearing. In Chapter 5 Roy-Jenkins described fraught relations with nurses where there was limited understanding shown of her respiratory requirements and only one nurse was truly taking notice of patient need that was not directly involved in the reason she was in hospital. 
These two portraits of patient living in acute care wards in Chapters 5 and 6 show patients holding up their end of the relationship, and nurses only sometimes responding in kind.

In the next chapter the focus falls again on a patient with a fractured hip. The picture shifts anew to more dismal internal realities of patient living in the ward. 


\section{Chapter 7 Suffering but it could have been a lot worse.}

Like Mr Snell and Mrs Roy-Jenkins, the third patient who wished to speak with me had also been in an orthopaedic ward. I began to wonder if I should reframe the research question to relate to aspects of hip surgery. For instance, Greenwood and King (1995) suggest that in Australia, orthopaedic nurses do not find their work absorbing. I began to wonder if I was uncovering the same dynamic in New Zealand. They found that nurses gave priority to the clinical pathway 'ideal' of patient recovery, put overwhelming emphasis on physical aspects of care, and that beginning practitioners were more likely than expert nurses to use age-related stereotypes in clinical reasoning. Greenwood and King criticised nurses for referring to other disciplines issues which were part of the daily work of nurses.

I wondered if respondents had experienced the same dynamics in orthopaedic nursing which Greenwood and King presented. That is, the Greenwood and King showed the 'nurse side' of orthopaedic nursing, I was hearing the 'patient side' of a nursing practice whose practitioners did not find their daily work "very absorbing." Accordingly I began a literature search relating to hip fractures, and patient needs for information. I uncovered many examples of better and worse patient information sheets, and advice from former patients in orthopaedic wards. I read clinical pathways and tried to match them to the patient stories I had already considered. It did not seem to me that any pathway or plan of care would have been sufficient as a response to these patients' needs, or have helped the nurses meet older clients' expectations. I briefly considered the development of a series of 'niche plans' which were intended to be a more tailored response to the requirements of different gender, age groups and medical intervention, and so on. Such a task seemed impossible. 
Although both Mrs Roy-Jenkins and Mr Snell had 'fractured hips,' the commonalities were not many. It seemed there was no alternative to an aware human, alert to the requirements of medical technology, who could be a link between the needs of the patients and the needs of the acute medical condition.

At this point in the research project the issue for me became, not merely to uncover the problems as patients saw them, but also to seek clues as to the solutions as they saw also. In the stories of Mrs Roy-Jenkins and Mr Snell in Chapters 5 and 6 issues of mobility and how to live in one's body when the recovery time was delayed and complicated in some way were emerging as possible motifs for me to attend to. What patients needed from nurses when patients did not 'progress' as expected on the critical pathway was also important. Each story was different in some way from the experience of the previous patient's, first because the person had a different way of being in the world, and second because, even though the stories related to orthopaedic medical practice as a common framing element, they were quite different in their cause of admission and the tale of the subsequent events. Fortuitously the patient in the current Chapter, Miss Shepherd had rich and pertinent observations to make which illuminated such an issue.

This interview in this chapter relates to an admission to an acute surgical ward following a fall outside her house when Miss Shepherd fractured her hip. She found the fracture completely shattering in emotional as well as physical terms, and felt she was still in some shock as to the subsequent changes in her life. She was 80 years old at the time of admission and lived alone in her own home with home help support. As the chapter heading above indicates, the experience in this ward was a difficult one. 


\section{Life profile}

Miss Shepherd lived in a townhouse close to a small group of shops. A friend was just leaving as I arrived. The house had many photographs, and plants and mementos. She described herself as a person who liked her privacy. I'm a person who likes my own home, and I'm very lucky to have had my own home. She also described herself as a very busy person. She had been a nurse all her life including geriatric nursing. She was invited to do her Maternity training, which at one stage was the only postregistration course for nurses in New Zealand. She did very well in the course topping the Dominion. However, the involvement of parents with their babies meant she felt on the fringe, whereas with the sick you felt you were being helpful to them and they needed you. She loved working in theatre, but found that nurses were not expected to follow up patients after they left the theatre: they looked at you in a particular way as if to say "well, honestly it's none of your business". She had also travelled the country as Dominion secretary for registered nurses, and worked in general hospitals.

She was a caring person who looked after first her father and then her mother until she was 101. During this time she continued to work part-time with terminally ill patients. She does not really distinguish between her paid and unpaid work, and had continued to work for community organisations until she was 79 . She misses

meeting the public, through the whole spectrum... all colours, all cultures... I loved it in Sacred Heart hospital because you were meeting so many people. And at Silverstream Community Centre, they meant a lot to me those people and I found myself very 
concerned about their incapacity and still do - I think of them frequently.

She has a number of sisters, one of whom is in daily contact with her by phone, and a lot of nephews and nieces. She showed me items she knitted for new babies who were born to her wide circle of acquaintances.

Over the course of her life l've had a massive amount of surgery one way or another and each lot l've come through. I'm quite game - each time I just pop up and wait for more. About five months before this fall which led to the fracture Miss Shepherd had been in hospital with her back and

[I] came out quite stooped and crooked. My own doctor said to me, "My girl, the time has come for you to use a stick", and I said "Never!" and he said, "Look, sit down a minute. Do you think any less of a person using a stick?" I said, "Of course I don't." But I still didn't use a stick - stubborn, I suppose, proud, very proud.

Prior to her fall and admission to hospital she had pneumonia. But now I wonder if it could have been that I wasn't really capable of doing what I thought I could do outside so I had this tumble. 


\section{Circumstances of admission -they heard my screams up in the next block}

The day of her admission to hospital began at 7am. It was a lovely Sunday morning and I thought "oh what a glorious day". Miss Shepherd had had the grass around her house replaced with concrete to reduce the maintenance and almost immediately she went outside, she fell. I hadn't been out there five minutes when I went on the concrete, and that concrete is very hard, and I wished I hadn't had my lawn taken up. At 7 am no one was around. For some time there was no one to call out to, but eventually someone did come and called an ambulance. The first ambulance was not able to deal with the situation. I believe they heard my screams up in the next block as they tried to get me on the... though the trolley was on the ground. Miss Shepherd doesn't like to recall this period. Eventually a second ambulance was called and she was admitted to hospital. A surgeon who had had previous dealings with Miss Shepherd was on duty. She was quickly admitted and had surgery within hours. The day passed in a haze and her first conscious memory is of waking up in a single room.

\section{The Ward pockets full of Panadol}

In contrast to the day of surgery Miss Shepherd remembers a lot of her times in the post-operative ward. Pain seemed to be a constant theme. The nursing staff and Miss Shepherd found it difficult to find a common understanding of her pain. One of her first memories was the little machine that gave you morphine small doses when you pressed the button. The nurses constantly entreated Miss Shepherd to use this more often, but

I kept feeling it wasn't bad enough. All the time I would feel well it's not bad enough yet... $\{C W$ Can 
you think about that first day? ... What happened when they told you to push the button? What was going on then?\} Well I suppose I was quite quiet. I know one of them came in and said, you've only pushed that once. Which shows that I wasn't in a lot of pain. \{CW Did she tell you how much you were able to press it?\} Yes - "as often as you like. We want to see you press it more often." $\mathrm{CW}$ did she say why? No, just to relieve, I suppose. I was suffering, but to me I felt it could be a lot worse.

Miss Shepherd remembered getting out of bed the second or third day. Both anticipating the event of standing on her hip and the actual standing experience were difficult for her. The staff told her what to do and she trusted their judgement, but it did not seem adequate.

\{CW can you remember getting up? What was it like? Awful ... I think a lot of it is nerves. "Get out of bed." "I can't." And of course they helped you and you do. And then when you get back in again and settled down, you are quite amazed at the achievement. But there again, you see they know what they're doing. And I do think a lot of it is apprehension and a certain amount of fear. ICW was it awful actually doing it or was it awful anticipating it?\} I think when you came to do it, it was very painful. Yes to get on to it. They gave me some Panadol. ICW were you prepared for the pain?\} Yes, I must have been. "This is going to be..." There again, how much is imagination? $1 \mathrm{CW}$ did you push your button and have more pain relief 
when you were getting up?\} No, that had gone then. I think after that I only had one injection...

Later the pain continued in her hip.

Looking back this leg was wrong from the very start. I was always asking people would they please lift my leg in, and often and often they would say, "oh come on you can do that yourself". I'd say, "I can't" -- "oh yes you can, come on". That'd be the sister... any of the staff...The pain in trying to lift it into bed and they'd say "come on you can do that."

Miss Shepherd discussed the pain in her leg with her specialist. He took an X-ray and said "I'm almost sure I know what's doing that: the prosthesis is moving about in the bone at the bottom end and it's got a stem about that long." Now that she was home again her leg was still sore

enough to make me really squeal and yelp, you know - trying to get my leg into bed is murder... It's only on movement... I'm conscious of a knock, a little knock in myleg. $\{\mathrm{CW}$ and was that there all the way through?\} Nobody picked up that I was complaining about this leg. Well I thought it was all part of the thing.

The sense that no one shared or understood her pain is one that has continued post-discharge: a couple of times l've said to myself out loud "My sisters have no idea what l'm suffering." Silly sort of thing, but that's how I feel, nobody really knows how painful it is to move. 
Miss Shepherd showed the nurses relating to her pain through attention to the technology - the patient controlled analgesia - or through medication - the Panadol or an injection. As a caring nurse herself, interested in the needs of others, she expected nurses would be interested in her needs. As a nurse she liked to care for patients who had needs. In her professional capacity she had opposed the training of nurses in Polytechnics. I said it would never work, I was wrong. That was my attitude when they first started training the nurses (outside hospitals). I said, "well it's not going to work", but it did.

The training 'worked' in the sense that nurses related more easily to the equipment than a gregarious and sociable person like Miss Shepherd.

If they've got some equipment, fancy equipment, advanced equipment to look after, that's fine, but I had the feeling some of them were beginning to forget the needs of the patient. They'd rush in and check on your intravenous...providing they had complicated enough machines to look after, they were quite happy. They mustn't forget bedside techniques and what means so much to a patient.

Miss Shepherd was ambivalent about the role of technology in progress, particularly when considered alongside the nurses' interactions that were related to the technology.

She tried to keep quiet about the fact that she was a nurse.

\{CW do you think being a nurse made a difference?\} I tried not to be critical. l'd gone in and never let on...and I would watch and listen... You sort of ooze interest - you can't shed it, you can't shed it wherever you go. I wouldn't want to...It's no 
good going in there and saying...(pause)... Well so often they tell you things you know so well, you know, "now we're going to take your blood pressure." They tell you even your pulse and your temperature using that silly thing in your ear. $1 \mathrm{CW}$ you thought the thing in your ear was silly?\} I think some of these things are getting a bit silly - I don't know - they often questioned them. "We'll take it again," so in again it would go. It was hilarious to me, it really was. And then they'd buzz round with their little wheels and that was the part, I think that you resent, was being told things, but there's no overcoming - they've got to go ahead.

Although she kept it quiet she was a nurse, this information was surely in her notes, and few of the nurses valued her expertise, or managed to find common ground with her in spite of a shared profession. The new technologies that the new nurses were expected to manage generated a climate of uncertainty. Nor did she find the 'new' culture of openness and information sharing a helpful one. The approach was stereotyped rather than individualised, and depended on this patient taking the initiative.

You're a step ahead of them, because you know. $1 C W$ did they tell you your blood pressure?\} Yep. \{CW And did you want to know? No it didn't worry me, except when I went on a diuretic I was told, "Well that diuretic is probably doing you far more harm than good." I wanted to know why, but I didn't ask. ICW you couldn't ask the nurses?\} Well they started taking the blood pressure twice a day, so I just presumed it was having an effect on the blood pressure which I found 
out in the Centre is a bit low. You do like to know all the answers, but is it to your advantage sometimes?

Miss Shepherd had reservations about current training for nurses. Nurses' attention to the technology was competent, but their selfcentred conversations were a trial.

Quite often talking in the room their own private... Um... Their day-to-day happenings with their families, with their husbands. One was moving house and she was going out, way out somewhere to live. This sort of cross-conversation - I didn't think it was very good, but it's human nature. I suppose as they do their work, they're entitled to chatter among themselves.

By contrast the enrolled nurse who best typified all that a nurse should be was married with children and Miss Shepherd knew of her career plans. However she did not tell the patients this without being asked. She was interested in their needs and wants and they responded by being interested in her. A key aspect of this nurse's expertise was what she had learned from experience, in contrast to the registered nurses,

-a lot of the young ones just simply haven't had a lot of experience yet. This nurse was an absolute gem. This special one was, I presume, almost middleaged, she had more understanding... No, I think her attitude would be experience - there's nothing like experience...She was so willing. And experienced in getting people up... there was one next door - two nurses would come to get her up and she would call out, she was in obvious awful pain, and this girl could take it 'sloowwlly' on her own, and seemed to have it 
off to perfection. This she did with all of them... and you so hoped she'd be your nurse the next day.

However Miss Shepherd never did get allocated to this nurse. She discussed this nurse with the other patients in her room. They were all women who had been redone, one a knee, and the others hips. And they were trying to correct things which had gone wrong. And we all felt that the nurses showed a certain disinterestedness in a pan, or helping you. Now don't think we went without that sort of thing. But who did it? It was mostly the community [sic] nurses... one on that ward was superb... even if she was delegated to the person next to you could ask her for something and she would do it for you - some slight thing you know whereas, but perhaps l've said enough...She would have done anything for any of the four of us, because when she came on duty you felt, oh, thank goodness, because you knew that there was this very human person. $\{\mathrm{CW}$ what made her human?\} her understanding. \{CW yes.. How could you tell she understood?\} By her very presence, by her reaction, the way she handled people, by the way she spoke to people. Some of them were a little harsh the way they spoke to you...

Miss Shepherd's conception of a superb nurse was one who would meet everyday requests reliably when patients were unable to meet their own needs. She was aware of the 'rehabilitation' focus.

\{CW tell me about having a wash in bed Well it was jolly nice to have your face washed and the rest of you, very refreshing...but, of course 
you're into the shower just as fast as they can get you - which is all part of the rehabilitation $1 \mathrm{CW} \mathrm{mm}$ $\mathrm{mm}$ \} I realise this - right from day one it's to get you up and away home - that's as it should be.

Miss Shepherd also relied on the other patients in her room for support and practical help.

One night I wanted particularly to ring someone - it was the only time - and they found you had to have a phone card or something. Well I didn't have a phone card, and the lady in the bed (next to me) insisted that I take hers. Little things like that where we helped each other... you know the little grabber? \{CW yes I kept saying to them, "could I practise while in here?" But, no, it wasn't till I left the ward and bought one that (I got one) but she would always pass hers over and I could use hers to pick up off the floor for someone else you know...l don't know why I didn't have one, and she (the other patient) would say to me "well you should be practising with your own", like. But I would use hers, or she'd pick something up for me, although she was confined to bed. There seemed to be a wee bit of delay in that. Why, I don't know, perhaps due to my not asking enough.

Miss Shepherd was pleased to be sharing a room and with the choice of companions. Being able to be in her usual role of "helping people" was helpful for Miss Shepherd.

I enjoyed it - I didn't like being on my own. I wanted to be with people. That's always been so - you see l've had a couple of lots of surgery in (private rooms) and I think it's better for you to have company. I'm 
sure of it because l'm always interested in someone else. Being on your own is not my idea when you're sick... except at night when they snored - and they all snored at different times, different pitches, it was terrible.

The nights and relations with night nurses were difficult.

\{CW so what did you do at night?\} I get by with very little sleep... l'd wake. l'd just lie there or I'd have to call for a pan or go across to the bathroom. And there again l'd have to ring to "lift my leg into bed"... l'd get out, yes, and push my way to the toilet, but I would say to them, "I don't think I'll get there" -being slow. And once or twice I didn't. The girl came and said, "What have you been up to?" And I said, "I knew I couldn't get there, I'm too slow," and there right across the corridor was a trickle. And then other times, “No, you can get up, you're not very far from the toilet." And l'd say, "well I have to ring you to lift my leg in."

This was not an isolated incident, as Miss Shepherd was often up at night.

ICW when you had the little trickle, what sort of response did you get there? Well you feel terrible - even to get yourself in to the toilet, park your walker, and then get in, and try to find a high toilet seat. And quite often I had a bit of an accident. One night, early morning I think it was (and you know how things can get hectic towards the end of the night shift) she got a bit irate about it. And I said, "I'm sorry, I couldn't have a pan, and I knew l'd never get there". I know even those night nurses who said to me, "No, you can get up", I 
like to think it's in my interests and not because they didn't want to bring a pan. $1 C W$ But you have some doubt? A little bit.

The way the nurses responded to her incontinence affected the way she felt about it also. There were particular nurses whom Miss Shepherd liked, and some she did not. One I called the robot because she was so inhuman - they're all different, and of course, you sort of hoped that you'll get a nice one.

Miss Shepherd compared the night duty systems and routines with those she had known.

One thing struck me was how little you see some of the night staff - very, very little - and as for coming round regularly as we did - it just doesn't seem to happen. Put it this way: they seem to respond to the bells rather than touring round regularly.

On some occasions Miss Shepherd found being assertive was useful with familiar hospital roles. The sister - we got on well together. She's a bit of a bully, but I found that if you stood up to her, we got on famously. Yet she was inclined to scare other people. Visitors were very important to Miss Shepherd, and she needed to take independent action to ensure their access to her was facilitated.

Twice my name was incorrect on the board at the entrance to the ward, and I made my way out and altered it twice. So I made sure it was quite correct... They (visitors) are important to you - you have a very restricted interest in a way. It was important to me so I put it right.

For Miss Shepherd visitors provided affirming support. 
Visitors came and I might see them off to the lift, and they'd say, "Oh, you are improving." I think outsiders perhaps see more than you do yourself... Don, my trustee came, and said, "Now this is a challenge," - l'd be walking and he'd say, "You must look on this as a challenge."

Nurses were also seen as part of the generic multidisciplinary team. Nurses and therapists issued their own challenges to Miss Shepherd's usual bent over way of walking

"You must stand up straight. Stand up straight!" And nobody realised, no matter how I told them, I wasn't straight to start with... and l'd say, "I can't." "Stand up straight, look ahead." Well, if l'd been looking ahead, l'd have fallen over long ago, because I needed to look at my feet. ICW from your point of view it's much safer to keep an eye out on where you're going Particularly, yes, it is. But on the footpath or anywhere, you'd get along watching your feet, and then all of a sudden you're told, "look ahead, look straight ahead." The whole world turned upside down at that.

Miss Shepherd already walked in a bent fashion for some time and had been advised to use a stick for safety. Walking with crutches in the ward was not a temporary interval until regaining improved mobility for Miss Shepherd: rather it was a reminder of her loss of independence and her decreasing ability to help herself, let alone others. Her GP's challenge to her not to see people on sticks as less than herself was a very poignant challenge. Pride was going after a fall. 


\section{Commentary}

Miss Shepherd portrayed herself as a private and caring person who liked to be busy helping people who had needs she could meet. As a nurse she had spent her whole life 'helping people' and had also looked after her parents when they were elderly. As well as paid work, she was actively involved in nursing politics and community services. She was a very experienced patient and in the past she had been able to benefit professionally from her experiences in hospital, by gaining a sense of what it was like for patients, but this reframing of her experience had not occurred after the fracture of her hip. The challenges to her identity ('I am not a person who needs to use a stick') had begun before this admission, and were intensified during the admission. Her experiences led her to doubt her previously competent judgement.

Miss Shepherd's memories of the emergency services are traumatic because of the pain and she remembers nothing of her time in emergency or theatre. She was still experiencing pain at the time of our conversation, and pain was very prominent in her stories of interactions with nurses. She portrayed registered nurses as being more interested in the technology, which delivered analgesia, than in truly helping her. She was an acutely admitted patient who arrived in the ward post-anaesthesia, and it would be difficult for the nurses to know Miss Shepherd's usual gregarious nature. There were two understandings operating in the story, both apparently relating to the same phenomenon of her pain, but never quite connecting. Miss Shepherd was quite quiet. The nurses were interested in encouraging Miss Shepherd to push the button as many times as (she) liked or have some more Panadol. Miss Shepherd was suffering but the nurses did not attend to her suffering. The fact that she hadn't self- 
administered more analgesia shows it wasn't bad enough. For the nurse (as with Mr Snell) it was an opportunity to 'instruct' the patient.

Lindholm and Eriksson (1993) reported the same dynamic operating in a community psychiatric facility. "The patients described the what of their suffering by using diagnoses, metaphors and symbols." ( $p$ 1356) The nurses, on the other hand, have a "tendency to explain suffering according to what they believe has caused it, rather than describing the suffering itself." (Lindholm and Eriksson 1993 p 1357)

Miss Shepherd's requests for help were interpreted by the nurses as inadequate analgesia, and resulted in exhortations to have more Panadol and to try harder herself. She expected more interactions which showed interest in her experiences or sought her preferences, and less technology-related interactions.

Miss Shepherd now feels that she asked for help with her leg but nobody picked it up. Picking up her leg was significant both as a matter of practical help, and as a metaphor for diagnosing the unexpected complication following the surgery. Thus the lack of practical help, the affront to her identity as an independent person (she would not have asked for help if a simple exhortation had been enough to achieve getting her leg back to bed), and the superficial interpretation of her request for help as a need for analgesia all combined to challenge her self-confidence. Nurses may well have been accurate in their evaluation of her lack of analgesia consumption, but to an independent and competent person like Miss Shepherd, a pain relief method which tapped in to her need for independence seemed to be required. By producing Panadol from their pockets, the nurses seemed to be subtly insulting her under the guise of caring. 
Miss Shepherd was sceptical about the place of technology generally - especially as it did not seem to be an improvement on the familiar ways of doing things. To have technology and drugs offered to her as a substitute for human relating further alienated her from the current culture of the ward - a culture which she had been particularly familiar with over the course of her life. Here was another challenge to her sense of identity.

The patient's experience of having nurses express lack of confidence in their monitoring equipment was not a valuing of openness, rather it was a wondering about the general expertise of the nurses themselves at a time the patient needed to be able to trust the nurses' judgement. The nurses were not oriented to the quality of the experience for Miss Shepherd.

The lack of interest in her suffering extended to lack of interest in other aspects of her care as well. The urinary incontinence she experienced while having to walk in to the bathroom at night, find the raised toilet seat and a place for her walker was humiliating. The nurses were unable to share imaginatively in the nature of the experience of incontinence for Miss Shepherd. The night nurses did not meet her expectations, neither in the way they spoke to her, nor in the routine safety checks. Some of them were robot-like in their interactions, and they did not tour the ward on a routine, rather they responded to requests. The nights were the only time Miss Shepherd did not appreciate the company of other patients.

During the day Miss Shepherd did not like to be on her own when she was sick - it was an advantage of a public hospital. The people who would do anything for you were the other patients, not the nurses. The people who kept her spirits up and encouraged 
her progress were the visitors, not the nurses, who simply issued orders: stand up straight...use the toilet... you can do it. What she wanted reflected back to her were signs of progress however tiny.

If the nurses did not meet her interpersonal needs, the other patients offered opportunity for the giving and receiving of help and social support. All the older patients who were in Miss Shepherd's room agreed that one particular enrolled nurse typified caring and concern. Freed from the need to manage the technology, enrolled nurses gave basic nursing. The excellent enrolled nurse, by taking things slowly and focusing on the patients, their symptoms and their activities, managed pain well. What she offered patients was time and her own humanness. By her interactions with other patients she gave hope to those observing, and she had the ability to learn from experience. On good terms with the charge nurse, and aware of patient allocation systems, Miss Shepherd had a wish in regard to the enrolled nurse - I so hoped she would be (my) nurse -but she never was. The transcript does not reveal the tone of sadness the tape does.

Although having set up professional groups for nurses and held very responsible positions, Miss Shepherd could not advocate on her own behalf in this situation. Nor did her good relations with the charge nurse extend to seeking any special nurses. The position of a health professional as a patient is a difficult one.

Miss Shepherd's time in this ward was characterised by a lack of care apart from one notable exception. A very experienced nurse herself, she did not agree with the priorities of the 'young nurses'. Although a gregarious and outgoing person, she was unable to find common ground with any of the nurses to communicate her needs. Her judgement was formed early in her stay in the ward during the first one or two days. 
As with Mr Snell, much of Miss Shepherd's lived relations with nurses were framed by differing understandings of pain. In her body she was suffering. She so hoped the nurse who had experience and insight would be allocated to her care, so that she might be taken slowly, but it was not to be. Instead, burdened with pain and expecting a personal response, she was diverted by interchangeable representatives of the nursing team to pay attention to technology; to things attached to her arms or probing her ears, distracted like a child who might cry; to pills produced from pockets like magic and put into her mouth like candies.

Her bent and slow body was urged along the corridors, others demanding that it lift its feet, uncurl the back and redirect the eyes searching the path for obstacles. The leg, now with the muscles torn and cut, the bone shattered and pierced with rods, refused to rise from the ground to rest on the bed. Exposed to gravity's wounding pull, it remained until some kind Samaritan would pick it up.

Like a safe harbour in a very rocky storm, by day the other patients and visitors anchored her, sending messages, giving gifts, discussing the blizzard as old hands, lashed together by their common purpose: to brave the elements and make safe journey home.

By night there was need for space, quiet and privacy to rest the tired body, or to get up to the toilet, if needed, and slip quietly back to bed.

Many barriers filled the space: barriers on the way to the toilet as the body trailed urine across the floor, and braved the anger of the night nurse -it seemed she only ever came to perform 
requested tasks before beaming back along the torchlight to another world-, barriers in spelling so one feared the longed-for visitors would never find their way to the right bed, barriers to getting equipment to pick up small items dropped on the floor by the body slowed in its reactions.

Lived time gave rise to comparisons with Miss Shepherd's own nursing worklife. Once the nursing ethos had been one of service to others, now the work was a means to fund the social activities and redecorate the house. Once helping people had been the nurse's joy, now the patients were expected to help themselves, mobilising their own motivation.

The 'lifeworld' in this ward was expressive of discomfort and dislocation. Important details were overlooked. People were treated as things, and "progress" in the form of technology only increased the nurses' unsertaintu, and the natients' lack. of. confidence. Apart from one enrolled nurse who shone throughout as all that a nurse should be, and the other patients in her room, it was difficult to find someone reliable. Even an assertive charge nurse was unable to affect the standards. The equivocal nature of nurse training undermined confidence in the ability of the nurses to care for patients as they needed to be cared for. Pain was an ever-present companion, disabling human relations, spoiling the professional interest, impairing human achievement, and infecting time and space.

This story was redolent with absent care. Like Mrs Roy-Jenkins, Miss Shepherd's relations with nurses, whose capacity to help patients was exceeded by the demands made on them, moved to the forefront of her experience. The (rare) experiences of effective care, the physical improvement in spite of the absent care, the resistance to increasing dependence: none of these 
perspectives was valued by Miss Shepherd. Unlike Mr Snell, Miss Shepherd had not got anywhere near her former levels of functioning. She could barely creep around the supermarket leaning on a trolley let alone enjoy the fresh air in her yard at $7 \mathrm{am}$ on a Sunday morning. Her expectations of herself as one of life's survivors and achievers were meeting huge challenges. The self was accustomed to companions on the journey where mutual help was a possibility. Self-determination was no longer enough to carry her through the vicissitudes of the experience of surgery.

The next chapter considers the story of yet a fourth patient with an orthopaedic diagnosis. Lorna, the patient in Chapter 8 , has a different cause for her admission, a different life path, and a different fracture site. Like Mrs Roy-Jenkins and Miss Shepherd she has other chronic illness conditions which require nursing help when her capacity to self care is impaired by the acute admission.

In this manner a composite picture is developed of the experience of older people's ways of being in acute care wards is developed. Each successive picture brings new aspects of nursing care to view, uncovers similarities with the previous pictures, increasing the intensity of both the brilliance and the shade of the phenomenon of concern, nursing care. 


\section{Chapter 8 Sort of standing up for myself}

Miss Shepherd, the nurse whose story has been portrayed in Chapter 7, was somewhat diffident about expressing her needs to the nurses. In the current chapter, Mrs O'Fee reveals how she also felt somewhat diffident about insisting on the help she expected from nurses. As expressed in the phrase above she thought of herself as an assertive and expressive person who was only sort of able to express and advocate for her own needs.

This interview relates to admissions to an assessment ward and an acute surgical ward following a motor vehicle accident in which Mrs O'Fee had received two fractures to her right arm. One was to her humerus, and the second, to her elbow was undiagnosed until 4 weeks after the accident. As well, her knees were badly bruised and she was shaken. Mrs O'Fee was marginally mobile before the motor vehicle accident and had had many previous falls. She was 82 years old at the time of admission and lived alone in her house with family and home help support. She wore one arm in a sling fashioned from bandages into a collar and cuff the day I visited.

\section{Life profile}

During a very long initial phone conversation with Mrs O'Fee, she gave me detailed directions to her house, including the use of the cable car, and invited me to call her Lorna. I have referred to her throughout the interview by her first name. She was a chatty lady who walked and talked at the same time. Since she had a walking frame and an arm in a shoulder sling, these activities seemed precarious, particularly as a central feature of her house was a large stairwell. She had lived almost all of her married life in this city and still lived in the two-storied house she and her husband 
had built on their section 41 years ago. She was now a widow with two sons and a daughter, and now lived alone although currently her attendant carer was in residence every night as well as some part of each day. Although a student, the attendant carer was a registered nurse as well as a friend of Lorna's family.

Lorna had received help on previous occasions from this carer after her cataract operation a year earlier, and on other occasions as well during exacerbations of her congestive heart failure or her arthritis, or on one of the many occasions when Lorna had fallen.

Lorna invited the carer into the conversation and she volunteered that Lorna was a very willful and friendly independent person: cheerful except when the weather's bad. Lorna seemed to find this description of herself very amusing. Lorna, in turn, volunteered snippets of the carer's boyfriend troubles, and what she thought the carer should do.

The carer had been asked to make sausage rolls and salmon sandwiches and social chat is interspersed throughout the interview. Lorna clearly enjoyed entertaining. Lorna had been a traditional wife and mother, and travelled widely. I spent a long time looking at wedding photos of children, school photos of grandchildren, and photos of Lorna's own recent birthday parties. She clearly loved family occasions and crowds of people, as in every photo she looked to be thoroughly enjoying herself.

However her social outings had begun to be curtailed even before this current admission to hospital because she had lost her confidence after a series of falls. An ACC assessment officer had told Lorna that she had had 16 accidents. Some of these Lorna felt were the fault of others, such as car accidents, or an accident on a bus in Suva, while some she felt were her own fault through 
hurrying. Oh l've had so many accidents l'm ashamed of myself. Sometimes the falls had resulted in minor bruising, and at other times she had experienced broken bones and collapsed lungs as a result.

The most recent admissions to hospital following the car accident had prevented Lorna from attending her son's engagement party.

\section{Circumstances of admission - that car's coming right at us}

The day of her admission to hospital began when Lorna and a friend set out to drive to an international airport on the first leg of a trip to Melbourne. Some 8 hours away from home, they were almost at the airport when they were involved in a motor vehicle accident which Lorna retold vividly.

This woman came right into us and shoved us into two more cars... We were both being thrown around in the front of the car and the seatbelts were stretching. I thought, thank God for seat belts, and I tried to hide my hands thinking the glass was going to break - don't know when I thought about my face, but I was thinking about my hands. The first car we were shunted into was a white one, and it was stationary. I remember we were thrown into it. I said, "Oh that car's coming right at us", but it was us going into the white car. All the windows in that car - the glass was hanging like leaves. Just bits of dewdrop strings it looked like. So people got the ambulance: the ambulance and the police and the fire engine, but they couldn't get the doors open. My friend got very badly bruised on her chest and her hands. I can still see - she had little hands, so 
fat and so purple. Her whole hands - both of them ... but she didn't get any breaks. I got the break in the shoulder, and also the elbow (but we didn't know about that until after I was transferred to another hospital), and also bad lacerations... So we were taken by ambulance and put in the assessment ward.

Lorna lost track of the time, but the accident occurred in the early evening traffic. Although intended as a short-term holding ward for less than a day, this assessment ward was a place for Lorna to recover for three nights until arrangements were made to fly her back to her home city.

\section{The Ward (no. 1) The Bs were at night}

Lorna said most nurses were really lovely, but she was unable to remember specific times with "lovely" nurses.

\section{\{CW did you have a wash in hospital?\}}

Oh yes, yes they were very good. They took me in a wheelchair, put me under a shower. $\quad$ CW what happened?\} Yes they stayed with me. Put on the gumboots, did my hair. I couldn't have done it, 'cos this arm, it was sore, you see. I got, what do you call it, deferred or referred or something down here (gestures to her side.)

The nurses' help with activities of daily living was taken for granted and unremarkable, as expected.

\{CW how did you get into bed in hospital?\} Oh they helped me in... I sat on the 
bed and they stood and (gestures) $\{\mathrm{CW}$ lifted your legs?\} Yes. My legs were really bad, they were really a mess.

During this period in the assessment ward, Lorna had a fracture just below the shoulder, and a second undiagnosed fracture below the elbow, which caused her considerable pain. To immobilise the humerus, she was given a collar and cuff, the lower loop of which rested part way along her forearm. She always had difficulty turning in bed even before the vehicle accident due to her arthritis.

[But now] when I had this accident, these legs drove me mad, they were so painful. You see they were pushed back under the dashboard... it was dreadful, it was just so painful, l'd start yelling before I sat down and before I stood up... \{CW did the Digesic hold your pain when you were in hospital?\} Well yes, I, I. (pause) $\quad\{\mathrm{CW}$ was it still quite painful?\} Well no, no it wasn't, but they were giving me morphine in the shoulder. No I wasn't in really bad pain then. l'd wake up at night and l'd be in pain, but if it was before four hours, I just used to wait. They wouldn't give it to me before then.

When she had to wait at night, Lorna had vivid recollections. Nights in the assessment ward were filled with people coming and going, noise, pain, waiting for medication and male patients in the beds beside and opposite.

The Bs were at night! I was there with different people coming in and out and the last night there was a Samoan man opposite me and one next to 
me. Everyone was lovely except those blasted ones the eleven o'clock ones. And I'll tell you another thing - you're asleep by eleven o'clock. They made such a noise when they came in laughing and chatting away. You'd sort of get wakened up.

Once awake, Lorna had to wait the full four hours for her Digesic. (Previously a district nurse had suggested to Lorna that Digesic might have been implicated in her many falls, and Lorna herself had wondered if it was a cause of her nausea and so had switched to Panadeine, but once back in hospital in the assessment ward she was again prescribed Digesic.)

Walking to the toilet was a requirement in the assessment ward, but the full history of Lorna's problems with mobility was not realised, or else the nurses were attempting to encourage independent behaviour. Whatever the motivation of the nurses, Lorna experienced their interactions as punitive, and inconsiderate.

And this time I was more nervous than ever about walking on my own after this motor accident. I had even been to a counselor in my hometown, but 1 was frightened in hospital this time. Another woman and a younger one were there. I said, "could I have a pan please?" "No pans in this shift!" See, I was only asking for a pan, because I thought it would be less trouble, so they wouldn't have to take me. So I said, "someone will have to take me." I did sort of stand up for myself but I was frightened to in case she took it out on me by giving me something to put me to sleep or something. 
She took me and she left the young one to bring me back.

The nurse attempted to induce Lorna to walk by coaxing steps, the way one encourages babies to take a few steps towards the hands of an adult.

She said, "come on, l'm only standing here." I said, "look, I fell at Dr Vaughn's feet a couple of weeks ago, you can ask him if you want to - I can't walk, l've got to have something to hold onto." So she came and took my hand... of course the bitches have had every other march on me.

Lorna's vulnerability in this situation was intense. Her inability to influence this situation when mobility had been a vulnerable area of her functioning for some time prior to her admission was generalised to 'every other' area of her care as well. The judgment was formed and remains. As with Miss Shepherd's use of the metaphor of 'picking up' her leg as an expression of her need, Lorna's choice of words here was expressive of her needs. The nurses could march while she was only standing there. The physical distance between the able nurses and their reluctance to physically bridge the gap to Lorna was reflected in their attitudes to her.

\section{Ward no 2 Marvellous}

After three days Lorna was transferred to a plane by ambulance and then sent home. She remained at home having full support of the activities of daily living from the current attendant carer for three days. Finally she rang her ACC case manager (who had previously been contacted by the social worker from the first 
hospital) to get her help reinstated. By mid-afternoon she had been assessed in her own home. The lady could see I wasn't capable of living on my own, and then (I) was sent to hospital. She much preferred her time in this hospital where she had been a patient many times before. Lorna didn't know anyone on the staff of the first hospital, but a doctor who was the daughter of a family friend admitted her to the second hospital. Lorna felt the late night visit by this doctor was evidence of commitment to her: (my son) keeps telling me you saved my life. Lorna later sent this doctor an invitation to her birthday party, but the doctor did not reply.

Throughout our conversation, Lorna searched for acquaintances whom I might know socially. At one time I wondered if the favourable reviews she gave the nurses in the second hospital might have been because she thought I might have known them. As she mentioned each health care professional she would say, "Do you know him/her?" However, it became apparent that this was Lorna's habitual way of relating to people, and she derived much pleasure from knowing relationships and connections between people. The nurses in the ward were old friends from her many previous admissions including a long admission the previous year for a back problem. Lorna was on first name terms with many of them.

So when I came in this time there was a Malaysian girl named Lisa - she was getting married over in Perth - she showed me the photo of her wedding frock and that... and there's the one that's in charge, Maree. I said to her "you look younger and you look fitter," "Ooh," she said, "you've made my day." 
As well as fitting right in to Lorna's social system, the nurses facilitated her maintaining contact with others.

Different ones would ring me and they'd push me along in the bed to the office to get the phone actually they brought one along one time, but it wasn't much good. And (my son) was ringing from Melbourne and another time someone rang from Timaru. The Sunday someone rang from Invercargill - she was one of my bridesmaids, and she said, "I believe you are having a party, can I come up for it?" "Oh," I said, "l'd have never really thought of it because I wouldn't have asked anyone from Invercargill."

As well as organising her birthday party while in hospital, Lorna kept in touch through the cards and letters she received every day.

In this hospital, Lorna still needed quite a lot of help with personal care. The nurses were marvellous - they used to lift me over, they used to get me over and wash my back twice a day... Sometimes there'd be three but always there were two.

Also in this ward Lorna encountered a male nurse for the first time.

I can't tell you what Mark's other name was, but he was so nice to me. $\{\mathrm{CW}$ How was he nice?\} Oh just nice and friendly... and in the morning for breakfast "what did I like (and) what didn't I like?" I didn't have breakfast foods, but I like my toast, but I hated (the hospital toast) and he used to crisp it for me. 
Throughout this period of five days in the second ward, the second fracture remained undiagnosed. Her arm continued to be very painful. Three weeks later she kept an appointment at the outpatient clinic where she saw a registrar.

And when I got there the chap said something about a mistake. I said I haven't made a mistake. He said the date, the 23rd, I think. I said it is the 23rd. He said he knew, but the computer - isn't it amazing how they always blame the computer - the computer was out of action a fortnight ago. So I waited and all the people were taken. And more came and were taken. My daughter had come so l'd have had someone to go with and she went and asked one of the girls who said, "I'll go and see the doctor." And she went away and didn't come back to us. So Katherine went to her again. She went away and came back and said, "the doctor will see you next." So I went in and then I had to go and have an X-ray. And when I got back I said to him, "I was really going to ask you to look at my elbow." When he saw it he said, "you'll have to go and have an X-ray." So I did. And the chair was hard, and this elbow was hurting so much. I didn't know what to do with it, where to put it sort of. Anyway it was after 5, the other doctors were waiting for him, and so he said "oh yes, there'd been a break and to do some exercises." And anyway I thought "BLOW."

She described herself as not behind the door when it comes to having a bit of a go, although in none of the stories in her conversation with me did she describe herself as 'having a go' at 
anyone. Rather the picture was of silent fuming, and simply taking some lateral action rather than confront the individual who was causing her concern and this pattern was repeated in the outpatient clinic. With the pain and such bureaucratic indifference, even with an advocate person present she was unable to be treated according to her needs. Lorna then transferred to another outpatient clinic. At the time of the interview, six months after the accident, she was still unable to dress herself, and her fractured arm, which she had previously referred to as her "good" arm, was functionally very limited.

\section{Commentary}

Lorna portrayed herself as gregarious and assertive, although with increasingly poor mobility providing a challenge to her confidence. Her attendant carer described her as friendly and willful. Like Miss Shepherd and Mr Snell her story is seen through a lens of ongoing disability and discomfort.

The circumstances of her admission were particularly traumatic relating to a motor vehicle accident which curtailed a trip to a son's wedding, although with enjoyment of dramatic events, Lorna relished describing the details.

Lorna was hospitalized initially in a town where she did have a son, but not a circle of acquaintances. She was not admitted to a general ward but kept in a holding area. Her recall of nursing staff was selective. Nurses who met her expectations (the day staff) were taken for granted, but nurses who challenged her need for assistance (the night staff) intimidated her. She escalated her requests for help. On diuretics, which usually had maximum effect at night, she asked for a pan, and received a stereotyped response: "no pans in this ward." 
In an environment with people who were culturally 'strange' to her, Lorna wanted more sympathy for her traumatic experience. She felt pain was not bad, but she lost sleep when awakened by the night shift laughing and talking and then by waiting for " 4 hours" to pass. Even when allowed analgesia she felt it was medication that had caused her mobility problems in the past.

Lorna liked to know relationships between people, but out of her home environment of 41 years, she was unable to name any influential contacts, or feel that she shared some social connection with any of the people around her. Lorna invoked a medical authority as proof that she needed help, but the nurses were unimpressed. This may have been a rehabilitation perspective, but it was not one Lorna shared. She was frightened of the nurses. One night nurse was more pleasant than the other was, but the intimidating behaviour of the older nurse affected Lorna's relationship with the second nurse.

The interaction of all the factors which Lorna revealed as underlying her nervousness about walking unattended reveals how complex the night nurse's task is, when confronted with a patient whose trauma was probably clinically much less severe than this department was used to dealing with. In addition the night nurses are relating to many more patients than the day nurses. Even if an outstanding personal and medical history had been able to be obtained from Mrs O'Fee when she was admitted to the holding ward, there simply is more of this information for night nurses to process. As well the contact is often made in an environment of muted lighting where some the patient responses are unobserved because of the low lighting. Nor do night nurses have the option of establishing a social or neutral relationship as 
day nurses often do. This would be particularly important where the patient values social networks as much as Lorna does.

In a sense the older patient is always 'atypical' - the longer the life, the more options there are for unique combinations of factors. It is not clear from her story whether Lorna felt the nurses were responsible for her longer than normal stay in this holding ward, but structural aspects of the health care organisation impacted on Lorna. She was discharged to her home unable to look after herself, when the nurses had information that would have indicated this. I wondered if a closer relationship with one of the nursing staff might have caused her elbow to be looked at again. I wondered too if the night nurses contributed to decisions about discharge planning.

When eventually admitted to her local hospital where she was well known, Lorna's second fracture was still not diagnosed. However here relationships with nurses were much pleasanter. Nothing was too much trouble: toast could be crisped, two or three nurses moved her gently so as not to cause pain, her bed was pushed to the telephone, wedding dresses shown to her. Lorna was on first name terms with all the staff and the picture was one of a haven of sociability and personal support. It suited Lorna. As a nurse I wondered how a busy surgical ward could sustain such a level of support. The one doctor she remembered had "saved her life". (I found this difficult to understand except in the context of Lorna's flair for the dramatic). A minor blemish was the doctor's non-reply to her invitation, but her previous social connections mitigated this rebuff.

The outpatient department was much less friendly, even though it was here she finally received a diagnosis, which enabled some recovery to begin. At this outpatient department Lorna had to be 
particularly persistent to get her needs met. Eventually she was so irritated with her treatment that she transferred to another hospital to access more user-friendly medical care. Whatever the glitch in the system, there was no individual Lorna felt could help her in this situation. The ward nurses apparently do not follow-up discharged patients, and Lorna made no mention of a primary nurse. Lorna now regards the nurses in this ward as part of her extended social circle: health care professionals have replaced her women's groups and many of her friends, as she finds getting out and about difficult.

During the conversation Lorna wanted to tell me about her birthday and her son's wedding as well as the visits she made, not just her time in the two acute wards. She described visits to a hypnotherapist, a physiotherapist, and her GP, and recommended the best cab company, describing in detail their mobility support for her. The 'busyness' of her life consists of visits relating to her health care.

Lived human relations in the two wards could not have been more in contrast. In the first ward Lorna clearly did receive some caring and competent help from some nurses. But, as with Mrs RoyJenkins, the negative experiences continually eroded her confidence in an already vulnerable area of her functioning -her mobility-, and overwhelmed the positive aspects of her relations with nurses. Another similarity to Mrs Roy-Jenkins' experience was that, in the first ward, there was no mention of a charge nurse. Lorna is a person who likes to know 'who is who,' and have the connections between people clear. She values a comfortable and equal relationship with authority figures, and lack of contact with such people, or dismissive treatment from them, challenges who she is. 
Lorna sees life in vivid technicolour. The motor accident confined her to the car while emergency services cut her out. She saw small details such as a car windscreen hanging like bits of dewdrop strings, and the fat bruised purple hands of her friend crushed against the steering wheel. This circumstance of her entry into the hospital carried its own request for tender care, quite apart from her previous history of marginal mobility, but the night nurses expected her to stand up for herself and walk alone.

While Mr Snell felt the distressing sights, smells and sounds of other patients at night had to be endured in a 'public' hospital, Lorna had no experience of sharing rooms with strange men. Threats assailed from within and without. Once she was awakened, the strangeness, her pain, the inappropriate analgesia, her inability to turn and seek a comfortable position, the noise and rudeness of the nurses all combined to maintain a state of vigilance in her. Her experience was much more vivid than Van Manen's hypothetical description of a similar situation.

Patients especially may have difficulty sleeping in a strange hospital bed. They may not sleep because they worry about upcoming surgery, or they may be roomed with people they do not know. Perhaps they are used to sleeping under heavy bedding and now they are covered by a meagre hospital blanket. Perhaps they are used to sleeping unencumbered and now they must lie in bed dressed in pyjamas or in a hospital gown that cuts into the neck.

(Van Manen 1997 p 353)

There was similarity between Van Manen's description and Lorna's experience, however, in the multiple stimuli. Even if one stimulus, such as pain, was reduced, the others remained, 
brushing the body, menacing the mind, warding off sleep and the stilling silence of the nightworld, threatening to overwhelm the integrity of the body and mind. Those who were expected to bring comfort to the body and balm to the soul joined with the opposing forces.

In the second ward there were no such problems. So fully did the conviviality of relations with nurses occupy her, that her story had no mention of other patients and almost no other health professionals. At the time she was telling me her story I was pleased she held to recounting stories of relations with nurses in the ward. However comparing her story with the other respondents, it was most unusual in an almost complete absence of any mention of other patients and only one mention of another discipline. It was as if the nursing care was the sole purpose of the hospital. In retrospect the non-diagnosis of the second fracture and the cool treatment Lorna received from the outpatient doctor meant she had needs she was unaware of, but which would normally have been attended to in an acute hospital. The nursing expertise here was invested solely in the interpersonal.

Lorna was on first name terms with all the nurses, including the charge nurse. They couldn't do enough for her. Here the human care for Lorna was so overwhelming from nurses that it seemed to push aside any other legitimate reason for her presence in the ward, such as diagnosing the second fracture. Once discharged from the ward she was abruptly left to her own devices again, cast back on her own (social) resources and those of her daughter and caregiver. When she re-entered the hospital system via the outpatient clinic, there was no nurse to advocate for her needs. Her daughter did her best, but Lorna felt she had been badly treated, and did not go back. 
In terms of lived time, so intense was her need to turn away from the unpleasantness of the accident, the disappointment of missing the son's party, and the cold refusal of the night nurses in the first ward to help her to the toilet, that she entered upon an almost frenetic round of gaiety in the second ward. She looked forward to her birthday. She was fully able to organise everything in hospital while simultaneously receiving almost full support in the activities of daily living, a remarkable testimony to the bonds of her human relations and the ability of this nursing team to respond. This future orientation was helpful in terms of immediate coping, and she did have the birthday to go home to.

The lived space in the second ward was portrayed as being focused on her bed. In contrast to Mrs Roy-Jenkins who was allowed to stay at her bedside for meals as a special concession, all services apparently came to Lorna's bed. If that was not possible and the mobile phone link was not too clear, then the bed could go to the phone. The picture is one of being immersed in sensual pleasure. Common, taken-for-granted, everyday kind of pleasures, not luxuries, but pleasures none the less. All aspects of the environment and interpersonal relation were designed to meet her expectations. The space was comforting, full of life and interest.

Lorna was silent as to her experience of her body in the second ward except as the nurses gently provided personal hygiene. There seemed no shortage of staff, as two or three nurses turned her gently and washed her back. Through these nurses intensely supporting Lorna physically and socially for three or four days, the terrors of the night were driven back. Confidence returned, and with it came the return of physical strength. With crispy toast and hot meals and delectable desserts came the assurance that the body was being sustained and, in a small way, indulged. 
Lorna presented the 'lifeworlds' in the two wards as contrasting studies in care and competence in meeting her needs. In the first ward she was in the shower with one nurse in gumboots. At night the nurses were noisy, rejecting of requests for help. Prescribed analgesia she had to wait for. It was medication which she had previously had concerns about. She knew nobody. All this severely shook the usually assertive person that was Lorna.

In neither ward did Lorna consider her other chronic conditions (arthritis and congestive heart failure) as the focus for concern, although it is possible to speculate as to why the night toileting debacle had such power to distress. For instance, although Lorna told the story as one where the unpleasant demeanour of the nurse and her already marginal mobility were the key factors, the fact that she wanted to pass urine at such a time was probably (as Miss Shepherd said) related to being prescribed diuretics. Once awakened, whether by pain or a need to pass urine it is not clear, other factors came into play to make the nights difficult.

In the second ward the 'lifeworld' was blissful. Unlike Miss Shepherd, who disliked the social chat of the nurses, Lorna thrived on it. Far from seeing at as a self-centred activity by the nurses, Lorna found it socially nourishing. The nurses helped her, but they were not her servants, they were friends. Surrounded by people she knew and liked, the world was a brighter place. Fun and pleasure re-entered the picture, and in a very short time she was back home, albeit with ongoing pain and disability. Confidence restored, she resumed planning her life projects.

In summary this chapter has presented yet another view of living in two acute wards. Nurses are represented as powerful people with skill and authority to grant or withhold favour from patients. In 
the next chapter a very different picture of nursing appears, although the nurses in the medical ward presented in Chapter 9 are generally much more personable and attentive to the totality of patient need than Lorna experienced in either hospital. 


\section{Chapter 9 It was urgent one way or another}

This interview relates to an admission to an acute medical ward for an acute episode of gastric bleeding. Mrs Brown had previously been in hospital with similar symptoms several times over the preceding few years. She was 82 years old at the time of admission and lived alone on the fifth floor of a block of flats with family and home help support.

\section{Life profile}

Mrs Brown was a woman who emigrated from Scotland to New Zealand 32 years earlier. She described herself in terms of the values of her family of origin and the work experience she had since coming to New Zealand. She comes from a long-lived family, both her parents having lived until their late eighties, and her four elder brothers ranging in age from 84 to 90 years with whom she corresponded. Her two eldest sons and her husband had travelled to New Zealand in the UK merchant navy and, after her sons settled here, they kept urging Mrs Brown and her husband to emigrate as well. Mrs Brown waited for 10 more years helping her mother run the family antique dealing business after the death of her father. Her good Scottish education had helped her to get a good job as firstly a clerk and later in the sales section of a Government department a month after arriving in New Zealand. This was 1964 when jobs were plentiful in New Zealand and Mrs Brown was astonished that she had been 
so easily employed without her credentials or skills being checked.

Hers was a family who valued not telling tales out of school, and in common with many Scots people the teacher was next to God. Her family were strict teetotallers: it was drummed into us and they were very strict. Another aspect of life in her family was minding your own business: I don't gossip or ask personal questions where do you live, or how old are you... I don't give a damn about anyone else's family and I don't ask. If they tell me, fair enough, but not ask. Because that was drummed into me from a kid: you don't ask direct questions, you don't ask personal questions. Life in a Scottish school had taught her to be tough, her left hand had been tied behind her back for a year to teach her to use her right hand, until her parents discovered. This education enabled Mrs Brown to be a proofreader in New Zealand, and she cannot understand people who cannot see grammatical and spelling mistakes. Books are constant companions. She is never lonely when she has some books to read.

Ten years after emigrating, Mrs Brown's husband died, and she stayed on in their rented property until their cat died, before moving to her current flat. She enjoys knitting when permitted by the arthritis in her neck, but no longer knits for charity, except in a very small way when she gave some patterns and some knitted slippers to people fund-raising for a trip to a marae. 
Mrs Brown had 'flu once during her 17 years of work in New Zealand which she felt indicated she had been a fit and healthy person until she began vomiting blood some years earlier. Each time this had happened she had been admitted to hospital, transfused and investigated extensively, before being discharged without a diagnosis. Mrs Brown felt this uncertainty, and began to doubt herself. But I couldn't understand to begin with why it was happening every six months, or whether you were bringing it on yourself - you must be imagining it, you know, you're bringing it on yourself. And I thought, no you're not, it's there. In between acute admissions, the medical staff had continued to investigate a cause for her symptoms on an outpatient basis. She had had three polyps removed and had a clean bill of health, followed by 3 colonoscopies and 5 gastroscopies as well as ultrasounds, $x$-rays and other tests which proved negative.

Mrs Brown kept careful records of her dealings with medical staff, and she showed me copies of laboratory reports, doctors' letters and notes she had made after appointments with medical staff. She felt she needed to do this as others were sometimes less precise about details than she herself was. Mrs Brown described an occasion when, just after she had the first colonoscopy, a new doctor took over her care and rang her at home asking her to come to hospital for yet another test, which she had not understood to be a repeat colonoscopy. Mrs Brown was very experienced in having examinations of the alimentary canal, but this time the doctor used a name she was unfamiliar with. However she was prepared to find out 
about this 'new' test. And he gave it a different name. And I said, "well I want to find out about this." The nurse in the outpatient clinic was apparently unaware of Mrs Brown's recent history of investigations, and began with her usual information. Well a fortnight later I went up to the hospital "get undressed, put on this," the nurse said, "I'm going to put this tube up your nose and down your throat." "Well wait a minute," I said, "I wasn't told..." I didn't mind the swallowing the blessed thing but the thought of the tube going up my nose and down my throat and dope being pumped in .. And speak about throwing a wobbly! Mind you l'd had no food really for two days previously- it was dry biscuits and cream crackers and clear soup or something... and I was feeling weak.

The nurses sent for the doctor. Mrs Brown felt the doctor had been less than forthcoming on the telephone, and he adopted first a confrontational and then a placatory approach which Mrs Brown still feels angry about. I was furious because this doctor hadn't told me. If he had said on the phone "This is what it means." So I raised hell in the $x$-ray department (chuckles). So they sent for him, and he did come, and he said, "I told you." And I said, "I've got a good memory, you did not tell me what was happening." "So, are you going to sign the paper or what?" So eventually I signed (the consent form). The nurses were helpful in getting Mrs Brown through the test. The nurses were extremely good and gave me ice cubes to suck and such-like: tubes down and I did everything I had to do. 
In one practical area, however the system's prior information, and nurses' practical support did not rate highly. One familiar aspect of the colonoscopy was particularly unpleasant on this occasion. Mrs Brown was incontinent of faeces in the x-ray department, and she wonders if this was due to having 2 colonoscopies in 2 weeks. That bloody awful stuff called Golitely - whoever invented that should be prosecuted and dosed with it because it's drastic $\{\mathrm{CW}$ it cleans you out? $\mathrm{O}$ it does more than that. I'd had 2 lots of that in 2 weeks. The note said you might have diarrhoea later, but it didn't say that as soon as you got off the X-ray table, it'd be running out. I was most embarrassed. Mrs Brown asked around and has some ideas about the information that should be given to patients. I'm not the only one it's happened to -l've spoken to other people and the same thing has happened. Now that should be put on the note, and they should tell the patient to bring some sanitary pads or something or... they should have them there for the patients... They should have something. I mean I had panties, which, of course as soon as I put them on were ruined and I had to throw them into a wastebasket. And I had a hell of a job getting home. I couldn't have risked taking a taxi, luckily my daughter-inlaw took me home.

This doctor this outpatient appointment relates to also left the hospital and Mrs Brown was asked by a third doctor to have a third colonoscopy. $\mathrm{CW}$ oh goodness, and what did you say?\} (I said), "No Golitely, never again - anybody can take it, but not me." He said, "We have this new stuff - it's 
not nearly so bad as Golitely - I would never give that to a patient."

Mrs Brown had found her experience with the second colonoscopy so embarrassing that she elected to go to another hospital. Here the preparation she was given was Fleet, an alternative to Golitely, and the test proceeded satisfactorily. Mrs Brown was concerned about the different costs that different sections of the health care system charged for Fleet. "It's time they stopped Golitely. (Fleet is) expensive, but it's not nearly so expensive in Britain. What the hospital charged me was $\$ 5.00$ on the bill and yet in the chemist's it was $\$ 20.00$ so you can see (who's making money) Yes the hospital could easily afford it. All went well after this test with her doctor giving her a clean bill of health. She was free of any symptoms for a year after the third colonoscopy.

Circumstances of admission cold as charity

Because she had several previous experiences, Mrs Brown was quick to recognise the familiar symptoms: I started vomiting blood- suddenly! But- no pain- (I) didn't feel any pain at all - just felt as though I was going to be sick, and then up it would come. Each time l've managed to get to a toilet or sink. $\{\mathrm{CW}$ and you vomited blood?... Bright red, or black or...? As black as you like. I was able to inform my son and daughter-in-law and he phoned 
for the ambulance. In the emergency place I was really suffering from shock because of the amount of blood l'd already lost and I was terribly cold. The place seemed terribly cold.

Mrs Brown cannot remember the individuals who attended to her at the emergency department, but she remembers the experience. Mrs Brown's daughter-in-law went with her to hospital and then returned home to collect her hospital "bag" that Mrs Brown always keeps ready. Mrs Brown relied on her family for practical support, but not for their actual physical presence. The sensations were many and varied. She (Mrs Brown's daughter-in-law) stayed here with the doctor while he was writing up the notes, then she took them up and I was put in to the ambulance - taken away. She brought up my clothes and toilet things...she wanted to leave them in the emergency place, but they wouldn't let her in to see me, and they were busy fishing around and checking blood transfusion stuff and asking questions. I wasn't in a fit state to answer for three hours and I was as cold as charity. $\mathrm{CW}$ you would have liked her in there with you?\} No, I didn't care whether she was there or not. \{CW you wanted to be warmer? I wanted to be warmer. I kept telling them, but, of course you don't get blankets now - it's all these acrylic or whatever they are cotton sheets. 
The ward - every attention

Mrs Brown went up to the ward with the blood and an intravenous line running. She was still cold until the ward nurses obtained extra covering for her. As in the emergency department, she finds it difficult to recall individual nurses in this acute stage, but vividly recalls her own experience. Oh I was cold until I got up to the ward, and then they piled on extra...they're not blankets, they're woven things. And then they gave me bedsocks ...different sizes and colours. Evidently the local Women's Auxiliary knit them... And I thought that was very good. And then my family brought me in my own.

Mrs Brown felt that the nurses cared for her by the amount of attention the nurses paid to her felt somatic experiences. Also getting my face washed, and "did I want something?" They cleaned out my mouth after (the vomit) ..it was flavoured sticks and they cleaned that out - they went to a lot of trouble, various things like that... and then they did wash me when I was at my worst. \{CW: what was that like? Very good. They were anxious to find out was the water warm enough or too cold - you know they were really concerned that I was made comfortable and felt comfortable. The nurses cared when Mrs Brown was past caring.

The second day Mrs Brown was in the ward, she was visited by a ward round. This was a dramatic experience for Mrs Brown and the medical staff. But they were all 
standing...(round my bed). There were students there as well, and the nurses, and naturally the doctor in charge of that ward - he is exceptionally good, always the same, even tempered - he's really excellent. However they were all there and there were quite a number of students. And they were asking me, and by that time they had my notes and a tall one with dark hair, and he said, (speaks very precisely) "Tell me what quantity of alcohol do you consume daily?" and that took my breath away because I never thought of being an alcoholic - never even thinking I was an alcoholic - And I was propped up and I think I must have had some (intravenous) things dripping and I said (very precisely), "I do not drink alcohol," and shshooosh (vomited) all over the bed and I remember their faces, the horror on their faces. They saw what was coming out, naturally. $\{\mathrm{CW}$ And what did the nurses do? $\}$ Well they grabbed the - things that were hanging on the back $\{\mathrm{CW}$ $\mathrm{mm}\}$ and I know one of them grabbed that and sort of held it round my face trying to catch what was coming out. I must have vomited a hell of a lot. And the next thing I wakened up in intensive care.

The public questioning of a private and independent person who had been brought up as a very strict teetotaller, who was feeling very weak, associated with the further gastric bleed had a lasting effect. The nurses gave practical help, and presumably assisted with the transfer to intensive care. They were passive bystanders in the ward round unless some practical help was needed. 
A nurse was also present when Mrs Brown had a liver biopsy, but her role there was as a silent bystander. Oh I had a liver biopsy as well \{oh goodness, you have had a lot - did you have that in the ward?\} Yes. \{CW and how was that?\} No bother at all - the man who did it was exceptionally [good]. $\{\mathrm{CW}$ And did he have nurses there as we11?\} No, he did it by himself. Oh there was a nurse there as well, but he did everything. He picked up everything and he put everything down exactly in its place. He was most thorough, because he had done colonoscopies and other things as well. He did it and then of course they discovered that I had hobnails on my liver but it's not caused by drink.

Later when Mrs Brown had returned to the ward from the intensive care the nurses gave her every attention. When she was having her transfusion they took my blood pressure every half hour and noted it and were very very exact. And the same when it came to getting these tablets. I had to have one half an hour before a meal and they were very exact in coming.

Mrs Brown did not only value precise timing and technical exactness. Two nurses came from intensive care to see how she was. And after I had been in intensive care and was down in the ordinary ward again they came to see me \{CW oh that was nice $\}$ Yes, well I was surprised. They wanted to know how I was getting on and they came to my bed and I had no recollection of them. 
Other nurses continued to surprise Mrs Brown with their prompt attention to her needs, and willingness to go beyond what she expected. I got every attention. $\{\mathrm{CW}$ did you ring the bell?\} Yes, one night about 11 o'clock and this particular nurse came galloping along - she said, "I knew when it was your bell." I said to her, "I feel I'm going to be sick." And she always had the tubs there ready. And she said," I was just going off duty", she said, I think it was a Friday or a Saturday night - and she was just getting ready to go off duty. $\{C W$ well that must have been nice to know they were thinking of you and looking after you in that way. $\}$ Oh yes and she came in a hurry. So it wasn't that I was a pest and rang the bell for no reason at all. They evidently knew if I rang the bell, it was urgent one way and another. But no, they cared for me, they asked, " anything we can do for you? Anything we can get?"

The night nurses also went beyond what Mrs Brown expected. She was aware of problems with the food contractors in the hospital at this time. Food was not kept in the wards. Twice after tests the night nurses went and got ice-cream and juice for Mrs Brown. There was some particular test that l'd had and I couldn't tell you what it was now - they even went and got it from a machine they got a tub of ice-cream and energy juice for me in the middle of the night. That was the sort of thing that you didn't expect. \{CW Was that because you had been nil by mouth? You hadn't been allowed to eat?\} I don't know - It was after I'd had a test I think and I know it was night time. And you see they can't keep food there. And they couldn't send for 
anything, but they got me a tub of ice cream - on two occasions they did that - it was called energy juice.

Mrs Brown was scornful of the hospital meals whose poor quality she attributed to wrong economic priorities. She thought the private hospitals provided food of a superior quality. (After discharge) oh by God did I enjoy bacon and eggs and did I enjoy Chinese takeaway - anything tasty . And I don't know - it's all right the hospitals having to save money here, save money there - they have to do it, but why save money on patients' food when the people are ill? If you go to a private hospital, you get proper food beautifully presented. You can't expect it to be presented in a public hospital the way they do it in a private hospital, but I forget what test I had previously and I went to a private hospital and I had the most beautiful scrambled eggs: fluffy, light, beautiful... $\{\mathrm{CW}$ and it lifts your spirits so much doesn't it? Well yes. I'm not a glutton. For the food at the local hospital was....well it wasn't the hospital that was doing it - you see they got rid of their cooks and chefs and everything else - and kitchen maids. Put the food out to contractors. Naturally the people who were running it were half - they were (the managers were) half in Hong Kong and half in this city \{ $\mathrm{CW}$ oh really? yes, so who was doing it here, god only knows. It wasn't right that even the food others were turning away should be given to sick people. Maybe it's a kill or cure! With this background understanding of the health care system, Mrs Brown was appreciative of the night nurses' efforts to get her something to eat, by 'working the system', and not 
merely accepting the status quo. These nurses also behaved in a way she did not expect, but did appreciate.

If Mrs Brown was deeply appreciative of the permanent ward nurses, looking after her was more of a challenge for the casual nurses. On one occasion a nurse attempted to take her blood pressure with a new and unfamiliar sphygmomanometer. Mrs Brown sought help for her. Well, naturally they're always short of nurses. Whether somebody was off sick, or it was a day off or ..It was only for a day and there was a young girl came in and she was a nurse to take the blood pressure on this particular machine - whatever you call it... you know: wrap around your arm/ and pop the little rubber tube on this state of the artpress the buttons / and they light up and everything works (I hope). And she hadn't a clue. (CW what was that like for you - how did you feel?\} It didn't worry me. I knew that she didn't know what to do with the blessed machine, so I asked a nurse who was passing would she mind showing this young lady who was a temporary from a nursing agency. And so she came...I said have you ever used one of those before? "NO." $\quad\{\mathrm{CW}$ you had to ask for help for her?\} Yes, I asked one of the nurses would she mind showing.. $\{\mathrm{CW}$ and did she? $\mathrm{O}$ yes, very willingly. $\{\mathrm{CW}$ but nobody showed her first? $\}$ No, well I suppose she'd only been trained on the old things, and she didn't know... She knew it was for taking blood pressures, and they must have said, "Go and take Mrs So-and So's blood pressure." But there was no written instructions. Mrs Brown understood the nurse's inability to use the machine as a failure of her training, but the ward nurses 
were ever ready to help this nurse once asked by Mrs Brown. The system did not support this 'young nurse' but Mrs Brown did.

A second casual nurse was competent in the technical aspects of nursing care but her relationship with Mrs Brown was initiated from a position of self-centredness, not patient-centredness in contrast to the ward nurses. Mrs Brown felt she derided her Scottish accent and patronised the patients in her room on account of their age. Well one time I had a casual nurse - well they're not really casual nurses $\quad\{\mathrm{CW}$ yes I know what you mean - they call them casual nurses\} - she was a very bright nice looking girl, came from Britain. Told us she had arrived from Australia a few weeks previously and then she had visited her sister, brother-in-law in Australia who had a huge farm, and now she had come here on the job. She came to take my blood pressure, or pulse or some damn thing, and she started skiting about my accent and by my replies she realised I didn't approve of it - she was very bright and cheery. She had the attitude you're all old folks, you're on your way out, so I'll brighten you up. $\{\mathrm{CW}$ a bit patronising? Yes, which old people don't need. And they're not so thick in the head they don't know when it's being done.

Later when the nurse returned to Mrs Brown, her behaviour was more subdued and Mrs Brown interpreted this as a result of the ward nurses having advocated on the patients' behalf. By that time however, Mrs Brown had formed a judgement as to the nurse's attitude to older patients and 
to her commitment to nursing. She departed and then when she came back to attend to me, she was quite different, so I think some of the other nurses had said something to her, because I didn't complain. I would have been ready to say something to her, but I think some of the other nurses possibly in passing had heard and said something to her, because her attitude was quite different when she came back the second time. My daughter-in-law was there and heard the second time, and she could see the difference and I said to Anne, "Well I don't fancy her as a temporary nurse in any case, and l've got the idea she has come to New Zealand to find a husband." $\quad$ CW oh, how did you get that idea? Because of her attitude. $\{C W$ she wasn't interested in nursing or what? $\}$ Oh she was qualified in nursing and she'd qualified in Britain, she didn't say in which hospital or where, but they are so badly in need of nurses in Britain, certainly coming here the money might be different. But without being asked she was so bright and so cheery telling us all the marvellous things she'd done in Australia- been there for a week or a fortnight or something and she thought it was marvellous there. And then the brother-in-law having this - she told us how many acres or hundreds of acres of a farm he has. I thought, "My lady, you didn't come here for the sake of nursing." That was just my feeling.

Mrs Brown felt that the nurse's unsought self-disclosure was inappropriate and showed a lack of interest in the patient's needs in contrast to the ward nurses who did not go off duty until they were sure the patients were safe and comfortable. She wasn't interested in any of them, She 
did the job of taking the blood pressure or whatever she was doing. The others weren't so tied up as I was.

Although Mrs Brown recognised 'nursing' as consisting of technical tasks such as taking blood pressures, this was not sufficient to being a good nurse. The casual nurse was qualified in a 'British' hospital - of which there was an underlying implication of 'better'. However she was not as solicitous as the ward nurses of the patients' needs and preferences, she was too ebullient, and energetic in sharing with the patients her own experiences.

Later Mrs Brown explained what she saw as the essence of nursing. She did not see nursing as a career, but as a patient-centred commitment. Mrs Brown compared nursing to medicine and other typically 'male' careers. If you need an electrician, you get a qualified electrician, or a plumber, you get a plumber so to me being a doctor is being a trade, a profession, that they have chosen. It's a trade - because they have studied and they have the knowledge. It doesn't mean they are any better than anyone else... But with nursing it's different. If you want to be a nurse and you know what - and especially in the old days - you know what you are in for, and you continue your training or your nursing, it's not a case of being a career as well, or a trade, it's because you are interested in people. $\{C W$ well that's a really interesting distinction $\}$ and getting them better if possible. As a researcher I regretted not exploring this comment further. Her point of view on this issue was one which, at the time, I found difficult to listen to with phenomenological 'tact', and I moved her on 
to another topic, but my suspicion is that Mrs Brown is not alone in this conceptualisation of nursing, and closer attention may be fruitful.

Mrs Brown was finally given a medical diagnosis after having a CAT scan. Mrs Brown had limited information about what to expect. On this occasion she felt this might be due to the unplanned nature of the test. She likes to be precise about details, but was unable to do so, because of the lack of 'time cues' that were available to her, but approached the experience with her characteristic forthrightness and humour. Eventually I had a CAT scan.. which was on my birthday. And... evidently one had been cancelled.. It couldn't have been a Saturday - my birthday was a Saturday. It may have been a Saturday, I couldn't tell you, the days are all the same there - you never see a calendar. However they were working and one had been cancelled - maybe they'd died in the meantime - so I was taken down for the CAT scan which lasted for quite a number of hours. \{ $\mathrm{CW} \mathrm{mm}$ did you know it was going to last that long?\} No I hadn't a clue - I knew that you went into this (gestures) $\{\mathrm{CW}$ hole? $\}$ you pass through this tunnel affair sort of business. But I was asked what sort of music I liked and did I want music? And I said no, I'm not interested in hearing music, it annoys me when you're put on hold on the phone. That annoys me, so I wasn't having any music. I should have asked for some Scottish country dancing! I said no, but if the fellow who was doing the test wanted to have it on - it doesn't worry me whether it's there. So he didn't have it on, he got on with it. 
Mrs Brown thought it was about a week before the result was communicated to her, this result being very productive in naming Mrs Brown's condition. To begin with nothing showed up, but then eventually they found these veins very enlarged veins leading into the liver. This is the diagnosis that Mrs Brown's brother had suggested to her initially, and which eventually she suggested to the medical staff. I wrote to him because I was so worried about the whole thing going on and on. And he wrote and told me one time that they were looking in the wrong place when they were looking in the bowels and so forth, and he said he'd been through all his notes and books and the only thing he could think of was a type of little varicose veins at the outlet of the stomach which would be bleeding every so often. He told me that long before they discovered it here, and really they haven't discovered it yet, but eventually I told them where to look.

On a previous admission she had found a 'nosy' room mate difficult to tolerate, and she had appealed to the medical staff. The previous time the woman kept asking all sorts of personal things which you couldn't avoid answering. You couldn't say "it's none of your business," and you couldn't say, "well why do you want to know?" And that time I got really narked and I said to the doctors, "I don't want to be stuck in a room with four people if that's what's going to happen". No doubt they thought I was a very picky person. Later she explained more of her relations with this woman. That's what annoyed me about the woman who kept answering questions until I did put her down. $\{\mathrm{CW} \mathrm{mm}$ what did you say to her again?\} 
Well she landed on me every time I went to the toilet and she would grab me. And eventually she said, "what was I doing now?" And I said, "I was writing a book about all the peculiar people l've met since I came to New Zealand." During the admission the conversation relates to, she saw a number of patients come and go in her room, and they all got on very well. She was able to sleep as she needed, including the daytime when she was very ill.

After five weeks, Mrs Brown was discharged from hospital to home. Her daughter-in-law wanted her to stay with them on discharge, but Mrs Brown said, "No, I'm not going to be landed on you, as long as I'm fit enough and my brain is active enough." The hospital arranged for six weeks of home help, which did not start until she had been home for three weeks.

\section{Commentary}

Mrs Brown portrayed herself as independent and private with access to medical information from her family in the United Kingdom, and practical help from her family in New Zealand. She showed commitment to life obligations. She was assertive and felt she had a good education and a good memory, which enabled her to meet the challenges of acute illness and an extended period of non-diagnosis of repeated dramatic and serious symptoms. The health care system had not always responded with integrity and precision, but she was persistent in assisting the diagnostic 
process in any way she found to do so. She had an expectation that the answers would be found eventually.

Mrs Brown remembers very little of her time in intensive care, but she was pleased and surprised by the nurses who displayed concern and interest in her progress. In particular the ward nurse who came in response to her bell at 11 o'clock one weekend displayed care in the sense of sorge. The nurse galloped. She was already attentive to Mrs Brown's needs before she got there, and communicated this to Mrs Brown- I knew it was your bell. This was not a routine and generalised attention. The nurses in the medical ward were very attentive to her comfort in terms of temperature, types of food, and careful monitoring of her signs and symptoms. Mrs Brown portrayed the permanent ward nurses as having a commitment to her as a person, her needs and preferences. This commitment was demonstrated through meticulous attention to timing and her comfort which helped her get better. She thought they advocated for her when a casual nurse was less attentive to the patients' interpersonal needs, but there is a total silence in her story of any medical and nursing interaction.

She was equivocal about the support she had had in a previous colonoscopy done on an outpatient basis. The nurses called for the doctor only when Mrs Brown refused absolutely to proceed with the test. The nurses were accountable for the absence of practical help on this occasion. The nurses shared accountability for inadequate prior information about what to expect after Golitely. They 
did not think of the perspective of the patient, and take action.

The marginalised position of 'casual' nurses (which Mrs Brown recognised as an ambiguously derogative term) is responsible for the only two accounts of nurses who did not meet her needs. The technical expertise of nurses she took as a sine qua non, and excused the one nurse who was unfamiliar with equipment, on the grounds of her youthfulness and training on old equipment. The second casual nurse she found non-helpful and ageist. The nurse was interested in her own concerns, not those of the patients. Even when the casual nurse moderated her tone after she returned the second time, Mrs Brown attributed this change to the ward nurses. The active interpretations made by patients is an element in the dynamic transaction that nurses need to learn to attend to very early in the relationship.

In contrast to the casual nurses, the ward nurse who answered Mrs Brown's bell instead of going off duty when strict attention to timekeeping would probably have permitted the nurse to leave, and the night nurses who obtained food when the normal systems of the hospital were not operating, showed persistence in meeting the personal needs of patients. They also demonstrated an expert competency which Benner (1984) calls "knowing when to depart the protocols of the organisation." These nurses' gift of their time and imagination showed an awareness of 'what it was like' for this patient. 
Mrs Brown's experience of lived time was different in the hospital then outside it. She was aware that she could not be as precise in her timekeeping as usual because of the absence of time cues in the hospital. However this was not an issue for her because in every way the nurses cared for her obligations in regard to time: medications were always on time, appointments were always kept.

At several stages in the conversation I tried to confine Mrs Brown to comments about the actual ward events. This proved to be phenomenologically naive on my part, as it is clear from the foregoing analysis that many earlier experiences reached into the present hospitalisation and retained a potent influence. Mrs Brown would tell the whole of the story as it was present to her, and her narratives laid bare her aspects from the past as these were with her in the medical ward. The lack of diagnosis, the changing doctors with different approaches and even different names for the same procedure, the previous accidents in outpatients; all these I had thought originally were somewhat irrelevant precedents. However I was in her house, she had invited me, and I needed to listen to her until I heard the story of the ward encounters with nurses. Mrs Brown was wiser than I was. These all were encounters with ward nurses. I, however was enacting a nurse/researcher role which was focused on the events in the ward only, just as surely as the nurse in the outpatient department had focused on the event of the colonoscopy itself and left the patient to deal with the sequelae. A phenomenology that begins with the four existentials uncovers such time shifts as the patient has present to her, 
and so frees the relationship from restraints of current assessment ideologies.

Mrs Brown did not portray the nurses as being aware of or asking about all these complex memories in her temporal landscape, but the way the nurses approached her and the scrupulous care they offered dovetailed with her expectations and enabled her to live in the ward with these past fragments and, eventually, to look again at future projects. The ongoing relation from all the ward nurses was one of care especially when Mrs Brown was past caring. They cared even when she did not know they cared as in the case of the ICU nurses. She could entrust her body to them, a body sometimes behaving in frightening and dramatic ways.

The first action she recalled nurses in the ward performing for her was warming her cold and shocked body arriving from the Emergency Room. Their concern was practical, not primarily technological (although she had intravenous fluid and blood running), and even extended to knitted bedsocks from the Women's Auxiliary. Mrs Brown knew she was with practical people.

Her lived body presented many challenges to the nurses and they met them all. The most dramatic was the second day in the ward when she was publicly questioned as to her drinking on the ward round. The medical staff may have been unable to diagnose her problem, but her body replied eloquently. By throwing up, Mrs Brown literally answered the insult of the implication that she drank too 
much alcohol. This was not a time for metaphorical subtlety. Mrs O'Fee felt she was sort of standing up for herself metaphorically and physically when the nurses were reluctant to help with her shaky mobility. In this instance the response of Mrs Brown's body was anything but subtle. The diagnosis was hidden from the medical staff but the reality of her lived experience could not be doubted. Several of the interviewees alluded to their feeling that a problem without a medical 'name', while very real to themselves, was not always taken seriously by others. The seriousness of Mrs Brown's condition could no longer be doubted, but she did not describe any health professional as acknowledging this to her.

While the doctors stood around evoking vomiting, nurses cleaned up and got her in to the Intensive Care Unit. In time they even learned to anticipate her body's requirements. One nurse galloped to answer her bell putting aside her own social life on a Saturday night. They cared for her body washing it with all solicitude, attending to every little detail of temperature and comfort. She could sleep whenever she wanted to, and especially at night. Special food was not too much trouble even at $2 \mathrm{am}$. These nurses were attuned to Mrs Brown's notion of a nurse as someone who was interested in people...and getting them better if possible...not in a career. The lived relations were characterised by human commitment.

The 'lifeworld' of this ward was peopled by nurses who dwelt in the landscape with the patients. They were not ever-present intruding on privacy, bossing the patients 
around, or asking questions of the medical staff, but they did attend with professional promptness and concern to all the therapies required, and responded with practical good sense to the unexpected. Like good Girl Guides they were always prepared. When medical staff came and went, performing investigations, questioning patients, treating emergencies, nurses stood silently. They never intruded on the medical staff's prerogative of diagnosis or asked how it was for the patient. In the physical activities of the ward they were the mainstay of patients. Nurses took responsibility, seamlessly weaving physical care modalities with initiating enduring interpersonal relationships. They watched over the patients when new staff arrived, coaching, warning, looking out for the patients' interests. They were pleasant, calm and resourceful, skilfully working the failing systems of public health to nurture and nourish those entrusted to them. 


\section{Chapter 10-going to a picnic}

The experience of Mrs Brown in Chapter 9 represented a unique perspective on life in a medical ward. This chapter offers a unique viewpoint of elective surgery, but shares a common aspect with the first four interviews in that the surgery related to the medical speciality of orthopaedics.

This interview relates to an admission to an acute surgical ward for an elective knee replacement. Mrs Main's knee had first been investigated with ultrasound thirty years ago and had been specifically monitored by her surgeon for three years with a view to this surgery. She was 74 years old at the time of the interview and lived with her husband in the family home they had first moved to 39 years previously. They were having lunch when I arrived, and her husband made a cup of tea for me and carried the tray with her lunch into the lounge so Mrs Mains could walk with her stick.

\section{Life Profile - a fortunate person}

Mrs Main looked younger than her 74 years and laughed often through out our conversation. She described herself as a very fortunate person.

I think if I was to leave this mortal coil tomorrow I could say l'd had a very good life. Not everybody could say they'd had seven healthy children.

She had been fortunate in her family of origin where her mother gave very good care to the children in her family. Her mother was a wonderful nurse who used to care for the people in the neighbourhood for free in the days before state-provided medical benefits. Quinsy, and kidney problems and pneumonia. One man vowed and declared my mother had saved his life. 
Mrs Main's good fortune had extended to unexpectedly recovering from an undiagnosed serious illness when she was five, being very ill with peritonitis when she was thirteen.

We had just come to town and that's why we didn't have a doctor. We couldn't get a doctor and I was rushed into hospital - when they were having their lunch actually and it's amazing - this will probably interest you- a gynaecologist said to me that often when people have peritonitis they aren't able to have children.

Mrs Main continued to be fortunate going on to have seven children, including twins, a novelty in her family of origin. As an adult she had a deep vein thrombosis after her veins were stripped in her fifties, and a clot behind her eye in her sixties, all of which she recovered from with equanimity.

The Mains' took their eight children on gold digging holidays for a number of years, and the eight all have wedding rings made of the gold the family panned. These holidays did, however affect her knee, she now feels.

It didn't help, and when you're washing the gold dish you're bending over. But you do things when you're younger you don't think about when you're going to be old what's going to happen, you know?

Mrs Main shares her potential for arthritis with other members of her family. She has a philosophical approach to the challenges life deals to even the fortunate. I think you always get the bitter with the better, don't you? 


\section{Circumstances of admission - the preceding year - a jolt to the confidence}

The year before this current admission Mrs Main had an unhappy experience in hospital. Lacking a medical diagnosis, in extreme pain, and with a ward organisation which allocated different nurses every day, she felt

my confidence was, you know jolted a little bit... I

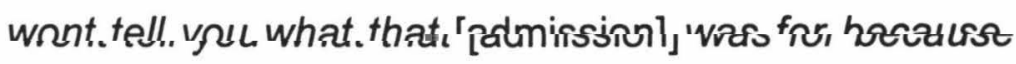
that sort of signifies what ward l'd been on. I sort of went in apprehensive, I suppose, although I was in agonies, you know I didn't mind going in - anything to get rid of the pain. They couldn't find out what was wrong with me, and um they sent me home and the doctor was really very very good. But it must have had something to do with the hospital or the lady in charge of the ward, but you never ever had the same nurse. One in the morning, one in the afternoon, and the next day you'd have someone entirely different, and in the whole time I was there - and I'm trying to think- in the whole time I was there ah Wednesday, Thursday, Friday, - I was there for about 6 days - I never had the same nurse twice. Mrs Main interpreted the treatment she received from the nurses as not taking her symptoms seriously: and perhaps they looked at my chart, and thought "oh, they don't know what's wrong with this woman, perhaps she's putting it on".

In addition to this fear, was the ward nurses' ageist approach which was validated by her daughter (also a nurse).

And I can remember my daughter getting terribly irate one day when they said - someone passed the 
remark, "isn't she a dear old lady". And she said "you're not old," and I don't feel old either. You know - people tend when you are in your seventies, people in hospital sometimes tend to regard you as um [pause] losing, not losing your marbles, I don't mean that, but they sort of think that you are still not thinking the same $\{\mathrm{CW} . \mathrm{mm}\}$ - You're still not the same person inside that you were when you were smaller $1 \mathrm{CW}$. yes - they look at you differently? They do look at you differently, you know.

Since this traumatic hospitalisation Mr Mains had also been in hospital after waiting for six months with a condition which was potentially life threatening, and Mrs Mains' only surviving sister (of a family of four) had been seriously ill and not expected to survive. In fact her sister had so many things wrong with her, Mrs Mains thought she could now be considered 'old', although she resisted this label for herself.

Well my sister - they didn't expect her to see her 80th birthday and she's 83 and she has a lot of things wrong with her and they've given up, you know they don't know what keeps her going, I think she's 'old.' (CW You think she's old, yes I think she's old. I think when I get to that stage - when l've got all the things wrong with me that she has- I think I'll be old ICW you think you'll be old then (Laughter) You'll feel old\} l'll feel old. I suppose I should feel very fortunate that in my family people have always been very clear in their minds before they've gone - you know what I mean? ICW You've picked your genes well) yes (laughs) We've got rheumatism. 
This familial rheumatism continued to give pain in her knee, waking her up at night. Mrs Mains became extremely apprehensive about the planned knee surgery. Her General Practitioner (GP) was very understanding, and talked everything through. Mrs Mains remained depressed, and was eventually prescribed some medication which was later increased as the time of the surgery drew closer.

And when I got put on this stuff - it was only 25gms, and Jean [daughter] tells me they're not habitforming. Because to me going all through my life and not needing help and being in my seventies and then feeling that I needed to have medication to get over fears.

My doctor said to me, "Your emotions are much stronger than your head." And it's true - I talked to myself like a Dutch uncle, but it still made no difference. It was absolutely incredible. By the time she received the date of her surgery everything was sort of building up...I thought I'm not going to be able to go through with this, and he (GP) upped the dose. He said, "instead of taking one, take two," so I was taking 50 (mgs) so I sort of went in - not exactly cloud nine, but I was much more sensible. 


\section{The day of admission -all people need to do is smile}

Fortified by the wise advice and judicious prescribing of her GP, and with major family support Mrs Mains found the day of admission surprisingly pleasant. The hospital organisation and relations with nurses more than met her expectations, and allayed her fears. The pre-admission clinic was conducted by a nurse from the ward and the house surgeon.

And the lady on the desk - well they couldn't have been nicer. As I say they gave you a little form, took me to the ward. The girl was very nice - it was a nurse, it wasn't a clerk. It was one of the nurses and it was prior to Christmas and so they all had Christmas earrings on and they were so cheerful.

Mrs Mains was grateful that everybody approached her with confidence and with good cheer.

[The anaesthetist] was an extremely nice person and you know I think it makes a great difference to elderly people if they're handled with confidence when they go in and if people can smile. That's all people need to do - smile.

In contrast to the ward a year earlier, this ward was well organised, and Mrs Mains thought highly of primary nursing, the written information and the approach of the nurses.

They made you very welcome, and there were never any awkward moments. They gave me this little circular about the hospital, the ward and all that who the charge nurse was, who the doctor was, and they gave you a nurse. If she wasn't on duty, you got someone else but they obviously stipulated that you had one-on-one. When I first went in they did 
take me on a tour of the ward, the nurse who took me in showed me where everything was and showed me where I would be. She said, "you'll be in a little room on this side to begin with." No, they really tried to make me feel at home.

Mrs Mains did wonder why the house surgeon had stressed how painful the surgery was, but he also emphasised the arrangements for analgesia. She knew exactly which room she would be in after surgery, who her nurse would be, and her family were able to be with her right to the door of the theatre. She found all this consideration of her needs lightened her apprehensions considerably. Anyone would have thought I was going to a picnic.

\section{The Ward - Everything a nurse should do.}

The day of her surgery Mrs Mains went to theatre at $2 \mathrm{pm}$ and remembered nothing until she woke up back in the ward at $6 \mathrm{pm}$. By the time her family came that night to see her she was sitting up reading. You know my daughter said, "if only l'd had my camera here to photograph you," [and to see] my husband's face because he was highly delighted. Fortune had reappeared on Mrs Mains' horizon and she surmised that the prolapsed mitral valve thought to be due to an undiagnosed bout of rheumatic fever as a child, meant that she was given an epidural and a lighter general anaesthetic than normal, a combination which helped with postoperative pain, as well as other usual complications of anaesthesia, such as nausea and drowsiness. [My husband] was obviously thrilled to see me so bright. And I just sailed through.

The next day the physiotherapist got Mrs Mains out of bed: 
the physiotherapy lady got me out of bed and made me walk to the wall and back again. \{CW and how was that?\} A bit shaky... I think they were cruel to be kind.

Mrs Mains' confidence was restored by the two nurses who were allocated to her care

I had a nurse this morning and then again the next morning. And I only had one change the whole time I was there when this particular nurse I had went off on holiday - it was just prior to Christmas. But she never forgot a thing - not that I would have really, but she never forgot your medication, she always put ointment on my heels and my behind - she did everything a nurse should do - she was really good.

Mrs Mains' confidence in her nurse's commitment to her needs enabled her to enjoy the nurse's company as well. She was interested in personal information about the nurse.

After 13 years she was going back to Laos to see relations. She was an Asian of some kind. She was just a little wee lady and I got quite a surprise to find out that she had a daughter who had gone on exchange to America. She must have been quite old, but to me she seemed quite young. But she was extremely efficient she really was.

Mrs Mains' confidence in the nurse's ability to attend to her needs when she herself was unable to was not misplaced.

I did something very silly for about three mornings in a row - I kept on blacking out when I had my shower in the mornings. I was all right when I got up in the morning first thing, go to the toilet, have my breakfast, but as soon as I got into the shower, for 
some unknown reason l'd black out. And I can remember there were operations on one morning, and they were a bit short-staffed, and this dear little Asian nurse she had me in the shower and I did it and she had to get me back in the chair in a bit of a state of undress (laughs) and there was no-one to help the poor girl.

Mrs Mains felt that the nurses' ability to assume responsibility for her when she had no control over or understanding of what was happening to her was a result of the charge nurse's expertise and relationship with the ward nurses.

The morning I was to come home, they were very short-staffed, and the charge nurse (she was an absolutely wonderful woman and I think it generated through her staff.) She'd hand out meals if they were short-staffed, and if someone couldn't go to morning tea- "Oh l've got Mrs so and so in the shower,"she'd say, "oh that's all right I'll see to them." And of course I did it to her (blacked out). And of course she said, "Tt, tt, this won't do." And she took my blood pressure lying down and standing up. The house surgeon came and he took it and it was no better so that's why they didn't let me out (as soon as expected).

Mrs Mains' primary nurse went on holiday and she was allocated to another nurse who was equally solicitous of her needs.

The next half of my stay I had this other lady and honestly she was absolutely marvellous - she really was. She couldn't do enough for you, she was such a gay happy lady. She had been nursing for a long time. $\mathrm{CW}$. oh right - she had a bit of 
experience?) Oh, yes, they were both very experienced.

The second nurse had an assertive approach which initially required some adaptation on Mrs Mains' part, but which she later welcomed as evidence of thoroughness.

I got quite a surprise once with this second nurse I had when she came on in the afternoons before she changed her shift there was no half measures with her. When the visitors had gone she'd whip you into the bathroom and [indecipherable with laughing] and she got very protective about my poor old bottom and my foot, because my heel got into a very bad state, and I didn't realise that it was because that leg had been operated on that it got so terribly raw. And they had a cover on- you know those clear covers- to protect it. She was very good, and then of course she came on, I had her in the mornings. Forget the name, she was rather nice.

There was one nurse in the ward who was not quite so blithe. With her own positive approach to life and fortified by the positive cheeriness from the other nurses, Mrs Mains was prepared to explain the nurse's behaviour in terms of the stability of people's personality over time.

And out of the whole staff there was only one nurse who struck a jarring note, and I think that people don't make allowances for people's personalities. She used to get a bit cross, but I think she was a good nurse, but she was just abrupt in her manner.

The nurse's abrupt manner was not a conscious choice, nor was it an integral part of 'nursing'. 
She couldn't help it - you know? She was abrupt in her manner. I never had her, she would bring meals sometimes and I know she was abrupt to other people sometimes. I still think she was probably a very good nurse, but you know, I don't think you can change nurses' personalities. And perhaps I was just fortunate, although they all seemed to have nice natures, and I don't think you can go into hospital expecting everybody to be... you know (pause) all... \{CW. little blossoms? all sunshine.

Mrs Mains offered further reasons for the surly behaviour on the part of the nurse in the unreasonable behaviour of some patients:

I know that nurses have got to put up with an awful lot really because some people are not reasonable. I suppose l'm not patting myself on the back. I don't like complaining.

One unreasonable patient complained and the nurse dealing with her earned Mrs Mains' admiration. During her stay, there was a civil defence alert and all the patients were transferred very quickly to another hospital - a process which the patients found traumatic.

[Nurses'] patience must get stretched sometimes, because some older people do get sort of crotchety. ICW. Yeah. What were the other people in your room like?\} Well one old lady she was in her eighties, and she had been a nurse, and I couldn't understand why she was the way she was if she had been a nurse. She was a very crotchety old lady, and she must have tried the nurses' patience a great deal, but they were so nice to her, they really were. One day we had come back -and she had lost things before- we came back from the (civil defence) emergency, and she vowed and declared that 
somebody had taken this $\$ 50$ out of her locker. And the nurse said to her in a very nice way, "Now you know that you shouldn't leave money in your locker." The Red Cross nurse had gone somewhere to cash her cheque for her and ... come back and given her the money and of course we were whisked off, you see. It was all done in a big hurry. She had lost something once before and it had been found. I'm sure that it was there because not even the cleaning staff were allowed in the ward (I had some flowers there and they were all dead when I came back) (laughs) ICW. So you were sure nobody had been around.\} Oh nobody had been there. So for about two or three hours there was this uncomfortableness. And the nurse, I could see her getting cross, and she said, "Could I have a look?" "No, no, no," she said, " You can't have a look, l've looked, it's not there." And then she found it and she had to go down and apologise. But throughout it all the nurse was very good because a lot of people would have got really cross about it. So they have an awful lot to put up with. I mean it must be really hard for them to be pleasant and to keep smiling when people are being unreasonable.

One aspect of Mrs Mains' pre-admission apprehensions had related to using the toilet at night. She wondered if the nurses would accommodate the older person's need to empty the bladder more frequently.

That's one thing that worried me about going into hospital, because when you're elderly you go to the bathroom more - very, well at least once a night, you know? After all you must wear out, and a trip to the 
bathroom at night time sort of seems to be what most (older people experience).

In addition there was Mrs Mains' own personality and her dislike of putting others to trouble in contrast to the elderly crotchety nurse. And I have never ever liked ringing the bell at night time. If it didn't make a noise in the ward it would be all right - you know if it would just flash down where the nurse was.

When at home she had been awake quite a bit with the pain, but the surgery was so successful (I'm just lucky that I had a good surgeon), the pain was considerably diminished and sleep was no problem in spite of sharing a room with others after three days. Mrs Mains tried to be quiet, and the night nurses were very quiet.

When Mrs Mains eventually had to ring the bell about 6 in the morning, the night nurse

would come, she would materialise. She was the loveliest girl, she never said very much - she had the loveliest smile and she would always have a pan in her hand. She always knew what you wanted. People only ring the bell at night for a pan. So she was lovely, but I didn't have much to do with the night nurses.

The night nurses wanted Mrs Mains to stay in bed, so she did. They didn't like you getting out of bed - me especially. Mrs Mains interpreted this in light of her own symptoms. [CW So you didn't get out of bed at night even before you came home?\} No, because I was sleeping right through, and I suppose because I thought I might do something silly and I would fall over, I never got out. 
One aspect of ward organisation was in contrast to her previous experiences of hospitalisation, and it suited Mrs Mains very well: she retained her own medication apart from the analgesia and the anti-inflammatories.

Perhaps they don't do it with a lot of people, but they let you have your own medication. My medication has always been taken off me in hospital and they've doled it out but some things I didn't have and they would meticulously bring it out at certain times.

Precision in timing of medication was a characteristic of all the nurses.

I was on Voltaren and they were giving me Panadol every four hours. And you know they never forgot the nurses were very good, they really were. The girls in the afternoon were just as good with medication. They never forgot to bring the medications.

Mrs Mains has continued to make good progress after this surgery. The surgeon is very pleased with her, she sleeps well at night, and apart from a tendency to have 'slight blackouts', which she can now recognise and prevent anything worse happening, all is well physically and psychologically. She is tailing herself off gradually form the "helping" pills her GP gave her.

The only negative to the experience is the trouble she put others to.

Jean said to me, "Now Mum if you have to will you go back and have the other one done?" And I said, "mm now l'm going to have to think about that." She said, "why will you have to think about that?" I said, "Well, 
because you know me - I hate putting anybody to any bother."

Her family had been extremely supportive and Mrs Mains showed me a trellis and some flowering annuals that an out-of-town daughter had planted in her garden so she could sit out there during her convalescence.

Reflecting back over her elective surgery, Mrs Mains found none of her previous apprehensions had been realised. Noone specifically addressed her fears, but she attributes her 'sailing through' to the example set by the charge nurse.

I think the whole staff there reflected on the head...

They sort of reflected her charm and personality - she was lovely. Yes I can't speak highly enough of the staff, they couldn't have been better. ICW Well, that sounds as if you've had quite a... Oh I

enjoyed my last stay in hospital.

\section{Commentary}

Mrs Mains portrayed herself as an extremely fortunate person both in her family of origin and in the support of her eight children. She had met and survived with good humour a number of challenges to her health. Things she couldn't change, she accepted, and those she could control, she actively took responsibility for. She had inner resilience from the example of her mother, from whom she also derived many of her expectations of nursing. This resilience had taken a battering over the year before the elective surgery, with her own loss of sleep, the ill health of her husband and sister, and a traumatic experience of hospitalisation. 
From her initial attendance at the pre-assessment clinic the ward nurses were in tune with her needs. She required reassurance that this was going to be a positive experience both in terms of the health outcomes, and the way others related to her, so as not to disturb her newly regained sense of confidence. The nurses achieved this by planning for her information requirements and interpersonal support. They facilitated her family involvement. She retained control over her own medications, and the environment was to her liking. She didn't always feel comfortable with other patients' interactions with nurses, but they did not concern her, personally, and indeed were further evidence to Mrs Mains that these nurses were doing all a nurse should. Nurses should be patient and kind with the old, crotchety and ill.

She compared her treatment in this ward with that of a year earlier where the lack of a medical diagnosis in the face of severe pain and the constantly changing nurses had contributed to a depression on discharge. She wondered about being able to get to the toilet at night without incurring the night nurses' impatience and being a 'trouble to others.' Other patients in this study have indicated that the night nurses were sometimes difficult to find common understanding with in regard to their toileting needs. Mrs Mains' night nurse, however, turned up with a pan in her hand. So important was this aspect of her care that Mrs Mains felt it was the only reason people ring at night. There was congruence between the nurse's informed guess and Mrs Mains' needs. Far from being impatient at the end of a busy night shift, this night nurse had the loveliest smile. As a nurse I wondered about the wisdom of discharging a patient with a history of blacking out, who had never toileted herself independently at night, however this has not proved to be a problem. 
The ward culture and organisation hinged around the charge nurse who led by example. Patients could control aspects of their care if they wanted to, such as their medications, but the nurses could cope when the unexpected happened as well. This ward had apparently retained experienced staff who enjoyed being there. Meticulous attention to timing was a reassuring indicator that the staff had the patients' interests at heart, and were competent. Nothing was too much trouble, everybody was friendly and outgoing. The ward culture could even carry the one nurse who was abrupt and morose. The allocation of primary nurses was helpful and therapeutic.

It may be argued that elective surgery is a much less complex event to negotiate than acute unplanned admissions, both for nurses and patients. Nevertheless, Mrs Mains' needs were not just straightforward ones as her history of the preceding year showed. Her needs related to much more than the technical aspects of the knee surgery. Indeed the technical aspects of care figure very little in her conversation. They were taken for granted in the attendance at the hospital. Even the abrupt nurse was probably a very good nurse, although not able to meet the needs of a patient who had had some challenges to her normally robust self concept.

The lived human relations of this ward were full of pleasure and reassurance for Mrs Mains. The nurse met her with smiles and welcomed her presence. In many respects her experience of care was similar to that of Mrs Brown: responsibility belonged to the nurse, but the control was in the hands of the patient. If the physiotherapist was cruel to be kind, the nurses were always kind and patient, although one primary nurse was initially thought to be too brusque. However, once Mrs Mains understood the clinical reason for what she had understood to be intense hygiene measures, the nurse's brusqueness was re-evaluated as proper 
professional concern for her raw heel. The intensity of the nurse's approach was initially surprising, but in retrospect a meticulous regard for patient well being.

This framing of the patient experience centre-stage in the ward Mrs Mains attributed to the charge nurse influence: it starts at the top. The charge nurse was both director and actor in the drama. The plot consisted of patient support and monitoring, judiciously balanced alongside the need for patient freedom. This charge nurse was the only one who was seen by any of the six interviewees to actually engage in a clinical role (although Mr Snell inferred such a role). The whole atmosphere of the ward radiated from her calm charming and competent demeanour. In contrast to Mrs Roy-Jenkins' experience where one unpleasant nurse overwhelmed even the experience of the caring nurses, in this instance, the overwhelming cheeriness of everyone else engulfed the performance of one morose nurse.

What nurses did and said with other patients, and how nurses treated each other had a direct effect on the lived relations with the onlooking patient. The one nurse who was unsmiling and dour in her approach to other patients, was the only jarring note in the human interactions, but as she was never allocated to Mrs Mains' care, it never had a large impact on her. For Mrs Mains with her characteristic equanimity regained, it was surprising a nurse should speak to others in this way, but not of personal concern. She was an interested watcher when another nurse dealt with a patient who was a crotchety old unreasonable ex-nurse. Some patients were just 'impossible.'

The lived space of the ward was introduced to Mrs Mains before her surgery. This was a feature of elective surgery that was unavailable to the other interviewees in the study since they were 
all emergency admissions. Knowing where she was and where she would be before her body underwent surgery limited the intensity of the vulnerability. Walking again on the new knee required a lot of effort, as Miss Shepherd described with her hip fracture, but Mrs Mains' confidence was bolstered by the nursing support. The nurses did not issue any challenges to Mrs Mains' body that she could not meet. When her body came up with challenges of its own, the nurses were competent to respond.

This human environment enabled Mrs Mains to endure being evacuated to another spatial environment. Although walking up ambulance steps was a further physical challenge, Mrs Mains was able to mobilise the resources required, and even look on such an occasion as a small adventure. Such was the security of relations with the known primary nurse(s) and the charge nurse that a fairly significant upheaval in the surrounding space was managed with confidence and ease. Other patients did not do so well, and one patient's sense of displacement, and 'losing track' of valued possessions, led to an ongoing complaint, with consequent embarrassment. Mrs Mains' confidence in the nurses' trustworthiness was supported by empirical signs of high security measures. Even dead flowers, normally an indicator of less than adequate attention to detail in a hospital, in this instance, were signs of scrupulous attention to the patients' best interests.

The memories of the previous time in hospital were very close to Mrs Mains when she entered the elective surgery system. Unlike the earlier occasion, though, Mrs Mains had a medical diagnosis this time that was commonly dealt with here. The organised activities pre-surgery filled the time, and the quality of the experience was anything but depressing. The time of the operation just flew by and she was sitting up in a chair ready to greet her 
family four hours after saying goodbye to them at the door of the theatre.

The knee replacement proved to be a dreaded, but, in reality, small and even pleasant, interlude in the ongoing life of a family. In spite of such excellent family knowledge and support, as well as a lifelong habit of taking the bitter with the better, the fear evoked in Mrs Mains by her previous hospital experience almost prevented her using the hospital services of elective surgery this time. She had a well-established history of the condition spanning thirty years, GP and specialist support. She had also in the previous year been alongside her husband through life-threatening surgery and the realisation that her elder sister now had so many illnesses that she could be considered 'old'. The times, and the people, were changing for Mrs Mains.

The 'lifeworld' in this ward was characterised by meticulous planning and attention to detail all delivered in a cheerful and pleasant atmosphere. The spectres of the previous year were driven back. Support, practical, professional and interpersonal, was everywhere, from the charge nurse down, and extended to even the crankiest patients. There is no description of extensive psychological assessment, or any awareness of Mrs Mains' individual interpersonal needs, but the social relations which followed the establishment of professional competence, met this family person's needs exactly. Family weddings, school children's trips, holidays, all these were of interest to Mrs Mains. She could relax and enjoy the relationships with nurses because they took such good care of her by way of practical support and monitoring her physical needs. Aspects of care she did not need help with, such as her medication, and maintenance of her family roles, were left to her. In fact, it was just like going to a picnic. 
If earlier chapters described stories where patient framing was through a lens of disability, dependence and pain, Mrs Mains is an example of a story told through a lens of recovery and through contrast with an earlier dismal experience of acute ward experience.

All six stories reported have had both unique and common elements. Emblems of aspects of each story have been displayed at the section headings throughout. Each analysis has moved from individual information, to the patient story, to a portrait of life in the acute ward for the patient, and concludes with a hermeneutic explication of the four existentials as they have been shown in the story. The emphasis until this point has been on the individual and the unique.

In the next two chapters I propose to discuss the aggregated individual concerns and the hermeneutic explications in order to consider the common needs of older people in acute care settings. 


\section{Erratum}

Page numbering recommences at page 216. 


\section{Chapter 11 Small additions: unanticipated corroborations}

One unexpected result of using newspapers as a recruiting method was responses from ten relatives of older people who had died in hospital or who had had very traumatic experiences there. The patients were dead or too frail to recount their own experiences, but the relatives really wanted the stories to be told. Numbers of them were very distressed. As the issues for consent of the client were not able to be addressed and relatives' perspectives were outside my brief as I understood it, I have not included this material in the thesis. However their stories were further validation of the categories of non-care as outlined above.

My response to the relatives was consistent: I listened, told them their stories were outside the boundaries of the research, and I accepted any material they cared to send to me. The distress of these people continued to disturb me, and I eventually read some of their stories (with details concealed) to a conference where Registered Nurses were present. I telephoned or wrote to those relatives whose stories were used in this way and informed them of the event. All were pleased that there had been some nursing consideration of their issues, but still disappointed it would not be included in the thesis. The issues of consent and disclosure for these particular relatives are insurmountable, but Donnelly's (1997) account captures many of the same elements.

Several weeks ago, my 85-year-old mother broke her hip. After many hours in the emergency department, she was admitted to an orthopaedic surgical unit, where she spent the night and had surgery the next evening. On Saturday morning, her first postoperative day, I arrived at the hospital at $8.30 \mathrm{am}$ to find my mother sitting up in bed, her dementia 
exacerbated by the anesthesia (sic) and her untouched food tray pushed to the side. At first my mother did not know me, but with some humorous prodding on my part she finally oriented. I asked the nurse why my mother had not eaten. The answer was "she didn't care to have anything." I asked the nurse to heat the cereal and to get cold milk. I fed my mother, spoon by spoon, sip by sip. She ate everything on the tray. Her deep confusion at being in a strange place without her husband of 65 years and with some pain in her "leg," as she described it, resulted in her failure to know which end of the spoon to grasp. Her deeply developed sense of pride enabled her to say "I don't care for breakfast," rather than "I am hungry, but I forget how to eat breakfast."

In this story there is the same lack of practical help and the same lack of consideration to consider "who the patient is" both in terms of her previous competencies of daily living, and how she had come to be in the acute ward as there is in the stories of the people who spoke with me. Donnelly's mother had dementia, and so would not be recruited to such a research project as the current one, being unable to respond to newspaper campaigns. Nevertheless this was a very similar tale to numbers I heard on the phone. Although the relatives who telephoned me and who sent written accounts of their relatives' care were concerned at their relatives' non-care, their explanations given (if any) relate to ageism on the part of the nurses.

Donnelly, however, had a different explanation. She was able to both intervene with some understanding and to analyse as a nurse the situation of non-care she found her mother in: 
It became increasingly obvious that, had the nurse probed more deeply to discover my mother's lost capacity to feed herself, there would not have been time to feed her. Feeding my mother might have meant a missed dressing change in the next room, a delayed first post-operative ambulation for another patient, a delayed discharge, or a delayed response to the two patients moaning down the hall. The nurse was as attentive, competent, and caring as time and resources would allow. I fed my mother six meals that weekend...(emphasis in original)

After some comments relating to the American system of reimbursement in acute wards, Donnelly concludes the health care system's rapid rate of change, "do more with less" ethic, and romance with the promises and perils of technology continue to create challenge, conflict, and crisis for practising nurses.

The stories in Chapters 5- 10 do indeed reveal some ward situations not too far removed from that of Donnelly's mother. The New Zealand patients, too, attributed their negative experiences to the "rate of change", to financial constraint, and to issues surrounding the use of technology. The New Zealand interviewees also received unwelcome challenge from some nurses, and described interpersonal conflict with some. Relatives who rang certainly described some situations as "crisis."

The 'lifeworld' of the American ward was similar to many of the elements in the New Zealand wards. Issues relating to self care for patients, post-operative ambulation, discharge, and responding to patients who were confused and in pain, are the work of nurses internationally, and require further consideration by the profession. 
Thomasma (1994 p 96) reports Kelly's (1988) observation that families say nurses are "uncaring, cruel, rough, thoughtless, mean and indifferent." On the evidence of this project such an unmitigated negative picture cannot be sustained. However there are enough similarities between the two pictures of absent care for some concerns to be raised. The practice dynamic of caring for families, or caring for the patient while also allowing the family to 'see' the care, is a concept to be noted here. In Thomasma's view the curriculum of all health professions needs reconstruction to express more fully a relational ethic of care. It is important to see the negative and experience the quality of absent care. In the next chapter I turn again to the experiences of the six patients. In Chapter 12 there is an aggregated picture of absent care. 


\section{Chapter 12- Experiencing non-care}

In the next two chapters I propose to consider the patient descriptions collectively. "Each story has a meaning to the teller of the tale, to the listener, and to the researcher." (Ayres and Poirier $1996 \mathrm{p} \mathrm{163)}$. This suggests that there are multiple meanings in these texts. This is the nature of 'story', especially story as 'art.' Many readers will be able to 'see' things in the stories which I have left unexplored. As Ayres and Poirier point out, no text explains everything ( $p 165$ ). Especially those who have differing conceptual pre-suppositions will be able to extend the analysis along numerous alternative tracks. Inasmuch as I am aware of them I have tried to lay out my own influences and presuppositions in Chapter 1, and also in instances in the interviews when I was conscious of the "nurse voice" speaking in my consideration of the aspect of the particular story being recounted. There was attentive effort expended in not colonising the stories of these 'others.' Particularly when the patient description of nursing caused me some discomfort - even embarrassment - I was made aware of my own presuppositions and assumptions. In many of these uncomfortable moments I was made aware that to these informants I was the 'other,' as nurse, a juxtaposition of the usual clinical relationship in acute illness events.

Chapters 11 and 12 are not an attempt to take the preceding six stories and re-tell them in a new form which knows better than the original speakers did. Rather, as I responded to or prompted the shared material, there became a shared story of the telling of the acute ward experience. In a sense their stories became my stories, not to re-tell on their behalf (although I did see my role in this way initially), but to depict as part of my 'lived experience.' As a nurse, I bring many issues, experiences and concerns to the 
project. I turn now to this tale which both carries along and moves beyond the acute ward conversations.

Elements from the individual stories are segregated from their particular text, and now laid alongside elements from other particular texts to inform the meaning of the nursing situations and the response called forth in me, as a nurse. There is the move from the text of the interview itself to that of the "aesthetic text" (Ayers and Poirier $1996 \mathrm{p} \mathrm{165).} \mathrm{The} \mathrm{contexts} \mathrm{of} \mathrm{the} \mathrm{original}$ interviews and acute ward experiences have been unravelled from the text available. Now it is time to move beyond the boundaries of the original conversations overlaying salient issues and concerns with one nursing perspective. The focus of the picture moves from the explication of human and patient need to the nursing response to that need. Some nursing responses were supportive and enabling, others were dismissive of the patient need. This chapter deals with the latter.

\section{Introduction to the structures of non-care}

Many of the stories these patients told were of absent nursing care or of care that they needed but nurses were unable to influence in the 'system.' All experienced lack of care in various parts of the health care system (not just nursing). Different parts of the system interacted with each other to reveal an experience with an ongoing quality of its own. Standing from the patients' perspectives and hearing their stories as a nurse reveals that sometimes this was a lack of a medical diagnosis, or lack of appropriate information, or poor records systems in areas outside the wards.

Absent care as it related to nurses in acute wards was experienced as assaults on the person's identity, or a selforientation on the part of the nurse. Sometimes it was related to 
the initiation of the relationship, when it was difficult for the nurse ever to regain a relationship of trust. At other times it was related to a kind of 'talking past each other' illustrated most graphically in Miss Shepherd's experience of her pain. The responsibility for initiating the relationship and bridging the 'discourse gap' belonged to nursing, although all story tellers were ready to offer their own interpretations for the nurses' less than adequate or puzzling care. At yet other times absent care related to a failure to render practical help.

In all instances of absent care the nurse or nursing team failed to acknowledge who the patient was. Second they failed to take account of the circumstances which led to the admission. This was particularly noticeable when the admission was due to trauma, and especially repeat procedures. Third the nurses failed to relate to the technology in ways which enhanced patient trust in their clinical knowledge.

\section{Failure to acknowledge who the patient is}

The most dramatic example of a challenge to a patient's identity was the doctor inquiring after Mrs Brown's drinking habits on the ward round. For a life-long teetotaller and an independent-minded Scotswoman to be asked such an accusatory question so publicly, the experience was horrifying. The horror she felt being asked such a question was mirrored on the faces of the medical staff when she promptly vomited. Not all patients had such spectacular external responses to such challenges to their identity, but others felt equally distressed.

The nurse who disparaged Mrs Roy-Jenkins' name and suburb of residence, the nurse who attempted to train (her) to go without her oxygen, and the nurses who witheld the medication in an 
autocratic and erratic fashion all issued challenges to her habitual way of being in the world, both in the sense of the type of person she was and in the sense of disrupting her chosen activities. She understood interventions that related to the fracture or related symptoms, but other attempts to change her, whether well-meant or self-serving on the nurse's part, were not seen as caring or even intelligible. It is possible that the withholding the Ativan was an attempt by the nurse to lower the chances of Mrs Roy-Jenkins having another fall. If so, Mrs Roy-Jenkins did not understand this, or she valued relaxed breathing more highly than safe mobility. In the event no one (neither nurse nor researcher) sought the reason she was taking Ativan and the place it played in her life.

For a resourceful and intelligent woman who had been used to interesting times and special consideration from others when times were hard, resistance was the only option, holding fast to her sense of identity and waiting to go home so things could be as much as possible as before, even if at a level of functioning she recognised as lower.

Similarly Mr Snell was an academic whose stock in trade was communicating information through the medium of human to human contact. His need was for information although he did not hold the nurses solely responsible for this information lack in regard to weightbearing.

In retrospect Mr Snell felt his greatest need had been for practical information as to what constituted "non-weightbearing." He was looking for an explanation for his slower than usual recovery period. After discharge a friend had recommended a book (Pryor 1991) which contained information he would have found useful when re-learning to walk. At no stage did any staff member, let 
alone nurses, give information about the way he should have walked or was walking, in spite of his being observed walking by the charge nurse, the Medical Registrar and the Physiotherapist. This lack of information may be seen as a lack of practical help, but in the case of $\mathrm{Mr}$ Snell, it seemed there was a complete overlooking of 'who he was' in his worklife. He was an accomplished evaluator of information, but none was offered to him, either in written or verbal form.

Miss Shepherd was a lifelong professional nurse. She saw herself as at least the charge nurse's equal, but there is no hint that this was acknowledged. As a very experienced nurse as well as a very experienced patient she needed care from experienced nurses. As a nurse she had expectations of getting physical, practical and psychosocial help from the nursing team, but as a patient she expected the nurses to initiate the offer of help, and certainly to respond to her requests for help.

Aspects of "who she was" as a person meshed with each other in complex ways. She saw herself as a helper of others, she liked to be independent, and she liked to have her requests for help treated seriously. At night the nurses were openly rejecting of her request for help and then were irritable when she was unable to be continent of urine and lift her leg back into bed. Because of her professional experience she needed nurses who were understanding of her conceptualising of nursing. Not to do so put too large a burden on Miss Shepherd initiating her own requests for help and thus being forced into a dependent role when her self image was one of independence.

The meaning of independent safe mobility (a critical factor after a fracture) for her was that she expected to watch where her feet were on the ground since this was the way she walked before her 
fracture. A key aspect of Miss Shepherd's self image and identity was the way her body was when walking. Such a corporeal disposition was to ensure safety and security. The ward team constantly challenged her body without trying to find out why she was the way she was.

As well, the exhortations to stand up straight challenged her identity at another level. She was a competent and independent nurse. If standing up straight had simply been a matter of habit, or under the command of her will, she would have complied with such instructions long before. The body's composition carried a value which was quite in tune with the value of the mobility instructors: safety. The eyes wanted to look down for immediate obstacles, not scan the horizon for potential barriers.

The whole notion of independent mobility was an area where Miss Shepherd was particularly vulnerable, since her GP had already challenged her refusal to use a stick. He, however, did so from an apparently robust and longstanding relationship of trust. He knew "who she was" when he challenged her, the nurses showed no evidence they knew anything about Miss Shepherd other than expected medical outcomes for the surgical procedure. Opportunity to establish such a relationship of trust may become increasingly rare with shorter patient stays. Perhaps new ways of establishing or negotiating such a relationship need to be considered.

Impaired mobility prior to hospitalisation (especially when compounded with a diagnosis related to mobility) seemed to be an area that was fraught with difficulty. There was the aspect of physical identity, the way the person had come to compose and dispose their body. Then, too, there was the way the person conceptualised their 'self' - either as helpful and caring, 
independent, academic, or privileged, and so on. Whatever mobility interventions were put in place needed to take account of, and to tune into both these aspects of the self image.

In phenomenological terms this may be thought of as 'lived meaning' (Van Manen 1990 p 183). Speaking of teachers, Van Manen says they may want to be aware of how a learner meaningfully experiences certain situations, even though the learner may not be explicitly aware themselves. In situations where the nursing role called for teaching, or re-teaching certain skills such as walking, a failure by nurses to consider the conceptualisation of the self as well as the body's own prior ways of being, evoked significant distress.

A second aspect of 'lived meaning' is the connection between physical pain and suffering. As Miss Shepherd said. I was suffering but it could have been a lot worse.

“...we are not ourselves

When nature, being oppressed, commands the mind to suffer with the body."

(King Lear Act 2.scene 4.L103 -105 p 49)

Shakespeare's distinction between mind and body is not one, which sits comfortably with the phenomenological perspective of Van Manen who sees a unity of empirical and 'personal' elements in the experience. However it is a common mode of speech which points to a distinction between the physical symptoms and the existential experience of suffering. Pain is the only sense which has no objective reality. By this I mean that two people can look at the same tree or hear the same music. Their experiences may be different and have different meanings for them, but the fact of the tree or the music is usually considered to be independently verifiable. We can infer the presence of another's pain by asking 
them to describe it, and by comparing our own experience of similar situations, but we can never simultaneously experience it the way we can other sensory events. What Shakespeare does highlight is how the loss of personhood through suffering challenges the very essence of who one is, and leaves one alone in a unique way. Gregarious helpers of others may become passive traumatised recipients of care when suffering is not attended to, acknowledged, and borne. Offering analgesia to deal with pain is one thing; attending to the suffering person is also expected of nurses.

\section{Reifying technology}

While many aspects of technology in the acute wards were accepted as normal, and welcomed by some interviewees, others experienced the technology and the nurses' interventions relating to them as objectifying. Far from diminishing pain, the PCA in Miss Shepherd's case seemed to operate as an element in her experience of suffering. Suffering drained away energy.

In their desire to give Miss Shepherd some control over her pain management, the nursing team intensified her experience of pain. She expected warm and friendly human contact, for the moderate level of pain she experienced (it could have been worse). Instead, she was offered pills and PCA. There are many similarities between Miss Shepherd's experience in hospital in New Zealand in the 90s and that of Norman Cousins in the United States of America in the 70s.

"There was the utter void created by the longingineradicable, unremitting, pervasive- for warmth of human contact. A warm smile and an outstretched hand were valued even above the offerings of 
human science, but the latter were far more accessible than the former."

(Cousins 1979 p 121)

Happy nurses, in Miss Shepherd's experience, were the result of them having, as she said, complicated enough machines to look after. Brand and Yancey (1993) offer a telling metaphor: "as the eagle was killed by the arrow winged with his own feather, so the hand of the world is wounded by its own skill." By looking after the machines and not the person the machines were helping, nursing, in Miss Shepherd's eyes had simultaneously progressed and regressed. The hand of the world was wounding even though the skill (of the nurse) had advanced. Technology isolated pain from the pain-bearer. Intended to help with the relief of pain, if moved to the centre of the person's experience, technological interventions alone can add to the intensity of the suffering.

Mr Snell had less alienating, but still puzzling experiences with similar technology. The nurses in this acute ward initiated friendly human relations, and performed standard pain "assessments," but related to his pain at the level of technology. Some nurses were particularly insistent about the use of the PCA, as they were not insistent about any other aspect of care. Mr Snell did not feel pain, he had another source of analgesia in place as well as the radio and the interesting social life of the ward to act as distracters. But some nurses related to the technology more easily than to the patient's experience of pain. They 'problemsolved' in stereotypical (and perhaps protocol-driven) ways when the patient had no problem.

The nature of his pain relief assumed new importance to $\mathrm{Mr}$ Snell after discharge when he began to wonder if he had inadvertently caused his ongoing mobility problems by putting too much weight 
on the operated hip too early. Was pain a necessary indicator of how much weightbearing he should do? Was the modern propensity to avoid pain really of help? (Nowadays we are not very used to this (enduring pain) - there's usually some sort of medication.)

Relating to the patient at the level of the technology devalued the patient experience of pain, and incidentally, devalued the use of technology as well. Theirs was not a Luddite opposition to technology, or to pain relief, since all patients were particularly grateful for other technologies such as epidurals, femoral lines, and ECGs when they were appropriately supported through the experience and when the reason for the technology was understood within their lived experience of meaning.

Sandelowski (1997) refers to two perspectives of the relationship between nursing and technology. In a review of nursing literature since 1960 she points to the essentialist approaches of both "technological romantics" and "technological optimists." Counting herself among the romantics (that is, one who sees technology as an inherently seductive and reductive 'masculine' intervention essentially 'outside' the legitimate concern of nursing as a 'feminine' profession), Sandelowski's current contribution to this debate is to call for "historical and cultural studies of nursing and technology... to illuminate these different realities." (Sandelowski, 1997 p 173)

The current project did not seek to study technology specifically. Patient understandings regarding technology arose as they told their stories of absent care. There was wide variation in the ability of ward nurses to mediate the technology to these older patients. 'Hi-tech' areas such as theatre, recovery rooms and ICU managed the interrelationship between technology and human concerns 
with much greater ease. Based on the stories in this study it would seem there is need to echo Sandelowski's call in New Zealand acute care wards also.

\section{Failing to communicate between departments and systems}

These older patients experienced other puzzles too. These puzzles were not a source of interest as one might do a crossword puzzle; for the satisfaction of meeting and conquering the challenge of the puzzle. Rather they were perplexing mysteries which revealed to them the world was not as they thought it. Nurses, in particular, were sometimes not as expected or as they had been thought of over the preceding years of their lives.

These patients wanted to tell stories of less than adequate health care or puzzling behaviour on the part of health professionals which they could only explain by assuming that there had been some communication breakdown. Many of these breakdowns which they felt acutely at the time of the interview did not involve nurses in acute wards. Nevertheless they wanted to tell me these stories in spite of my discouraging such disclosure. I have referred earlier to my discovery that such stories were germane to the actual experience of the acute ward, particularly when the admission was unexpected and related to traumatic experiences of some kind.

One aspect of communicating between departments was knowing how those patients came to be in the hospital. It seemed particularly important for someone to acknowledge such experiences.

Miss Shepherd's story was framed by pain. The pain began right from the time of the fall and was particularly acute. Her fracture 
experience was highly traumatic and shattering in every way. After the tape had been turned of she told me that a friend had told her she had been confused post-operatively and tried to pick the colours off the surgeon's shirt. This may have made it difficult for her to recall any attempts by nurses to help her 'process' the previous trauma, but she was still haunted by the pain three months after the event.

Lorna's experience with the night staff in the holding ward challenged her already poor mobility. There seemed to be a lack of consideration of her previous physical self-concept, but there was an added dimension to her experience of the nurses' refusal to give her close support at night. Already having been characterised by ACC as a "frequent faller" and warned to take extreme care, she was initially refused help in walking to the toilet at night after a particularly frightening motor vehicle accident. Some acknowledgement of the reasons for acute admissions was expected from nurses. Even if she were physically able to walk, the stressful events leading up to the hospitalisation required sympathy and emotional support to enable her to face this further challenge to her mobility.

Subsequently Lorna also experienced a lack of communication between different health areas. The night nurses had information that indicated she was unable to live alone, especially in a house with a central stairwell, but follow-up after discharge did not occur in a timely fashion and Lorna had to activate a previous agency on her own behalf.

Mrs Brown also noted, without any allocation of cause or responsibility, that the hospital indicated she would receive six weeks home help, but that this did not start until three weeks after discharge. 
Breakdowns in communications with other parts of the health care system also had a major impact on Mrs Brown. She was repeatedly gastroscoped by doctors who changed, and who did not have access to each other's notes. She was given poor information concerning what to expect after gastroscopy. This latter event is one where Mrs Brown clearly felt the nurse could have prepared patients beforehand with more realistic information, and offered better practical help after the event. The picture is one of a system breaking down at a number of points.

The system breakdown had a major effect on Mrs Brown not being given a medical diagnosis, even though the eventual diagnosis was one which she suggested herself. Entering the acute care system with unnamed symptoms which might be psychological (as in Mrs Mains' experience a year earlier), or life threatening (as in Mrs Brown's case), or even worse, the result of stigmatised behaviour such as alcoholism, left the patient very much cast on their own resources, and caused the patient to wonder whether the people entrusted with her care were, in fact trustworthy professionals.

Another aspect of the systems in acute wards was the sense, expressed by all the interviewees, of the perpetual short-staffing which resulted in casual nurses being employed. These nurses Mrs Brown found either so inexperienced they could not work the monitoring equipment, or so self-centred that it was difficult to believe they had the patients' best interests at heart. The systems of employing and training nurses were sometimes found to be deficient in their support of new nurses and this impacted on the patients, although in a minor way. 
Perpetual short-staffing, and lack of experience of new graduates were also part of the picture of 'system failure' which Mrs Snell and Mrs Roy-Jenkins experienced. Perpetual short-staffing was the reason for some nurses' less than helpful approach, Mrs RoyJenkins felt. Both Mr Snell and Miss Shepherd felt the wards were peopled by many 'young nurses' who were not always confident in the management of equipment or the interpretation of results. If the nurses did not know these things, who did? Who was the resource person who looked out for the patients' interests?

The patients who experienced mis-management of their pain explained this as a failure of the different care teams to coordinate their efforts. The assessments, technology, the pharmacology were all freely available, but the interface which focussed all these on the particular patient need on the day was lacking. A failure to bring the patient experience into sharp relief in the picture of pain 'management' meant a failure, for some, of the actual relief of pain. Different caring teams handled different aspects of the care, and each team or individual had a fragment of the whole picture. There was no accountable person. The patient experienced it all, but was not in a position to assume such responsibility. Mr Snell, for instance, experienced the most acute pain of his life when his anti-inflammatories were omitted the morning of his surgery.

This aspect of the ward management systems of nursing care delivery was especially noticeable to me as a nurse. Primary nurses seemed absent except for Mrs Mains who had elective surgery. Also absent were charge nurses as clinically important people (apart from, once again, Mrs Mains' story). The charge nurses who were present did the duty rosters and engaged in some superficial conversation with Lorna and with Miss Shepherd. 
The charge nurse was totally absent from Mrs Brown's story entrapped as she was in the ambiguous space of 'having no medical diagnosis.' I shall refer in the next chapter to the solicitous care Mrs Brown received from the ward nurses, and it could be argued from this that there was no need for the charge nurse, a primary nurse, or any senior clinician to support her at this time or to advocate with the medical staff. However, I think she portrayed a quality of absent care in the ward which was more notable by contrast with the nurses from ICU. In one place in her picture of nurse caring there was an unnamed blank space. Certainly I as a nurse felt very uncomfortable about the silence of nurses when doctors were present in Mrs Brown's story. The ward nurses were not able immediately to engage with her because she was unconscious, but there is no mention that any nurse referred to this extremely dramatic event afterwards.

The validation of the inference I draw concerning the absence of a 'significant nurse' to Mrs Brown may be seen in Mrs Mains' account of her previous hospitalisation where she had no diagnosis and she had no primary nurse. This experience of Mrs Mains threw light on Mrs Brown's meticulous insistence on documentation of the reality of her story through test results, and medical records, and on Lorna's invoking of medical practitioners, who had previously treated various causes of her poor mobility, when nurses were inclined to be disbelieving of her ability to walk unaided.

Patients needed to expend energy dealing with emotional challenges and intellectual puzzles which were unnerving when inadequately supported through an experience of seeking a diagnosis in an organisation which existed to make diagnoses and treat diseases. Absent care extended to a failure to communicate 
across disciplines as well as communicating between departments and between shifts and levels of nurses.

\section{Failing to give practical help when asked}

Practical help took many forms. Failing to render help especially at initial encounter compromised the ongoing relations with nurses. Absence of help occurred both in a general sense associated with activities of daily living perhaps unrelated to the reason for admission, and in a particular sense where patients needed help with signs and symptoms consequent upon the particular reason for their admission.

An example of the first type of practical help was drying the back in the shower. Some nurses overlooked Mr Snell's need for assistance in drying his back in the shower, or they expected, with surgery to his hip, he could dry his own back. There were no negative outcomes from the failure of nurses to dry Mr Snell's back in the shower. It was not a major issue, as no physical consequences or distress resulted from this oversight, but it indicated that the nurses' expectations of this post-surgery patient and his own of them, did not match.

A second example of refusal of general help with the activities of daily living the patient would normally have carried out themselves was the nurse's reluctance to change Mrs Roy-Jenkins nightdress for one of a different weight. This refusal of practical help did carry overtones of unpleasantness coming as it did after a shower where the nurse had challenged many aspects of the patient's ways of being. This denial of help was an intimidating last straw in a conflict-ridden encounter which began with the nurse assertively refusing to help Mrs Roy-Jenkins access her usual oxygen supply in the shower as she did at home. 
Requests for help made by other patients were more closely related to the particular reason for the admission. It could be expected that surgery to a hip would result in difficulty moving or raising a leg. The ongoing offers of Panadol in response to Miss Shepherd's requests to pick up her leg were particularly discouraging to her, acting as indicators to her that she was not making progress as expected, that she was being more dependent than she needed to be, and that, as she had predicted, the training of nurses was not as proficient. Nurses were no longer helping patients.

In many instances practical help was forthcoming from other patients. Miss Shepherd's roommate lent her a hand extender to pick up things she had dropped. She clearly felt this equipment should have been supplied by nurses.

Nurses failing to offer or refusing practical help was disorienting to these clients. Mrs Brown's understanding of nurses as people who were not interested in a career, or a trade, [but]... interested in people... and getting them better if possible, was, I suspect, shared by others in the conversations. In this view nurses were, by their very natures, ready helpers of others. Clearly an explanation was needed for the times when nurses did not offer help, for the times when they stood their ground and told the patients that life in the wards would be conducted as the nurses wanted it to be, and not as the patients had requested. The meanings these patients offered for nurses' refusals ranged from laziness, to understaffing, to poor education, to just plain bloodymindedness on the part of the nurse. 


\section{Commentary}

At another level these patients' experiences of non-care challenge the existential location of myself and other nurses. The Greek story of Perseus and Medusa is well-known but not often thought about in relation to nursing. The goddess Minerva had caused the snakes to grow in place of hair after Medusa had been violated by the god Neptune. Many attempted to look on the face of Medusa because of her great beauty but always they were driven back by their own fear and by the salutary examples of those before them on the way who had looked on her face. All were, as Ovid says, "turned to stone by glancing on Medusa's face" (Melville, 1986, p 98).

There are many parallels to nursing in this myth. The things in others which 'turn us to stone' often spring from elements in their past which, if we were aware of, we would be particularly solicitous of. When nurses look on the face of human need, sometimes we are turned to stone and unable to respond. The six conversations reveal that some nurses did not make the journey to Medusa's stronghold: they journeyed elsewhere or they stayed in the place of their own need chatting about the weather and the new furnishings for home. Others set out on the journey but they were defeated on the way by inadequate resources or their own lack of skill in the journey; their own needs for knowledge and stamina were far greater than those of the patients. Some nurses did look fully in the medusan face of human need and were turned to stone, unable to respond with personal warmth, at times devoid of human activity at all, let alone competent professional activity.

Overwhelmed by the enormity of the need, the patient who is offensive to us, and the number of writhing snakes the modern health care system asks us to have regard for, a few nurses are 
petrified. When the patient is also from a social and economic class different from our own, or, perhaps from our own profession, and a generation who has a different grasp on the meaning of pain and technology to ourselves, some of us re-double our efforts to escape a Gorgon's glance, or stand transfixed.

However, in the end, the fascination and the climax of the myth belongs to Perseus, not Medusa. For the nurse to be able to unflinchingly observe the human need and act to meet it without hardening and becoming useless, the allegory - and the six conversations - suggest another alternative: we may do as Perseus did and look in a reflection. (To extend the allegorical elements of the exercise even further, Perseus' mirror was his burnished shield; indicating there is an inherently self-protective element in reflection as well, something very necessary "in a destitute time" (Darbyshire 1993)). Having regard for the other is not simply a matter of trying harder, better stress management, knowing more, although all these may be helpful on the journey. If at the end of the journey, when we look fully in the face of patient need, we are tempted to turn to stone, the Perseus story suggests reflection as a way of encountering human suffering and human need.

Reflection as a valued nursing activity is mentioned in the nursing literature in at least three forms. First, and most commonly, it is valued as a personal learning tool in nurse education. (Atkins and Murphy 1993). Second it is recommended to practitioners as a way of changing practice. (Street, 1991, Powell, 1989) This may be by journalling, or by discussion in a supervision session (Bishop, 1994) or in a facilitated group session. These methods all involve the "nurse's eye" view of practice. 
This project offers yet another way to reflect on practice. It is the sustained consideration by a non-caregiving nurse of the collective "patients' eye" view of nursing practice. In the former notion of reflection the nurse or student thoughtfully considers a moment of nursing or a practice situation. This process results in changed practice for the next analogous situation, and in some cases an ongoing passing on of the thoughtful consideration to the wider nursing community through publication. The motion of the 'reflection' is: nurse situation -nurse -other nurses/other patients.

In the sense the term, 'reflection', has been used in this inquiry the motion of reflection is: patient situation -nurse researcher -other nurses. This was not reflection with the express purpose of helping the patients to process their experience of nursing, but reflection in the sense that the image of nursing is seen by the researcher in the mirror of the patient story. Nursing consideration of patients' reflected stories of nursing care Is necessary if we are to "see ourselves as others see us," and not always to reflect on the others as we see them. The traditions and forerunners in hermeneutic phenomenology provide new options for reflection, and may balance the way reflection in nursing has been conceptualised and promoted until now. Shifting the balance of concern from the lived experience of the nurse to that of the patient offers more images of the phenomenon that is nursing care.

In the next chapter I turn to the shape of care as experienced by the six patients I talked with before discussing the implications of such a picture of nursing care for research and practice in Chapter 13. 


\section{Chapter 13 Mirrors of care}

As well as forms and feelings of absent care, the patients' stories offered images of practice that revealed the meaning and shape of care for these patients. Nursing which includes negotiating the systems, mediating interpersonal issues, precise technological and physical monitoring, and practical help and knowledge in the form of "tips" was excellent care for these patients. These aspects were not discrete entities. I intend to show how they were intertwined with each other in the care patients received. The ability to quickly evaluate a patient's life ways of being and acknowledge these as of equal importance to the expected health outcomes from the particular medical diagnosis was valued.

\section{Mediating interpersonal issues -initiating the relationship}

One aspect of good nursing care that all respondents experienced was the sharing of aspects of the nurses' personal lives. This reflects the findings of Taylor (1994). However, aspects of interpersonal sharing that are not evident in Taylor are present in these stories. As the preceding chapter shows, not all instances of personal sharing were received as caring nursing by these patients. There are certain pre-requisites to interpersonal sharing.

Mr Snell was the first respondent to mention the place that nurses' personal lives had in the patients' experience of hospitalisation. He described himself as a keen student of human nature. For him, the acute hospital afforded more opportunities for observation. He had knowledge of two nurses' personal lives. Both were very competent in their technical and professional relations with 
patients. These latter were the sine qua non of the nursing relationship. Taylor cites appreciating skilful nursing care as an aspect of the facilitation work of nurses. (Taylor $1994 \mathrm{p}$ 190). Once that skilfulness was established, however, there was opportunity for the nurse to reveal things about herself, even quite personal details such as would be ordinarily discussed in a relationship of some intimacy.

One l'm thinking of in particular - older she would be - oh in her forties, I think, twice or thrice married and never again!... She was a keen swimmer and talked about the various recreational things she was doing and sometimes she cursed her children - untidy rooms and this sort of thing... It certainly didn't interfere with the professional things she had to do.

An enrolled nurse who had an enormous fund of practical experience to draw on was going to study for a degree in nursing. Her duties were very much more limited (than the registered nurses'), but her attention to patients' practical needs meant that $\mathrm{Mr}$ Snell positively welcomed this information about her career plans. It was validating evidence of his personal judgement about the nurse's expertise.

Both $\mathrm{Mr}$ Snell's expert nurses were very experienced and it showed. They had enough confidence to engage with both the health issue under consideration in such a way as to inspire confidence, and the human person in front of them in such a way as to evoke interest and reconnection with life outside the hospital. Similarly Mrs Mains who had elective knee surgery, was very interested in the personal doings of her primary nurse: She was just a little wee lady and I got quite a surprise to find out that she 
had a daughter who had gone on exchange to America. As with $\mathrm{Mr}$ Snell this interest had been preceded by a friendly space initiated by the whole nursing team and a demonstration of the meticulous competence of the particular nurse:

she never forgot a thing - not that I would have really, but she never forgot your medication, she always put ointment on my heels and my behind - she did everything a nurse should do - she was really good.

A key aspect of this personal sharing was the initial establishment of professional competence.

The type of nous or interpersonal judgement that enabled nurses to know whether personal sharing was appropriate or not was may be thought of as phenomenological 'tact' (Van Manen 1990). Mr Snell drew attention to the ability of all the nurses to initiate a friendly and relaxed social space. "Hi, I'm Mary and I'm looking after you today." That sort of thing - but they never presumed. Not presuming while also taking responsibility for the social relation, (at least initially) is a sophisticated skill which not all young nurses had. Both of the nurses who impressed $\mathrm{Mr}$ Snell were at least mid-life.

The importance of nurses on initial contact being responsible for acknowledging some aspect of the patient's reality was evident in Mrs Roy-Jenkins' story. Nurses who admitted her to the ward at night after a day, which began for her at $4 \mathrm{am}$, were aware of this and admiring of her stamina in the face of such an ordeal. She experienced this as care, a thoughtfulness which showed these nurses were oriented to her concerns even before they met her, and they communicated this to her. 
One nurse (not my particular nurse) inquired after Mrs Roy-Jenkins' readiness for bed. When she learned of the hot burning feet, she stood and massaged them for at least ten minutes. This relationship of trust which the nurse initiated was even more valued because it was not seen as an obligation on her part to care for this patient, rather as a generous gift of time from a member of a team which was pressed for time.

Mrs Roy-Jenkins felt one nurse knew who she was, through previous family contact, even before they met in the ward. This set up an expectation that this nurse would see who Mrs Roy-Jenkins was and this link to her family would enable the relationship to proceed smoothly. Family contacts were important to Mrs RoyJenkins, especially in times of crisis, but there is no hint in her story that she utilised this contact on this occasion. She felt this individual nurse was very nice. This relationship did not begin with the hospital experience, and was a minor way in which Mrs RoyJenkins was able to maintain her links with her family.

This same dynamic apparently operated in Lorna's appreciation of the admitting doctor. Previous knowledge - even if vicarious family knowledge - was a short cut to the initiation of a relationship of trust, and also enabled that relationship to survive some buffeting. Nurses who did not have a previous connection with Lorna were able to initiate a relationship by paying special attention to her requests. The current system of food delivery in the institution did not deliver crisp toast but even new nurses were able to win respect and trust by making up for these deficiencies not just once but repeatedly. Thus negotiating the hospital systems (in Lorna's case, the kitchen and the ward) was an integral part of establishing 
and maintaining an effective interpersonal relationship which included characteristics of trust and conveyance.

Mr. Snell's experiences in Recovery had similar features. The determined talk, which enabled him to endure a bout of painful tendonitis without his normal medication, was preceded by evidence of professional concern by way of monitoring his physical wellbeing, and accompanied by continual attempts to obtain more precise monitoring. Theatre nurses provided a lot of fun for MrsJenkins through relaxed mutual exchanges in an atmosphere of intense physical monitoring.

Nurses in some positions faced inherent challenges to initiating relationships of trust and confidence. These included night nurses and casual nurses. Young nurses also seem particularly vuinerable, although this may reflect individual new graduates' positions as pool nurses. One young nurse could neither work the equipment nor initiate help on her own behalf and the patient had to care for her.

It is now possible to see the essential elements in initiating an effective relationship with these older clients. Although these are listed below, the order is not an indication of priority. Rather they are these patients' concerns which may allow nurses in acute medical and surgical wards to consider a wider range of options when meeting older people for the first time. It was important to be imaginatively aware of the quality of experience patients had undergone before entering the ward, especially in terms of trauma, pain, fatigue, and somatic experiences such as thirst and cold. This is a privileged place which ward nurses have in regard to their patients: they (almost) never receive them without some prior 
knowledge from theatre, emergency room, outpatients, or the ambulance services. An enhanced sense of alertness to the patient's experience prior to the ward led to the patients feeling that the nurses were oriented to their needs even before they came to the ward. No patients spoke of a sense of a lack of physical or clinical preparedness on the part of the nurses, but some individual nurses were not socially prepared for the initial contact. Patients preferred nurses who came to the encounter ready and able to discuss the patient's priorities. Such an imaginative and aware orientation is perhaps easiest for nurses in areas where routine elective surgery occurs: there are more common and predictable elements to imagining the patient's experience before entering the ward. As Mrs Brown's story shows, it is also possible in areas of greatest uncertainty and least predictability, such as a medical patient with an uncertain diagnosis. These patients needed and valued such an awareness from nurses.

This awareness was not limited to a bare knowledge of symptomatology, but also encompassed seeking out, acknowledging such experiences, and acting promptly to meet such needs as were discovered. It was important, once the nurse was aware of the patient need, to act either to meet the patient need discovered (that is, for warmth, for quiet, for pain relief), or to explain to the patient why in this situation the most obvious way of meeting the need was undesirable. This latter was the case when Mr Snell met the Recovery nurse. He understood that it was important to exclude cardiac causes for his shoulder pain, and personal support through a period of intense pain was a necessary part of this endurance on his part. (Whether another clinician would view such a situation in the same way is open to conjecture. What is important from this study, which looked solely at the 
patients' view of their needs, is the necessity for nurses to meet the expectations raised by their initial alert awareness to and inquiry after the patient.)

It was important to take responsibility for the first approach to the patient. This was such a taken-for-granted aspect of the social relationship, that it was noticeable only by its absence. The routine practice of nurses 'touring' their patients and initiating contact, by introducing themselves was very helpful to these patients. At one level this seems to conform to standard social norms of polite behaviour: if people are in your territory it is your task to make them feel welcome. However, for some patients it assumed other symbolic functions as well. It enacted, and made explicit to the patient the prior orientation of the nurse towards the patients' needs discussed above.

Nurse initiated contact also facilitated specific assessments later on if physical monitoring revealed abnormal findings. Patients did not know totally what they could expect in the post-surgery period, and they needed to know which nurses were going to be acting on their behalf if things were not as expected. In Mr Snell's case these prior conventional social formalities indicated the process of concern that was continued in interpreting his elevated temperature. For Mrs Brown, the 'casual' nurse, who sought to cheer the old dears up by talking first about her own interesting life, was not really interested in being a nurse. So important is this aspect of the relationship, that the nurse who omitted it was almost not deserving of the identity of nurse.

That so many negative stories of interactions related to night nurses supports the credibility of such an element. Night nurses 
are not usually in a position to initiate friendly social space with their patients, and to approach these patients with conventional assessment or rehabilitation interventions without such prior relating requires greater interpersonal skill.

As indicated earlier (see p 49), the particular collective experience these patients revealed was no doubt influenced by using newspapers to recruit. The specific respondents were people with a story to tell. There were unresolved aspects of the hospital experience that they wanted a nurse to know, or, in Mrs Mains' case, there were particularly meritorious aspects to the experience which contrasted with a previous episode in hospital.

It was important to demonstrate meticulous concern for monitoring change in the patient's physical status in a range of domains. The recovery nurse with $\mathrm{Mr}$ Snell did not just assess domains relating to the reason for his surgery. One of Mrs Main's primary nurses, initially thought too inquisitive and a little brusque, was later seen to have Mrs Mains' interests at heart when a raw heel was discovered. The charge nurse also promptly sought reasons for Mrs Mains' faint in the shower.

Absence of expected change was another aspect to monitoring patient status in functional areas. There was no assessment of the change in practice for Miss Shepherd when the team insisted she look up when relearning to walk. It does not seem unreasonable speculation to wonder if the initial approach to helping her walk had included an assessment of her normal mode of walking (that is, knowledge of who she was in relation to walking - either from her GP or the patient herself), the effort which was directed in encouraging her 'independence' and conformity to the expected 
mobility outcome for such surgery, may have been able to be directed towards earlier detection of her particular difficulties which lay in areas other than her gait.

Finally it was important to provide practical help as asked for rather than negotiating it, especially on initial contact. Older people are diverse in their lifestories, and all these patients were very experienced at being patients. They had some prior experience of acute medical and surgical areas to begin making interpretations of their own. It would be difficult, if not impossible, for nurses to be fully cognisant of all such elements on initial contact. The priority need seemed for nurses to indicate a caring willingness to respond to patient requests rather than instruct the patient in the interests of an ideology of independence (which coincidentally was perceived as a self-interestedness on the part of the nurse.) This aspect of initiating relationships with patients was particularly surfaced in the stories concerning night nurses. Mrs Mains was cheerfully given a bedpan at night right up to the day of discharge with no apparent ill effects. 


\section{Walking through the relationship.}

Once a relationship was deemed to be professional, and the nurses' vigilance in monitoring patients' physical status as well as the technology was evident to these people, personal lifestories could be exchanged. This moved the relationship from one where the nurse was solely responsible to one of increasing mutuality.

In Lorna's case some of the nurses in the second ward were old friends of hers and clearly fulfilled an ongoing social role in her life now restricted by disability. She was comfortable enough to comment on the charge nurse's weight loss. Lorna received 'help' that was both practical in the everyday activities of toileting, rolling in bed and showering, and enabling of her wider social life in maintaining phone contact, organising events such as her birthday party. Lorna portrayed her time in the second hospital as more interesting than both her time in the first hospital and her time at home afterwards. She did not anticipate increasing her circle of social contacts and visits from her house were (at the time of the interview) virtually limited to health professionals of one kind or another. Thus health professionals who provided practical 'help' find it easy to initiate a relationship of trust with Lorna. She welcomed information about personal lives and shared freely from her own life, but not at the expense of the type of the practical assistance she needed. In this case the professional care required was not technical, rather it was practical help in the sense of surrogate self-care, and creating a social space where Lorna's gregarious nature could flourish.

It is notable that information about pain was absent throughout this aspect of Lorna's hospitalisation even although she still had an 
apparently undiagnosed fracture which she interpreted as the cause of extreme pain both in the first assessment ward and in the outpatient department after her discharge from the ward. It is interesting to speculate whether the environment the nurses provided was so intense in its meeting of Lorna's social needs that she ignored other physical needs, which became more obvious to her with greater opportunities for solitude. "Fun", and "familiarity," both valued aspects of the nursing relationship in Taylor's work (Taylor, 1994 p 190), characterised Lorna's relationship with nurses she regarded highly.

Sometimes the mediation of interpersonal issues was with other patients. For Mrs Mains, Miss Shepherd and Mr Snell, the way nurses related to other challenging patients in the environment was also important in maintaining their confidence and trust in nurses. It was of interest to them to see nurses relating to other clients with care and expertise. Even at night, when they would all have preferred to be alone, it was still reassuring to see the calm way (some) nurses positioned the snorers or calmed the confused or appeared with a bedpan and a smile. Some challenges to peace and quiet were expected in 'public' hospitals, and the sense that the nurses shared these challenges and neither added to them nor held themselves aloof from the life of the ward by staying in the office, was a sign of caring work.

Mrs Roy-Jenkins appealed to the nurses on more than one occasion for quiet from the next-door TV, and they required the offending patient to wear her earmuffs. It was more difficult to negotiate such an outcome when there were cultural issues involved. Mrs Roy-Jenkins felt the nurses shared her powerlessness: they (visitors to another patient) couldn't be controlled, of course. 
It is now possible to see elements in walking through the relationships with these older clients. As with initiating a relationship, the order of discussion of the elements is not an indication of their priority. Rather, at any given time any aspect of the "walk" assumed importance to the individual patient. It was important for nurses who had established a relationship of professional competence to exchange personal information. Nurses were initially responsible for the relationship, but later both patient and nurse took responsibility for maintaining the relationship. This means authentic personal sharing without making the patients responsible for the nurse's needs is an expectation. It is a continuation of the relaxed social space initiated by the nurses. No patients revealed an ongoing relationship of mutuality, although intermittent mutual sharing was valued.

It was important to maintain the previously existing identities of the patients. No patient anticipated nurses being able to capture all of the patient's expectations on initial meeting. However over time, they did expect nurses to respond to cues concerning who the patient was with respect and concern. A pre-existing knowledge of Lorna helped in maintaining her usual social activities which were essential to her gregarious nature.

Mrs Roy-Jenkins expected nurses to, at the very least, not challenge aspects of where she lived. Although she discussed freely in the interview her special needs as a person of dignity who had weathered severe challenges in life by calling on personal and family contacts with people of influence, it is not clear that she felt 
comfortable doing that, or indeed had any such opportunity to reveal more of her personal identity when in the ward.

Similarly Miss Shepherd's identity as a nurse was apparently unable to be acknowledged. She tried to keep quiet about her lifelong work and interest in nursing. Coleman (1995) points out the double disadvantage that nurses as patients have. On the one hand they are often avoided by nurses caring for them, since it is thought they 'know' all that is to happen to them, and do not need the friendly information that others receive. On the other hand, because they do have some knowledge of some aspects of their impending experience, their anxiety is heightened and so they have greater needs for support. At a more mundane level Miss Shepherd's name not being spelled correctly on two occasions was a sign that her visitors might have difficulty finding her, and also of a less than precise concern for accuracy.

One interesting aspect of walking through the relationship was the way nurses related to other patients with challenging or irritating behaviour in the shared rooms. In this situation these patients often had the same or less information about the others than the nurses did. All informants observed nurses relating to confused or frightened, or convalescent patients, often older people, and almost without exception were admiring of the patience and concern demonstrated. It was important to model a calm demeanor, and to take things slowly. Although all respondents could tell of times when nurses did not have time for them, descriptions of nurses' interactions with others were frequently admirable by the amount of time an individual nurse spent with others. The enrolled nurse could get physically impaired and afraid people out of bed on her own. The night nurses could relate with a 
confused and distressed patient in ways that were both practical and pleasant. Nurses could spend time with forgetful and complaining old ladies when they misplaced their money, acknowledging their concern, but giving practical common-sense advice as well. This independent and pragmatic approach to interpersonal relations was admirable when practised with others. When patients were observers they admired the ideology of individual patient care.

Finally it was important in walking through the relationship to advocate to 'bend' established rules and customs. Having inquired after patient need, and expended some effort to meet that need; having maintained expected monitoring roles and activities to demonstrate competence, and delivered prescribed interventions, the nurses who then also went outside custom and tradition were truly caring. Examples were the nurse who massaged Mrs RoyJenkins' hot tired feet even although not her particular nurse, and the night nurses who went outside to obtain soothing and tempting food for Mrs Brown at 2am.

\section{Practical help}

Many aspects of practical help related to activities of daily living, especially mobility and hygiene. So taken for granted was the nurse support in relation to showering and washing that it was only mentioned in its absence or when specifically sought by me in the interview. Practical help was important as one major way that nurses could initiate a relationship of trust with these patients. And clearly in many instances nurses did so. The water was the right temperature for washing, heated blankets were delivered after patients had been cooled by theatre or emergency procedures, 
meals were cheerfully brought, and bedpans were delivered with a smile. When absent, such practical help was particularly noticeable:

I'm thinking about in particular getting me out of bed and into a wheelchair, and looking after this operated leg and getting me down to the showers. I think she was the only one who realised how important it was to rub my back with the towel after a shower and so on. Although she didn't have the training and so on she had a great deal of nursing experience and I was delighted to hear she was going to train. And that made me think in some ways of the less pleasant aspects of being there: the showers, the toilets and so on -making smells...

Having his needs for practical help met, Mr Snell was able to turn his thoughts to what it must be like for nurses to be in this ward. This would seem to be a necessary pre-cursor for the 'mutual phase' of the nurse-patient relationship referred to above.

I have already referred to the place practical help had in the initial establishment of relationships with patients. If expected practical help was denied, it was difficult to ever put the relationship on a sure footing again, and indeed led to a hypervigilance around other nurses in the ward to see whether they too were going to deny help. This enhanced the feeling of vulnerability patients had at such time. Denying Mrs Roy-Jenkins access to an oxygen cylinder such as she had at home when showering meant that her preexisting frail respiratory status was given an extra challenge at the very time she was in an acute recovery phase from a fractured hip. 
At the same time it was to overlook her ongoing chronic health problem which loomed very large in her daily management of her life.

It was important that nurses provided practical help as it related to toileting, especially at night. The two patients on diuretics had particular difficulties in this area which clashed with the nurses' priorities for their recovery. Here the treatment for another preexisting chronic illness condition offers challenges of its own. Mrs Mains' night nurse could silently and smilingly meet all such challenges. Experienced nurses could navigate the waters of maintaining the previous competencies of the patient while enhancing the recovery process from the current physical challenge.

Practical help was one of the major expectations all patients had of nurses. Everyday concerns were definitely within the purview of the nursing team. When present such nursing acts were unremarkable. Their absence however led to a powerful feeling of abandonment: if nurses did not help, who could? Some patients were reliant on their families, or other patients, for some help, but these alone could not meet all the needs. Especially there was an expectation that nurses would provide the practical help necessary as a result of the specific disease process or medical diagnosis: lifting a leg, or moving equipment. Being a patient meant one needed help from others. The 'helping others' in acute wards were nurses. As a nurse I suspected in some of the instances of absent help there was a rehabilitation agenda on the part of the nurse. That is: the nurse was 'really helping' the patient get to independence and home faster than if all requests for help had been met. What then became important was the interpersonal 
dynamic and dialogue which mediated the refusal to the patient. As patients, some of these people thought the nurses' refusal to help stemmed from laziness, or ignorance.

Practical help was an important marker of care. Often it did not involve monitoring or physically challenging situations. The patients were well able to struggle on alone or with the help of others. When present it enhanced and established a relationship of trust. It was the soothing of the "narcissistic wound to the ego" which was due to the aging body (Woodward, 1991, p 62). The combination of illness and age made practical help the sine qua non of nursing.

Whether this is a cohort perspective on the professional practice of nurses as 'good women' rather than professionals, as expressed by Mrs Brown, or a failure of the nurses to communicate their understandings and expectations to the patients is unclear.

\section{Negotiating the systems}

An effective relationship of trust was enhanced by the nurses' ability to negotiate the hospital systems. Sometimes these negotiations were between shifts and nurse organisation in the same ward. At others it involved departments separated from each other geographically. Consultation may have been going on between the systems, but the patients could only make sense of their experiences by assuming it had not taken place. Concrete evidence that the nurses could bridge the gap in a practical way between different departments was required. 
All interviewees brought to the interview an assumption that there were problems in the 'system'. Mrs Brown described her understanding of the food delivery system:

the food that the local hospital was...well, it wasn't the hospital that was doing it - you see they got rid of their cooks and chefs and everything else - and kitchen maids. Put the food out to contractors. Naturally the people who were running it were half they were (the managers were) half in Singapore and half in this city, so who was doing it here, god only knows.... Maybe it's a kill or cure!

Mrs Brown thought the food was not appetising for ill people, but it was within her expectations for a "public" hospital. She was most appreciative of the night nurses' ability to elicit food for her during the night after gastric tests especially as she recognised that it was not a simple matter of ringing the kitchen.

Mrs Mains had attributed her previous unpleasant experience to the systems set in place by the Charge Nurse. The systems in this hospitalisation, however, met her needs. They were initiated and maintained by the Charge Nurse, but enacted by the staff nurses. They could even withstand a civil defence emergency because the system of primary nursing delivered a means for Mrs Mains to become familiar with her nurses and to have confidence that monitoring of her physical status was proceeding with her comfort and safety in the nurse's mind. When there were few nurses to help the nurse in the shower (which Mrs Mains attributed to the lack of adequate funding), the system in this ward still delivered safety and instilled confidence. The humanising of the routine (the nurses all wore Christmas earrings) mean the system was 
unobtrusive except on reflection as to how well everything had gone.

Mrs Brown experienced the uncertainty of having no medical diagnosis, along with frightening episodes of vomiting blood. The nurses from intensive care (whom she had no recollection of) came to the ward to see how she was getting on. In this instance the concern for the patient was continued after the actual requirement of the hospital, but was evidence to Mrs Brown that these nurses had her interest at heart, and were not merely doing a job for pay: [nursing is] not a case of being a career or a trade, it's because you are interested in people. The previous tests and the lack of information from the nurses in out-patient department which had led to such a disaster with diarrhoea, and the coldness she felt in the emergency room, all heightened her vigilance in monitoring the ward team's ability to care for her when she was past caring. The notion that the nurses could meet the challenges offered by less than adequate 'public' system led to a shared sense of endurance.

These patients were well informed as to the different systems of delivering nursing care within a ward. Staff nurses, charge nurses, and enrolled nurses, casual and primary nurses, polytechnic training, and nurses doing degrees: all these were issues which these patients incorporated into their interpretations of their care. Systems of training, employing and deploying nurses variously impacted upon the shape of care. The 'ideal' nurse was very experienced, almost certainly mid-life, with a store of practical tips and able to administer the different technologies, assess and intervene in a range of physical modalities, and communicate across departments and disciplines, while maintaining the humanness of the patient centre-stage in the relationship. 
The ideal ward was one where relations between levels of nurses was relaxed and friendly because this flowed over to the patients. The charge nurse was clinically competent and medically knowledgeable, and could personally give care calmly in a crisis as well as support the less experienced nurses. Some system of assessing the comfort of particular patient nurse dyads was necessary for the therapeutic outcomes of confident recovery and even pleasurable relief of the symptoms which initiated the contact in an organisation which promises both 'health' and 'care.'

The ideal hospital was one where primary nurses were accountable and with authority to put things right when equipment didn't arrive, when appointments were indeterminate, when information was lacking and aftercare did not materialise. The systems in the hospital supported the nurses' ability to connect with human person that was the patient and to look fully on their need and respond.

In summary care for these patients involved an intertwining of four key essentials: nurses taking responsibility for initiating the relationship by knowing who the patient was in terms of identity and in terms of preferred activities, for expressing and demonstrating meticulous concern in the timing and delivery to the patient of treatments and monitoring, practical help and knowledge, and negotiating the systems both within the ward and across other hospital departments. This is what these six older people would have liked to receive from nurses. In the next section I turn to the nursing response, considering the picture of care exemplified here. If we think hermeneutically, what is the message for nursing practice in these essentials of care. 


\section{Commentary}

It is Watson's contention that the "evolutionary edge in the health care system" can be depicted in the expressive elements of caring in nursing. (Watson 1987 p10). She offers a number of metaphors as pictures to explore elements in the tacit knowledge of caring. It is clear from the foregoing analysis of the stories of care and non-care that a simplistic (or even complex) checklist of 'dos and don'ts' for nurses in acute wards will never capture all the needs of older patients. Some patients need to be alone during the day, others hate it. Some patients enjoy knowledge and information, others prefer to leave such things to the professionals, preferring instead to look for the signs that such professionals are indeed knowledgeable on "their" territory, the ward. As nurses we can only look with differing perspectives in the glass. The patients hold the mirrors up to us and we, if alert, capture a glimpse here, and a gleam there of the path we must take. We cannot hold all the pieces, but we can see a way. As Watson points out "it is in poetic language that lasting transmissions of enduring truths and meanings can be found, while technical scientific terms constantly change with scientific discoveries."

The first image Watson suggests is "holding up the broken end of the arc of the medical industrial complex." (Watson 1987 p 11) This is not a stubborn resistance to progress and technology, but rather an acknowledgment that all is not well in the acute hospital, and a call to strenuous effort to repeople the 'dark Satanic mills' with joy and colour, as of the arc of the rainbow. The rainbow is symbolic to many peoples: the pot of gold, the lifting of a curse, the mingling of tears and laughter. It is a gift which appears, but also 
in Watson's metaphor it is a charge which requires serious work and effort by nurses to be sustained.

Watson's second metaphor gives a clue as to where the serious work might have to be expended. The left hand and the right hand need to join forces. Watson identifies the left hand with the traditional concerns of nurses and women: meaning, and the private, the person, the particular, the intimate. Although she identifies the right hand with the public, factist, impersonal, rational practice of medicine which is rooted in (among other things) "the diagnosis of disembodied disease," (Watson 1987 p 12), I take the metaphor of the left hand and the right hand to be a challenge to join hands with all who care for the patient. To the patients in the stories here the kitchen was just as important as the operating theatre in bringing life, ease, and a sign that the body was again enjoying pleasure. The serious work of extending nursing's venture outside the walls of the ward, and the safe boundaries of our own discipline means to talk the language of the others: to speak of patients with the physiotherapist, to speak of medicine with the patients, to speak of social work with the manager, to speak of home with the homecare workers.

This appears onerous a multi-faceted impossible task, but one more metaphor from Watson holds it all in a single image. A single nurse can encompass such an exacting task if it is seen as "a silver bridge" (Watson 1987 p 16). The silver bridge is transforming and can span a flood of all the torrents rushing through the ward daily. Having opened our eyes to the responsibility, we see the curse of consciousness, having seen the achievement of the bridge safely across the flood and the patient safely home, we see the blessing of consciousness. "Nurses grasp that the whole caring 
consciousness of the nurse can be in each caring instant; caring consciousness can transcend time and space and physicality. The silver bridge is the link between humanity and technology." (Watson 1987 p 16)

Indeed even those nurses-bridges who were not yet silver or whose were tarnished, still were bridges. The rushing torrents threatened and some bridges at times seemed about to collapse, but all safely broached the mediated (and therefore meaningladen) experience to arrive, not back where they had been, but for all the older patients in a new and unexplored place.

Each of the older clients wanted to tell a new perspective on themselves at the end of their acute ward stay. For some it was an awareness of loss and disability, for others it was to resist the physical decline, for yet another a restoration of good fortune. In the geography of the new territory nurses who cared both acted as guides, carried some of the equipment, and furnished the maps along the way.

Dreyfus links such new perspectives on the part of the patients to the caring work of nurses.

Caring, in the context of illness, consists in keeping open possibilities that can be saved in the world of the sick person, while aiding the person in letting go of possibilities that are no longer realistic... human being is a unique way of being in that human experience and actions follow from selfinterpretations. 
If this is so (and it has been an assumption of this whole inquiry project that it is so), these stories show that "care is a way of being which must be understood, preserved and enhanced... by nursing as a caring practice." (In Benner 1994 p ix) Living in the wards cannot be theorised, but may be understood. Similarly, the nursing work of care can be explicated, captured and chosen or rejected through the consideration of Watson's metaphors.

In this chapter I have looked in the patient/mirrors, shining the spotlight on the essential common features of care for older people in acute wards. In the next the focus moves from possibilities for individual patients to the possibilities for nursing practice generally, and further possibilities for nursing research. 


\section{Chapter 14 Concluding Comments}

This project has sought some answers to the question, "what is it like for people over 75 years to receive nursing care in medical and surgical wards?" In Chapters 12 and 13 one answer was given in relation to the response of nurses to their need. When older people did not receive care there was a quality of absent care which was understood as:

Failing to acknowledge who the patient was,

Reifying technology,

Failing to provide practical help when asked,

Failing to communicate between departments.

In Chapter 13 a different answer was given. When care was experienced, nurses:

Mediated interpersonal relationships, both taking responsibility for initiating the relationship and finding out 'who the patient was,' and engaging in mutual maintenance of the relationship,

Provided practical help as asked, rather than negotiating it,

Negotiated the hospital systems, both within the ward and across departments.

Each of these essentials of the 'cared for' experience was derived from re-thinking the stories of six older people who had been in acute wards within four months of speaking with me. Each individual story was seen in successive stages of the story-as-itwas-told, then portrayed as a portrait, and finally in relation to the four existentials. The essential themes in Chapters 11 and 12 emerged from a process of re-thinking their stories in relation to the four existentials of lived human relations, lived space, lived time and lived body. These four were aspects of the terrain of the 'lifeworld' 
which included the patient's orientation towards and their experience of the world, as well as nurses in a particular historical context.

If re-thinking provides categories and themes such as the above, this may have descriptive value, but beyond the inherent interest in such a description, have limited value for the practice of nursing. Re-flecting on both the individuals' stories and the aggregated pictures of care and non-care moved the project to a new level of analysis, to one of myth and metaphor. Here the 'poetizing' practice of bringing the world closer into view through the artistic, communal languages which unite us as humans with the ground of our being was engaged in through a process of writing and rewriting. The analogy of the myth of Perseus and Medusa, and Watson's metaphors of the broken arc, the joining of the left hand and the right hand, and the silver bridge are offered at the end of Chapters 12 and 13 as a means of considering the picture in ways beyond the conceptual. Here I moved between the particulars of the aggregated picture of care/non-care to the universal human need for care we all share and express through story, myth and metaphor.

Over all the poetizing activity was the metaphor of re-flection. The patients were regarded as mirrors reflecting light on the differing practices of nurses within the current health care system. Each story held up a new mirror. I, as the hearer of the story and the viewer of the image, looked into the mirror as a nurse, drawing attention to certain features in the portrait of care. I, in turn, reflected on the image, and then re-reflected the picture of care through the activity of writing and engaging in dialogue with others and the literature about the items in the pictures.

Re-cognising the need for care of these older people also evoked a consideration of new ways of learning to know nursing. This 
project utilised Van Manen's hermeneutic phenomenology. I have discussed above the new way of conceptualising reflection as a metaphor for knowledge which resulted from Van Manen's methodology. The particulars of such a hermeneutic phenomenologic method of inquiry have been rich and inherently rewarding in themselves. The process of re-cognising continues in the next section where I consider aspects of the method and the phenomenological underpinnings. This section considers the limitations of the study, and is followed by the implications for nursing of the answers to the question, what are the needs for nursing care for people over 74 years in acute medical and surgical wards?

\section{Limitations}

Limitations may be seen as the boundaries and legitimate sphere(s) of utilising the discoveries of the project. Acknowledgement here hopefully will enable the reader to assess the implications which follow in the next section.

First there are limitations inherent in the particular phenomenological method used. Hermeneutic phenomenology makes no claim to generaliseability. Rather the stories and analysis stand alone inviting the reader to re-cognise the human and universal elements which can be shared in such a context.

As reported in Chapter 3 this investigation was informed by other disciplines that influence nursing thinking such as sociology and developmental psychology. It included some consideration of literary themes and popular literature. The main data source, however, were stories from interviews with older people who had recently been patients. As such it was some pictures of the 'cared for' experience. Their stories were framed by current understandings and expectations they held regarding their 
recovery, and how easy or difficult their recovery had been. A strength of this approach is the availability of such information to a practitioner. The project thus has a strong clinical orientation, although some may want to critique its methodological purity as it adopted an eclectic interpretive approach. It seems to me that clinical practice necessarily values such an eclectic approach, since the lifeworld of acute wards contains all the values, understandings and perspectives on care, illness, and age that are present in the community generally.

An obvious limitation of such an approach is the limitation to one interview with one follow-up opportunity to comment from participants. It was necessary for practical reasons to limit the ongoing nature of the interpretations to conclude the thesis. There was a summary given at the end of each interview where I indicated some key understandings I had made from their story, and the participants were invited to agree or refute such a summary. In this respect I consider that the process of arriving at such a summary was very similar to that available to a nurse following up a patient shortly after discharge. Thus the process I used was accessible to other nurses, and has a strong clinical applicability.

Hicks (1996) claims that there is dissonance between the qualities of a good nurse and a good researcher. There is a need for integration of the conflicting constructs attached to each role before nursing can claim to be a research-based practice (and a corollary, although Hicks does not draw the parallel, is that such integration is necessary before research can claim to be a nursing-situated practice.) Van Manen's approach to researching lived experience with its emphasis on care-fulness in hearing voice, intuiting, and phenomenological reflection seems very close to practice activities. 
Where the claim to practice familiarity breaks down is in the writing and re-writing of Van Manen's approach. Practitioners, even the most highly reflective, do not usually engage in such sustained periods of reflection. For one thing, they relate to many more patients over the course of a week's work than this project has done. In particular, night nurses meet and deal with patients in contexts far different from the context of this research. Thus to consider knowledge derived in one context (the patient's home) as relating to information about another context (an acute ward at night), challenges the project's claim to consistency of 'fit' between practice and research, and deserves further exploration.

Some may criticise the practice of data interpretation by a sole researcher. However there are problems with any method of data analysis and interpretation. In this project a number of measures were taken to support authenticity of the analytic process. Cheryle, as thesis supervisor, provided "collaborative discussions" (Van Manen $1990 \mathrm{p} 100)$ at every stage of the project. Aspects of the thesis were presented to students and colleagues at Whitireia Community Polytechnic School of Nursing, as well as an international research conference and their comments and critiques incorporated into the writing. If one accepts that "writing is the method" [of phenomenology] (Van Manen 1990 p 124), then it follows that it is the writer's task to bring to speech the elements in the phenomenon of concern through "re-thinking, re-flecting, recognising" (Van Manen 1990 p131). It is possible to engage in such activities in a group or by revisiting individual participants, but, again, this is not usually a method available to the individual practitioner. Thus the sole researcher echoes the sole practitioner, and aids in maintaining the research orientation. 
Van Manen (1990 p31) points out that lived experience is researched by

A real person, who in the context of particular individual, social, and historical life circumstances, sets out to make sense of a certain aspect of human existence...A phenomenological description is always one interpretation..

Ultimately the judgement as to undue idiosyncracy on the researcher's part is for the reader to make.

\section{Implications of the project: practice}

This project has implications for practice, and for further research. The implications for practice of nursing care are firstly personal. For part of the period I was enrolled in this thesis I was practising as a clinical nurse specialist in an Assessment ward for people over 65 years.

An immediate implication of such a phenomenological approach to research was the influence it had on my practice. For instance, I was much more aware of the many ways care is experienced by patients, and this made me more thoughtfully attuned to the multiple options open to them, and some of the points where the health care 'system' could break down. I was definitely more concerned for the needs of relatives than previously.

As a specialist my daily work included writing organisational protocols, clinical pathways, and other assessment documentation. I was acutely aware of my role as a risk manager and the legitimate requirements for such documentation. Each successive form was helpful in a limited way in assessing some aspect of patient and 
organisational need, but none put the patient understanding in the foreground of the nursing relationship. I began to see how using the four existentials in a tactful and reflective manner was a safe and effective way to maintain a patient-oriented stance in the current health care system with its increased demands for accountability and documentation from a profession only recently aware of its cognitive and epistemological responsibilities.

For instance, if I was showering a patient, I was not only attending to their hygiene and assessing their self care abilities, and readiness for discharge, I was also asking myself how this patient

was experiencing 'tnèr' boay at this time. Some questions I asked (sometimes silently) were:

Is the shower too hot, too cold, the chair uncomfortable? Has their pain or toilet needs been attended to? Is my gaze on the older body one of care, or fear for my own aging? Is the space in the shower sufficiently private, both visually and aurally, too small for maintaining comfortable human relations, or physically challenging? What are the ways-of-being this patient brings to the social and human encounter, both in terms of preferred activities and the sense of personal self. Is their selfconcept one of humility and a dislike of being centrestage with too much fuss, or are they privileged and expectant of special care? What are the "memories that leave their traces" (Van Manen 1990 p 104) which are present to the encounter? What future options and fears are open to them right now?

Thinking as a nurse of the four existentials: lived space, lived time, lived corporeality, and lived human relations, enabled me to monitor patient need in a way which did not add another form to the pile nor hindered in any way other documentary and therapeutic 
requirements of care. I developed a renewed appreciation for the role of the nurse in enhancing or diminishing a patient experience. By thoughtfully attending to the four existentials, an effective beginning assessment and analysis of patient need in any given situation is possible.

Second, this project has implications for practice generally. When regarded from the lived experience of acute illness, the older patients' interpretations of the illness and close human relationships are seen as a central obligation for nurses to attend to. Overlooking this central focus causes a further wound to acutely ill patients which they carry to subsequent life experiences and especially to subsequent experiences of acute illness and nursing.

Nurses also need a thoughtful and aware knowledge of older patients so they can develop a quality of understanding of the patient situation and meanings of illness.

Nursing practice which eschews the hubris of certainty for older patients, whose lived experience of the world and meaning of illness is different from those of the nurses, would involve a secondary place for care management plans, performance indicators, productivity maximisation, and technology risk management. This is not to denigrate any of these perspectives in the practising nurse's repertoire. I would however, based on the elements in the patient experience uncovered in this project, move them to a secondary place in the practice of care.

Third the project has implications for nursing as a discipline. There is a moral core to the response to patient need. That core structure is revealed by the experiences of the six patients reported here, and the demands they make on the nurse-patient relationship. "Nursing ... is a caring practice whose science is guided by the 
moral art and ethics of care and responsibility." (Benner and Wrubel 1989 p xi) Nursing is a discipline where skilful moral and human agency is required of its practitioners in both technical and social senses. Competence in the clinical relationship and concern for the patient's experience of illness and the ward context was expected of nurses. Barriers to such practice by nurses could be explored by action research methods.

When care, as exemplified in Chapters Eleven and Twelve, is at the core of the nursing relationship, we are forced to reconsider not only practice, but also nursing education and administration of systems. There is an obligation to confront the barriers in the person and work of the individual nurse and nursing groups as well as the barriers in the health care delivery system. In the next section $\mid$ consider the implications of the project for nursing education.

\section{Implications of the project: nursing education}

Nursing education involves teaching content, process and assessments. The conversationalists in this project attributed very few nursing actions to ageist attitudes. Education which enhances increased awareness of the needs of older patients would not involve guilt-evoking sessions about ageism. However education which gave access to some aspects of the lived histories of older people may enhance students' conversational repertoires with older adults.

Students are often exhorted to look up medical texts when new patients arrive. It is a much rarer educational event when they are referred to some historical text to increase their understanding of the life events of particular people. For instance, in this project, it may be that some common ground with Miss Shepherd, gained through reading the professional journals of the time of her practice 
experience would have enhanced a relationship which was not enhanced by a knowledge of technology, rehabilitation strategies and repeated offerings of pharmacological interventions.

On the other hand, Miss Shepherd was very aware of the inherent ambiguities in her "patienthood" (to use Coleman's term). The teaching and learning of judgement is called for in the nurse in such a situation of patient need. Such judgement would seem to be innately hindered in an educational approach which relied on the knowledge of disciplines such as sociology and human development as they were reviewed in Chapter Two.

It is sometimes claimed that the humanities increase selfawareness and enhance perceptiveness of others' needs (Darbyshire 1994). Other helpful educational approaches would include individual case teaching where the patient (and family) experience is valued as highly as the knowledge of the disease and the interventions. Assessments would value the patients' perceptions of the student practice as highly as the nurse's or the educator's.

\section{Implications for nursing systems}

Nursing systems which enable individual patients to have their needs met at both professional and clinical levels, on the evidence of this project, involve consideration of the induction needs of new nurses and of casual nurses. Familiarity with equipment and common sequelae of surgery, or better backup in the form of clinically experienced nurses would seem to enhance patient confidence in nursing that was truly caring.

Apart from Mrs Mains' story, effective continuity of care was unknown to these patients, and deserves further study. On the one 
hand, when the relationship with the primary nurse worked well, it was empowering. When it was not so comfortable, the relationship contributed to the patient feeling captive to a pervasive association of mistrust. Charge nurse review of primary nurse 'fit' with particular patients would seem to be a useful future direction.

Clinical leadership was often inferred rather than seen in action by these patients, and further research to determine a form of clinical leadership which has resonance with older people, and which met their expectations is indicated.

Continuity of care in the sense of better handover of care between nurses on different shifts, and between different departments and disciplines would also be enhanced by an exploration of different models in relation to patient expectation, need, and outcome.

Some patients were interested in seeing the continuity of care. Others wanted to be re-assured that all was being taken care of somewhere else. New ways of determining patient need in just how much of the system communication nurses should make overt to particular patients would be useful.

This project has been shown to have implications for nursing practice, both personal and general, and for nursing education and systems. As a research project it also has implications for the development of knowledge as well. The nest section considers methodological implications, and suggestions for further research.

\section{Implications of the project: nursing research}

The implications of the project in terms of research are twofold. First I shall consider recommendations for further research arising out of this project, and second a specific consideration of the method and methodology utilised in this project. 
This project offers a simple yet comprehensive way of assessing patient need whatever the contextual biomedical and managerial documentary requirements. Further research to explore the value of the four existentials in establishing patient need more effectively is indicated. Such research needs to explore the nurse perspective on such an approach as well as patient satisfaction with such an approach. There is need too for particular exploration with patients from more diverse cultural backgrounds.

This project explored patient need from the patient's perspective with the response of one non-caregiving nurse. A multidisciplinary approach (including that of the patient) to researching particular patient experiences may make overt multiple perspectives on the same happenings.

In view of the strong response the research project evoked from patients' relatives, it would seem there is a need to replicate it with patients' relatives.

Finally this study has implications for quality improvement initiatives in relation to patient satisfaction. The present study offers a possible model for phenomenological research into other lived experiences in health and illness. It is of practical concern to nurses to know, not only how much the patients do (or do not) value their care, but also how to re-present care to older people. Quantitative data obtained in patient satisfaction surveys only incidentally gives any indication about what nurses can do about the issues raised. For instance, Hudson and Sexton (page 25, above) show that nurses and patients can agree numerically about the place of pain management in a hierarchy of priorities. This study shows that even when such agreement is present there may not be a common understanding as to the content and process of the negotiation of care. 
The notion of the lebenswelt may be useful to explore in other contexts where patients share common lives for a period of time, such as extended care facilities.

Nursing in acute wards involves being with patients who have some need for care. Phenomenological research offers the possibility of responding to the unexpected and perhaps the unwelcomed, aims at understanding in context, and promises insights into the everyday and taken-for-granted. Van Manen's claim is that phenomenological research "begins in the lifeworld" (Van Manen 1990 p 7). This study shows it can also be responsive to patient issues and clinical need. There is a growing body of evidence from nursing research reviewed in Chapter 2 that such research perspectives are also open to multiple contexts where patient vulnerability is an issue.

When this thesis was almost finished I was given Gersie and King's (1990) work on storymaking. Their observation that "stories are where reason does not go" (Gersie and King 1990) has implications for the practice and evaluation of nursing which current methods of conceptualising and evaluating the worth of nursing have only just begun to explore.

Their claim is that healing involves improving access to creativity. The stories offered by participants in this project did not explore creative modalities, but only hinted at the meta-stories revealed by such modalities through metaphors and the dialogic space with the listening interviewer. When the (nursing) performance becomes ritual, patient ability to receive 'help' is compromised, the nursing 'care' is tarnished, and the patient left alone with disease, pain and suffering. The re-telling of the illness story re-flects the practice of nursing, and also re-acquaints the teller with the place of the story in their own life story. One implication of such a research 
methodology is that a similar approach in future might involve more therapeutic and creative modalities

Second there is consideration of the specific methodology of hermeneutic phenomenology as described by Van Manen. Some of the implications of the methodology have been considered in the section on limitations. At this point I reiterate the theme developed earlier, that the research practice of hermeneutic phenomenology is very close to the nature of nursing practice in a ward context. It allows further refinement of data such as that of Hudson and Sexton (see p 25), and it provokes consideration of new aspects of the care these older patients needed.

In terms of the specific research events described in Chapter 3, several of the plans proved unworkable. The time frame of interviewing patients within two months of discharge proved too short for these patients. Two patients were four months after discharge by the time they spoke with me, and this was a reflection on the slow progress they made after the surgery.

At times it was difficult for me not to be depressed with hearing about less-than-adequate care, and I wondered if I wanted to be associated with a profession which engaged in such practice. At other times I was amazed at the generosity of interpretation of the older clients. Without any sense of forgiveness for wrongdoing, they considered all the multiple variables, and especially the changing face of health 'reforms' pressing on nurses.

In the section on ethics I had planned to act if the telling of less than adequate care seemed to be a distressing event for the clients. I had no such plan when such stories depressed me! In the event the telling and re-telling of the stories to colleagues and through this thesis has led to some resolution. It does raise the point as to how a caring profession cares for itself. 


\section{Conclusion}

This study set out to explore the question, "what is it like for people over 75 years to receive nursing care in medical and surgical wards?"

Through individual interviews with older people recently discharged from such wards, common essential themes were uncovered which were simultaneously illustrated and distilled in myth and metaphor. Thus the patient stories were gathered up into larger universal stories.

Initially hermeneutic phenomenology offered a possibility of approaching being old and a patient in an acute care ward from a different perspective. That is, it did not seem to have been done before! However the discipline of maintaining both an oriented stance toward the phenomenon of concern and flexibility toward new and unknown perspectives has proved increasingly captivating. The opportunity to value both the old and the new seems logically to be of crucial importance when older people are patients in the current medical industrial complex which seems as pervasive in New Zealand as the United States.

Attentive listening to patient stories for indications of phenomenological essentials has the potential to enhance patient care as well as the dialogic space between clinician and researcher, and between writer and reader. Throughout the project I have attempted to give a pre-eminent place to the voices of the older patients who spoke with me. The chapters 5-11 are the central orienting stories, which grounded the lived world of the thesis and the nursing response in chapters 12-13. Re- 
considering, re-flecting, and re-writing is the researcher's task and this is reflected in chapters $12-14$.

As a nurse, and as a researcher I am grateful to Mrs Roy-Jenkins, Mr Snell, Miss Shepherd, Mrs Brown, Lorna O'Fee and Mrs Mains for sharing their stories with me. I hope the experience was a rewarding one for them also.

Their legacy to me as a nurse is to re-affirm the importance of the human relationship in the clinical work of acute wards, and to challenge future practice as to the interface of the complex systems in a modern hospital. Researching lived experience as explicated by Van Manen has been central throughout this journey. The phenomenological imperative of returning $z u$ den sachen, to eidetic reduction and to an exploration of the lebenswelt does not involve the practitioner in epistemologies, which compete and even conflict with those of the researcher.

Van Manen's exposition of the four existentials has informed the understanding and lived experience of nursing care for older adults in this study. Both the context of the ward, and other hospital departments and disciplines, and the contexts of the older person's life need to be taken account of for depth of understanding to emerge. Nursing care is revealed as a complex and highly sophisticated human activity. The moral commitment required to 'hold up the arc' is revealed as an invitation to the profession, not to try harder, but to engage more with the revealed perspective of the patient.

It is not surprising if the novice practitioners or the marginalised (such as night nurses) sometimes do not meet all expectations of negotiating the systems, mediating interpersonal issues, precise technological and physical monitoring, and practical help and knowledge. What is hopeful is that there are the traditions of 
hermeneutic phenomenological inquiry which offers the possibility of nurses using their practice knowledge in the service of research in the discipline. 


\section{References}

Ayres, L., \& Poirier, S. (1996). Virtual text and the growth of meaning in qualitative analysis. Research in Nursing \& Health. 19, 163-169

Atkins, S. \& Murphy, K. (1993). Reflection: a review of the literature. Journal of Advanced Nursing. 18, 1188-1192

Bartjes, A. (1991). Phenomenology in clinical practice, Chapter 12 In G. Gray, \& R. Pratt (Eds.), Towards a discipline of nursing. Singapore: Churchill Livingstone

Beare, P.G. \& Myers, J.L. (Eds). (1990). Principles and practice of adult health nursing. St Louis: Mosby

Benner, P. (1985). Quality of life: A phenomenological perspective. Advances in Nursing Science 8 (1), 114

Benner, P., Chesla, C., \& Tanner, C.A. (1996). Expertise in nursing practice: Caring, clinical judgement, and ethics. New York: Springer 
Benner, P. \& Wrubel, J. (1989). The primacy of caring: Stress and coping in health and illness. Menlo Park, California: Addison Wesley

Biggs, S. (1993). Understanding ageing: Images, attitudes and professional practice. Bristol, Buckingham: Bristol, PA, USA: Open University Press

Bishop, V. (1994). Clinical supervision for an accountable profession. Nursing Times. 90 (39), 35-37

Bishop, A.H., \& Scudder, J.R. (1990). Nursing: The practice of caring. New York: National League for Nursing.

Brand, P., \& Yancey, P. (1993). Pain: The gift nobody wants. London: Marshall Pickering

Brown, L. (1986). The experience of care: patient perspectives. Topics in Clinical Nursing. 8 (2), 56-62

Bytheway, W.R. (1989). Becoming and being old: Sociological approaches to later life. London: Sage 
Cameron, B.L. (1993). The nature of comfort to hospitalised medical surgical patients. Journal of Advanced Nursing. 18, 424- 436 .

Cleeland, C.B. (1984). The impact of pain on the patient with cancer. Cancer. 54, 2635- 2641

Cohen, M.Z. (1987). A historical overview of the phenomenologic movement. Image: Journal of Nursing Scholarship. 19 (1), $31-34$

Coleman, N. L. (1992). On the other side: nurses as patients. In D.E. Gaut (Ed.), The presence of caring in nursing. New York: National League for Nursing.

Crotty, M. (1996). Phenomenology and nursing research. Melbourne: Churchill Livingstone

Cousins, N. (1979). Anatomy of an illness as perceived by the patient. New York: W.W. Norton and Company

Darbyshire, P. (1993). Preserving nurse caring in a destitute time. Journal of Advanced Nursing. 18 (4), 507- 508 
Darbyshire, P. (1994). Understanding caring through arts and humanities: a medical/nursing humanities approach to promoting alternative experiences of thinking and learning. Journal of Advanced Nursing. 19, 856- 863

Donnelly, G.F. (1997). Editorial. Holistic Nursing Practice. 11 $(4), v$

Duffy, J. R. (1992). The impact of nurse caring on patient outcomes. In D.E. Gaut (Ed.), The presence of caring in nursing. New York: National League for Nursing

Erikson, E.H. (1982). The life cycle completed. New York: W.W. Norton

Fox, N. (1989) Landmarks: Poems 1937-1987. Auckland: Puriri Press

Gersie, A., \& King, N. (1990) Storymaking. London: Jessica Kingsley

Gilling,A., \& Gilling, M. (1997). Older people in New Zealand: An annotated bibliography of research on older people in New Zealand.1986 -1996. Wellington: Age Concern 
Greenwood, J. \& King, M. (1995). Nursing orthopaedic patients:

'profoundly absorbing' work? In G. Gray \& R. Pratt (Eds).

$\underline{\text { Issues in Australian nursing 5: the nurse as clinician. }}$

Melbourne: Churchill Livingstone

Hammond, M., Howarth, J., \& Keat R. (1991). Understanding phenomenology. Oxford: Basil Blackwell.

Heidegger, M. (1962). Being and time. (J. Macquarrie \& E.

Robinson, Trans.). New York: Harper and Row. (original work published 1927)

Hicks, C. (1996). Nurse researcher: a study of a contradiction in terms? Journal of Advanced Nursing. 2 4, 357- 363

Holmes, C. (1993). The politics of phenomenological research in nursing. .In Nursing Research: Scholarship for Practice. Geelong, Victoria: Deakin University Press

Hudson, K.A. \& Sexton, D.L. (1996). Perceptions about nursing care: Comparing elders' and nurses' priorities. Journal of Gerontological. Nursing. 22 (12), 41- 46. 
Keats, D. (1988) Skilled interviewing. Hawthorn, Vic toria: Australian Council for Educational Research

Kleinman, A. (1988). The illness narratives: Suffering, healing and the human condition. Basic Books

Le Sueur, M. (1986). In J. Alexander, D. Berrow, L. Domitrovich, M. Donnelly, \& C. Mclean, (Eds). Women and aging: An anthology by women. Corvallis, Oregon: Calyx Inc

Lindholm,I., \& Eriksson, K. (1993). To understand and alleviate suffering in a caring culture. Journal of Advanced Nursing. 18, 1354-1361

McKee, P. (1987). The art of aging: A celebration of old age in western culture. New York: Greenwood Press

Maloney, S. (1993). The lived experience of loneliness in older women in residential aged care. In Nursing Research: Scholarship for Practice. Geelong, Victoria: Deakin University Press 
Mayer, D. K. (1986). Cancer patients' and families' perceptions of nurse caring behaviours. Topics in Clinical Nursing. 8 (2), 63- 69

Meleis, A. (1985). Theoretical nursing: Development and progress. Philadelphia: Lippincott

Minichiello, V. (1990). Indepth interviewing: Researching people. Sth melbourne:Longman Cheshire.

Miller, B.K., Haber, J., \& Byrne, M.W. (1992). In D.E. Gaut (Ed.), The presence of caring in nursing. New York: National League for Nursing

Ministry of Health. (1995). Mortality and morbidity data 1993. New Zealand Health Information Service: Wellington: Ministry of Health

Ministry of Health. (1997). Public hospital and selected morbidity data 1995. New Zealand Health Information Service: Wellington: Ministry of Health 
Morse, J. M. \& Johnson, J.L. (1991). Toward a theory of illness:

The illness constellation model. In J.M. Morse, \& J.L.

Johnson (Eds.), The illness experience. (p 315- 342).

Newbury Park, Ca: Sage

Munhall, P.L. (1994). Revisioning phenomenology: Nursing and

health science research. New York: National League for Nursing

Nelms, T.P. (1996) Living a caring presence in nursing: A Heideggerian hermeneutical analysis. Journal of Advanced Nursing. 24, 368- 374

Oriando, I. (1991). The Dynamic Nurse-Patient Relationship. New York: National League for Nursing

Perimutter, M., \& Hall, E. (1992). Adult development and ageing. $2^{\text {nd }}$ ed. New York: John Wiley and Sons

Peterson, C. (1996). Looking forward through the lifespan: Developmental psychology. $4^{\text {th }}$ ed. Sydney: Prentice Hall

Poole G., \& Rowat, K. (1994). Elderly clients' perception of caring of a home-care nurse. Journal of Advanced Nursing. 20, 422- 429 
Powell, J. H. (1989). The reflective practitioner in nursing. Journal of Advanced Nursing. 14, 534- 543

Pryor, S. (1991). Getting back on your feet: How to recover recovery mobility and fitness after injury or surgery to your foot, leg, hip, or knee. Post Mills, Vt. Chelsea Green

Radsma, J. (1994). Caring and nursing: A dilemma. Journal of Advanced Nursing. 20, 444- 449

Riemen, D.J. (1986). Noncaring and caring in the clinical setting: Patients' descriptions. Topics in Clinical Nursing. 8 (2), 30- 36

Riley, J., \& Omery A. (1996). The scholarship of a practice discipline. Holistic Nursing Practice. 10 (3), 7-14

Roberts, J. (1990). Uncovering hidden caring. Nursing Outlook.38 (2), 67- 70

Sachs, O. (1984). A Leg to Stand on. New York: Harper and Row 
Sandelowski, M. (1997). (Ir)reconcilable differences? The debate concerning nursing and technology. Image: Journal of Nursing Scholarship. 29 (2), 169-174

Shakespeare, W. King Lear. G.I. Duthie, \& J.D. Wilson (Eds.1968), Cambridge University Press

Snell, C., Fothergill-Bourbonnais, F., \& Durocher-Hendriks, S. (1997). Patient controlled analgesia and intramuscular injections: a comparison of patient pain experiences and postoperative outcomes. Journal of Advanced Nursing 25 681- 690

Spiegelberg, H., \& Schuhmann, K. (1994). The phenomenological movement: A historical introduction. Dordrcht: Kluwer Academic

Statistics New Zealand. (1994). New Zealand Now:65 Plus. Wellington: Statistics New Zealand

Stewart, D., \& Mickunas, A. (1974). Exploring phenomenology. Chicago: American Library Association

Street, A. (1991). From image to action: reflection in nursing practice; Geelong: Deakin University Press 
Swanson, K.M. (1991). Empirical development of a middle range theory of caring. Nursing research. 40 (3), 161-166

Tanner, C.A., Benner, P., Chesla, C., \& Gordon, D.R. (1993). The Phenomenology of knowing the patient. Image: Journal of Nursing Scholarship. 25 (4), 273- 280

Taylor, B. (1994). Being human: Ordinariness in nursing. Melbourne: Churchill Livingstone

Thomasma, D.C. (1994) Toward a new medical ethics. In P.Benner, (Ed.). Interpretive phenomenology: Embodiment, caring and ethics in health and illness. London:Sage

Van Manen, M. (1990). Researching lived experience: Human science for action sensitive pedagogy. State University of New York

Van Manen, M. (1997). From meaning to method. Qualitative Health Research. 7 (3), 345- 369

Walton, J., (1989). Nursing practice in New Zealand Hospitals: Staff nurses and enrolled nurses: An investigation into the 
nature and organisation of nursing practice. Wellington:

National Action Group

Watson, J. (1987). Nursing on the caring edge: metaphorical vignettes. Advances in Nursing Science. 10 (1), 10-18

Watson J. (1988). Nursing: Human science and human care. $2^{\text {nd }}$ ed. New York: National League for Nursing

West, J.W., \& Stein., M.S. (1982). Critical Issues in Behavioural Medicine. Philadelphia: Lippincott

Wither, A., \& Hodges, I. (1987). Elderly people in view: A bibliography of New Zealand research 1972-1985. Occasional paper No 29, Wellington: Department of Health

Woodward,K.(1991). Ageing: Its discontents. Indiana: Bloomington

Younger, J.B. (1990). Literature works as a way of knowing. Image: Journal of Nursing Scholarship. 22 (1), 39- 43 


\section{Information Sheet...}

....about a study concerning older people' needs for nursing care in acute medical and surgical wards.

I am a nurse who has worked with older people in hospitals, rest homes and the community since 1982. I am interested in finding out stories of times when nurses cared for older patients. (By older patients I mean people over 75 years) I am interested in what it is like for people over 75 years in hospital, how you experienced being acutely ill and how nurses cared for you.

This study is for my Master's Thesis at Victoria University, Wellington. If you want to check ID, or know more, or have any concerns you may ring my supervisor at Victoria University:

Cheryle Moss

Dept of Nursing and Midwifery

phone 044721000

I would like to interview people over 75 years of age within two months of their discharge from a medical or surgical ward in the Greater Wellington Area. People who have been patients in both private and public hospitals will be welcome. I can only speak English, and you would need to be able to be able to take part in an interview of about an hour. After a week for you to think it over, I will ring you to see if you still want to be interviewed. If you do, I will make an appointment for a time and place that suits both of us. I will tape the interview.

I will then type out the interview and you can see this if you want to. One week after the interview, I will ring to check if you want to add anything. The final report in the form of a thesis, and any published findings of the research will not contain any specific identifying information. You are welcome to read the final report if you want to.

At any time you can discontinue or withdraw, and I will destroy your information, or you may request it returned to you. At no stage will you be identified, nor the hospital you were in.

If you want to ring me my phone number is : 043884301

Thankyou for reading this

Christine Wilson

Nurse Researcher 
Appendix B

\section{Consent form:}

Older peoples' experiences of nursing care in acute wards.

lave read the information sheet regarding the M.A. study by Christine Wilson, student at Victoria University,

\section{understand that:}

this study has been approved by the Victoria University Ethics Committee and the Regional Health Authority Ethics Committee.

2. $\quad$ the record of my interview will be coded and my name and address kept separately.

3. I may view my own interview transcript, and the final thesis if I want to.

4. the record of my interview, and all details identifying myself or the care institution will not be released at any stage of the research. Individual information will not be released to any person except with my specific authorisation.

5. at any stage I can withdraw from the study, and request any information obtained be destroyed.

6. $\quad$ aggregated results of the whole study only will be reported.

consent to be interviewed and to participate in this research.

Signed

Date.

Signed (witness).

Date.

Signed (researcher)

Date.

Do you want to see the transcript of your interview? yes no (please circle)

Do you want to see the finished report?

yes no (please circle)

If you have any concerns about ${ }^{3}$ this study you may contact the Chairperson, Central RHA Wellington Ethics Committee, Wellington Hospital, Private Bag 7902. Tel (04) 3855999 ext 5185. fax: (04) 3855840. 